\title{
Institutional image: A case study of George Mason University
}

Elizabeth Anne Acosta-Lewis

College of William \& Mary - School of Education

Follow this and additional works at: https://scholarworks.wm.edu/etd

Part of the Higher Education Commons

\section{Recommended Citation}

Acosta-Lewis, Elizabeth Anne, "Institutional image: A case study of George Mason University" (1989). Dissertations, Theses, and Masters Projects. Paper 1539618599.

https://dx.doi.org/doi:10.25774/w4-rd0n-7784

This Dissertation is brought to you for free and open access by the Theses, Dissertations, \& Master Projects at W\&M ScholarWorks. It has been accepted for inclusion in Dissertations, Theses, and Masters Projects by an authorized administrator of W\&M ScholarWorks. For more information, please contact scholarworks@wm.edu. 


\section{INFORMATION TO USERS}

The most advanced technology has been used to photograph and reproduce this manuscript from the microfilm master. UMI films the text directly from the original or copy submitted. Thus, some thesis and dissertation copies are in typewriter face, while others may be from any type of computer printer.

The quality of this reproduction is dependent upon the quality of the copy submitted. Broken or indistinct print, colored or poor quality illustrations and photographs, print bleedthrough, substandard margins, and improper alignment can adversely affect reproduction.

In the unlikely event that the author did not send UMI a complete manuscript and there are missing pages, these will be noted. Also, if unauthorized copyright material had to be removed, a note will indicate the deletion.

Oversize materials (e.g., maps, drawings, charts) are reproduced by sectioning the original, beginning at the upper left-hand corner and continuing from left to right in equal sections with small overlaps. Each original is also photographed in one exposure and is included in reduced form at the back of the book. These are also available as one exposure on a standard $35 \mathrm{~mm}$ slide or as a $17^{\prime \prime} \times 23^{\prime \prime}$ black and white photographic print for an additional charge.

Photographs included in the original manuscript have been reproduced xerographically in this copy. Higher quality $6^{\prime \prime} \times 9^{\prime \prime}$ black and white photographic prints are available for any photographs or illustrations appearing in this copy for an additional charge. Contact UMI directly to order.

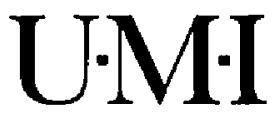


Order Number 8923049

Institutional image: A case study of George Mason University

Acosta-Lewis, Elizabeth Anne, Ed.D.

The College of William and Mary, 1989

$\mathrm{U} \cdot \mathrm{M} \cdot \mathrm{I}$

300 N. Zeeb Rd.

Ann Arbor, MI 48106 


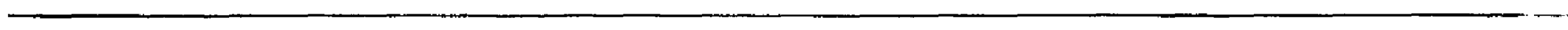

- 
INSTIPUTIONAL IMAGE:

A CASE STUDY OP GEORGE MASON UNIVERSITY

\author{
A Dissertation \\ Presented to \\ The Faculty of the School of Education \\ The College of willian and Mary in Virginia
}

\author{
In Partial Pulfillment \\ of the Requirenents for the Degree \\ Doctor of Education
}

by

Elizabeth Anne Acosta-Lewis

May 1989 
INSTITUTIONAL IMAGE:

A CASE STUDY OF GEORGE MASON UNIVERSITY

by

Elizabeth Anne Acosta-Lewis

Approved May 1989 by

Cohn R. Theisin.

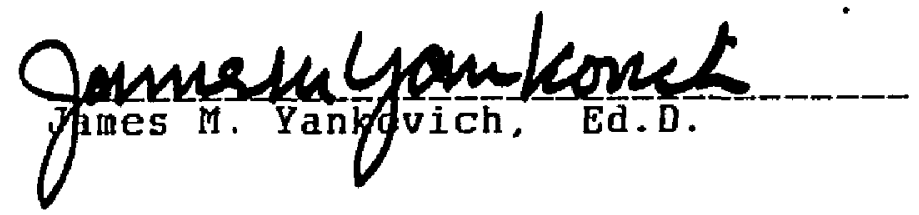

Rogen \& 3 Balwar Rogex G. Bàldwin, Ph. $\overline{\mathbf{D}}$.

Chairman, Doctoral Committee 


\section{Dedication}

This study foremost is dedicated to Rob, for inspiring confidence, and to Zach, for offering diversion, as well as to many others-Mon, Dad, Nancy, Genene, Bob, Jan, Mary, Anne, and ny professars and friends, Dr. Roger Balduin, Dr. John Thelin, and Dr. Jim Yankovich-for providing

intellectual, emotional, and child support. 
CONTENTS

CHAPTER ONE: Introduction . . . . . . . 9

The Research Problem . . . . . . . . 9

The Research Question . . . . . . . 14

Subsidiary Questions . . . . . . . . 15

Terms . . . . . . . . . . . . . . . 16

Data Collection Procedure - . . . . . 16

Resources . . . . . . . . . . . . 16

Method of Analysis . . . . . . . . . 18

CHAPTER TWO: Review of Literature . . . . 22

Historical Background . - . . . . . - 22

The Importance of Image . . . . . . . 24

Irage and Marketing . . . . . . . . . 27

Resistance to Marketing . . . . . . . 29

Involving the College Community

and Others............ . . 33

Conclusions . . . . . . . . . . . . 38

CHAPTER THREE: The Mission . . . . . 40

Changes in Mission . . . . . . . . . 42

Mission and Marketing . . . . . . . . 44

The Mission Statement . . . . . . . . 46

Beliefs and Values:

The Root of Mission . . . . . . . 48

Beyond the Mission Statement . . . . . 50 
CHAPTER FOUR: The History . . . . . 52 George Mason, The Man . . . . . . 53 The Name. . . . . . . . . 54 George Mason, The University . . . . 54 Building a Campus . . . . . . . . 74 A New Direction . . . . . . . . 78 Conclusions . . . . . . . . 78

CHAPTER FIVE: The Players ....... 81 People and Culture . . . . . . . . 81 George w. Johnson . . . . . . . 82 Characteristics of a Good Leaders . . 87 The Administrative Team . . . . . . . 90 The Board of Visitors . . . . . . . 92 The Business Community . . . . . . . 93

The New Paculty . . . . . . . . . . . 95 The Students . . . . . . . . . 103 Conclusions . . . . . . . . . 105

ChAPTER SIX: The Plan . . . . . . . 107 The Changing Environment . . . . . 108 Strategic Planning . . . . . . . . 109 Multiple Initiatives . . . . . . . . I12 Curricular Innovations . . . . . . . 115 Technological Innovations . . . . . 133 Administrative Support . . . . . . . . . 137 
Conclusions . . . . . . . . . . . 147

CHAPTER SEVEN:

Marketing and Public Relations . . . . 151

Marketing and Image . . . . . . . . . 154

Who is Involved in Image-Making? . . . . 155

Steps for Building an Image . . . . . 164

The Global Image . . . . . . . . . . 166

Communications . . . . . . . . . . . . 168

The Four $\mathrm{R}^{+} \mathrm{s}$ of Image-Making . . . . . 170

Conclusions . . . . . . . . . . . 177

Chapter EIgHT: The Physical Campus • . 179 Location . . . . . . . . . . . . 179

The Master Plans . . . . . . . . . . 180

Growing Pains . . . . . . . . . . . 186

Conclusions . . . . . . . . . . . . 189

ChAPTER NINE: The Cultural Campus . . . . 192

Traditions . . . . . . . . . . . . 196

Rites, Rituals, and Ceremonies . . . . . 201

Community . . . . . . . . . . . . 208

CHAPTER TEN: Conclusions . . . . . . 211

The Problem . . . . . . . . . . . 211

The Findings and Discussion . . . . . 212

Implications for Purther Study . . . . . 224

Postscript . . . . . . . . . . • . 226 
BI BLIOGRAPHY . . . . . . . . . . . 228 
"In the face of change there are two basic responses--the bureaucratic and the entrepreneurial. The bureaucrat builds higher sea walls; the entrepreneur looks for a better surfboard."

\author{
--George w: Johnson \\ President ${ }^{-}$s Message \\ The Mason Gazette \\ Hay 6, 1983
}


CHAPTER ONE

Int roduction

\section{The Research Problem}

A recent flurry of news articles concerns the efforts of several universities such as the University of Virginia, George Mason University, and the University of Maryland to attract distinguished faculty to their institutions. George Mason University (GrU), for example, "has gone to great lengths to bring academic heavyweights to what had been until recently a little-known state institution on the outskirts of Washington. No longer do colleagues at academic meetings peer at name tags and inquire, 'George who?" several facuity members now note proudly" (Mclilien, 1986, p. 14).

Seeking superior faculty is only part of George Mason*s unfolding strategic plan, but a part that is particularly important to the university ${ }^{-s}$ goal of strengthening its academic reputation. In fact, most of $\mathrm{GMU}^{-} \mathrm{s}$ recent planning initiatives have focused on enhancing its academic image. For example, GMU is revising its law school program to highlight law and economics, a somewhat risky and controversial move, but one Dean Henry Manne envisions as "making George Mason the nation"s first law school to specialize solely in the economic movement" (Chiacu, 1987, 
p. 5). Simultaneously, GMU is working with the Virginia Community College System to establish a center for training commity college professors and presidents. "It's a great idea,- and the program will certainly lure out-of-state teachers and administrators to GMU, said Dr. Richard J. Ernst, president of Northern Virginia Community College" (Cox, 1987, p. B5).

Since GMU was established in 1957, its image has changed dramaticaliy. It emerged 32 years ago "as a twoyear branch of the University of Virginia. At that time, 17 students attended classes in a converted elementary-schooi building" (McMillen, 1986, p. 15). Now GMU is a prominent public four-year university that can claim among its faculty economics professor James M. Buchanan, winner of the 1986 Nobel Memorial Prize in Economic Science, in addition to nany other preeminent professors. "Getting a Nobel validates a lot of things we are doing that weren ${ }^{-t}$ noticed before," says the university's president, George w. Johnson" (McMillen, 1986, p. 14).

What factors have been most important in shaping George Mason's image? How has George Mason planned, coordinated, and controlled the image-making process? Have the efforts of the past few years brought about substantive change or is GMU enjoying a rise that one administrator from a neighboring institution calls "a product of "more hype than 
substance ${ }^{-*}$ (McMillen, p. 14)?

The importance of institutional image to higher education has been recognized for many years. Mackey explained in 1980 that

Publicity is no newcomer to the colleges. In an 1869 inaugural address Charles W. Eliot, the president of Harvard, spoke of the need for the university to "influence public opinion toward learning." In 1900 he engaged the services of the Publicity Bureau, the nation's first public relations firm, to obtain national recognition for Harvard. The years 1900 through 1917 saw pioneering publicity programs coming out of such prestigious institutions as Barvard, Yale, the University of Pennsylvania, Chicago, Michigan, and Wisconsin. (p. 28)

During the last two decades the image of higher education institutions, collectively and individually, has become even more important as competition among colleges and universities for students, faculty, and resources has become more aggressive. Activities and services such as alumi affairs, public relations, publications, fund-raising, and governmental relations have received increasing attention from presidents and trustees. Many institutions are 
bringing marketing experts from business into their advancement offices. Large sums are spent each year on glossy viewbooks and annual-giving reports. Images continually are being formed, shaped, and changed. There is a need, therefore, to understand better the concept of institutional image, how it is developed and how it fits in with institutional planning.

There are particular problems which discourage the study of image. One is that the term "image" is hard to define. Huddleston and Karr (1982) point out that the amount of literature concerning college image has increased during the past few years, however, sufficient knowledge about the topic has not progressed accordingly. "Part of the problem is that the concept of image is acknowledged as - something,- potentially immeasurable, and ambiguous" (p. 365), they say. Nevertheless, Litten (1981) says, "We need insight into what the public knows or believes about higher education and its institutions; [and] how these perceptions are formed" (p. 108).

Robert Topor wrote two books dealing with how image affects educational organizations: Marketing Higher Education: A Practical Guide (1983), and Institutional Image: How to Define, Improve, Market It (1986). The first discusses the importance of inage as a component of the marketing process in higher education, and the second 
focuses on specific ways to build a successful institutional image. Topor sees marketing and image-building as a cyclical process that begins and ends with research (1986, p. 53).

While Topor supplies a "cookbook" approach of sorts to image-making, the complexity of image invites scrutiny from another perspective. Deal and Kennedy (1982) studied nearly eighty companies looking for organizational characteristics that foster consistent successful performance. In one quarter of the organizations examined, subsequently labeled "strong culture" companies, they found that personnel held similar beliefs, values, and aspirations that were communicated through many means including rites, rituals, ceremonies, heroes and symbols. These symbolic factors contribute to the distinctiveness of an institution's image, therefore, institutional "culture" should be considered when examinining the image-making process.

Ten years ago, Mayhew wrote in Surviving the Eighties that

One of the major generalizations from this study is the value to an institution of a long, well-established image which, over time, attracts loyalty, students and resources, The dynamics of such image building are well elaborated by both Meyer 
and Clark. The big question is whether institutions not having a well-established charter or saga can, under vexing circumstances, actually create one. The literature is silent on the subject. (Mayhew, 1979, pp . 151-2)

George Mason University appears, on the surface, to be one institution that is meeting the challenge of creating an image. In this study some of $\mathrm{GMU}^{-} \mathrm{s}$ efforts to create a prominent image are examined and compared to the strategies outlined by Topor. In addition, more subtle "cultural" factors such as rites, rituals, ceremonies and heroes are scrutinized to determine their effects on GMU's image. This approach adds a new perspective to the marketing concept of image-making.

A limitation of this case study approach is that the results are not generalizable to the larger higher education community. By focusing on one institution, however, the study provides a detailed, comprehensive examination of an elusive topic and a framework for the study of other institutions. The two-part research question and subsidiary questions follow.

The Research Question

How do George Mason ${ }^{-5}$ efforts to improve its 
institutional image compare and contrast to the approach outlined in Robert Topor's books, Marketing Higher Education, and Institutional Image: How to Define, Improve, Market It? Are there strong cultural factors evident at George Mason, such as those discussed in Deal and Kennedy's Corporate Cultures, that influence the image it is attempting to create?

\section{Subsidiary Questions}

1. Is the image GMU seeks to project consistent with its mission?

2. What significant events in GMU's history have influenced its present image?

3. How have the president, trustees, faculty, students, and others shaped $\mathrm{GMU}^{-} \mathrm{s}$ image? who are $\mathrm{GMU}^{-5}$ "heroes" and what effect have they had on its image?

4. What systematic methods such as strategic planning and marketing have been used by GMU to build and project its image?

5. Who largely bears the responsibility for planning how GMU's image will be enhanced?

6. What role does the public relations office have in this process?

7. How do GMU's publications influence its image?

8. How does the physical plant--the architecture, 
technology, library, dormitories, and sports facilities-affect $\mathrm{GMU}^{-5}$ image?

9. What institutional rites, rituals, ceremonies, myths, and other expressions of institutional culture exist and how do they influence GMU's image?

\section{Terms}

Image: The sum of ideas, feelings, beliefs, and perceptions that people hold about the university.

Cultural factors: Elements such as environment, beliefs, values, rites, rituals, heroes, ceremonies, and communication networks that influence the operation of an organization.

Data Collection Procedure

\section{Resources}

In Uebster"s New Collegiate Dictionary (1976), image is defined as "a tangible or visible representation" and also as "a mental conception held in common by members of a group and symbolic of a basic attitude and orientation" (p. 571). These definitions express two perspectives from which this study of image-making at GMU was approached; image as contrived manifestation and image as symbolic perception. To satisfy the examination of image-making from each.of 
these perspectives, both the tangible plans and activities that GMU used to promote its image, as well as expressions of GMU's culture--beliefs, values, rites, rituals, heroes, and myths--were sought.

Various data were examined, including archival files on comencement, other ceremonial events, the presidents, and the history of GMU; Board of Visitor minutes and news summaries; brochures, catalogs and other outreach materials; budgets; internal memoranda; master plans; self-studies; and student, faculty, and regional newspapers and magazinez. Interviews were conducted with representatives from the office of admissions and the office of student activities; the president and executive vice-president of the university; directors of alumni affairs, public relations, student financial aid and university activities; faculty and students. The campus tour offered by the admissions office and several days of campus observation also provided helpful information.

In addition to the primary resources, Topor's Institutional Image and Marketing Higher Education, and Deal and Kennedy's Corporate Cultures, two other books were particularly useful, although neither concerned image-making specifically. These are Searching for Academic Excellence by J. W. Gilley, K. A. Fulmer, and S. J. Reithlingshoefer (1986), and New Priorities for the University by E. A. 
Lynton and S. E. Elman (1987). Searching for Academic Excellence, published by the American Council on Education, concerns 20 "on the move" American higher education institutions. The book discusses the characteristics and "shared conditions of excellence" that distinguish these 20 from other colleges and universities. One of the authors, Gilley, is the executive vice-president (and, at the time of this research, acting provost) of GMU; not surprisingly, the university is one of the 20 featured in this book.

New Priorities for the University considers the economic, environmental and societal changes facing those in higher education today. The authors propose ways of turning new challenges into opportunities, noting that the university"s tasks remain the same: "to be the prime source of intellectual development for society" (p. 1), however, they suggest that the ways in which these tasks are carried out must change. New Priorities is germane to this study for many of its suggestions are already part of GMU's institutional plans.

\section{Method of Analysis}

Although parts of this study extend back to $\mathrm{GMU}^{-5}$ beginnings, the major focus is on a five year period that began in 1983, the year in which, says Gilley, GMU`s promotional surge began. A five year period usually is sufficient to identify trends according to Gilley et al. 
$(1986)$.

Topor*s books were used as guides in examining the tangible plans and activities that GMU undertook to enhance its image. For example. Topor states that research should be the foundation for all marketing endeavors, therefore, evidence of research as well as a formal marketing plan were sought. Topor also asserts that the image an institution seeks to create must be based on reality. Aithough a truthin-advertising audit was beyond the scope and purpose of this study, interviewing and observing $\mathrm{GMU}^{-} \mathrm{s}$ constituents and studying documents and GMU's outreach material indicated that what is consciously presented by the institution is not a product of contrived gimmicks but is based on solid ground. Data collected through the techniques that Topor. Deal and Kennedy suggest--interviewing, observing, and reading--were compared to Topor`s process of image-building to ascertain how GMU*'s process both conforms and differs from that prescribed by Topor.

The examination of symbolic phenomena--myths, rituals, ceremonies, and so forth--identified by Deal and Kennedy proved more difficult. These data largely are open to interpretation. However, as the thesis of this study contends, these elements are an integral part of institutional image and the difficulties inherent in studying them do not diminish the need to include them in an 
overall study of institutional image-making. Deal and Kennedy suggest several ways of reading and evaluating organizational cultures. These include studying the environment for clues about the organization; reading what the organization says about itself through reports, press releases, brochures, and other publications; testing how the organization greets and treats strangers; interviewing pertinent people; observing how people spend their time; and listening to anecdotes and stories that pass through the cultural network.

A qualitative research approach that relies on techniques such as observation, intervieus, and document reviews is becoming more accepted in the fieid of education. Bolman and Deal (1984) state that investigation of symbolic phenomena (and the study of image fits this discription) is unlikely to require traditional social science research methods.

Easily quantified questionnaires and highly structured experimental investigations are ill suited to subtle shades of meaning and affect that are so critical in symbolic analysis. If symbolic perspectives grow and prosper (as we believe they will), they are likely to bring with them a revival of traditional fieldwork methods from 
anthropology and sociology and to promote the current interest in qualitative methods and ethnography. (p. 223)

Because the qualitative approach is best suited to a study of emerging institutional image, it was used in this study of GMU. 
CHAPTER TWO

Literature Review

The literature providing the base for this study is comprised of articles, books, and research projects concerning the concepts of image, culture, marketing, strategic planning, and evaluation. This review covers readings on the history of image-making in colleges and universities, the importance of image, the link between image and marketing, resistance to marketing, and ways of involving the college and larger commuties in enhancing image.

\section{Historical Background}

Mackey (1980) discusses the early efforts of Harvard, Yale, and others to influence public opinion of their institutions and of education generally. She notes that the controversy of whether or not "advertising" by colleges and universities is appropriate to the academic setting was an issue at the turn of this century just as it is today. For example, Henry S. Pritchett, president of the Carnegie Poundation in 1910, felt that advertising was responsible for the presence of many ill-prepared students on campuses and was, as far as the students were concerned, "almost wholly bad" (Mackey, 1980, p. 29).

Pelletier (1985) states that the public relations 
function in American colleges and universities has been in place since the beginning of the university when college presidents first established relationships with political and business leaders, but he notes a significant increase in its importance during the last three decades.

In the late 1890s, Cornell University began to place advertisements in New York newspapers, and President Eliot of Harvard worried about Harvard's image versus that of Johns Hopkins. The University of Chicago issued a recruitment brochure in 1896. By 1910 several American universities had fullfledged public relations departments (Veysey). By the late 1930s there were more than 200 college publicity offices. Marketing came of age, however, in the late 1960 s and the 1970s, in response to the dramatic changes in society, the economy, and government policy. (Pelletier \& McNamara, $1985, p .56)$

Topor (1986) believes that the future of higher education will be increasingly competitive. This competitive environment will make the efficacy of institutional image even more important than it has been in the past. 
As competition grows for quality students and faculty, funding, research grants, donations, legislative recognition, alumni support, corporate support, media recognition, and visibility, institutions will become more and nore concerned about their images. They will need to maintain distinct positions in the competitive nonprofit marketplace, much as corporations strive to achieve and maintain product positions in the competitive forprofit marketplace. And success in the marketplace largely depends on how an institution has been, is, and will be perceived. (Topor, 1986, p. vii)

\section{The Importance of Image}

If any authors have discussed the importance of a positive, distinctive image to an institution (Clark, 1970; Hall, 1986; Huddleston and Karr, 1982; Kotler and Fox, 1985; Ries and Trout, 1981; Schoenenberger, 1984; and Topor, 1986). Rosenzweig (1987) stresses that colleges and universities must be concerned about the images they are projecting to their various audiences, especially to those in dashington, D.C., where critical decisions concerning higher education are made. Topor, whose recent book discusses how to define, improve, and market institutional 
image, says

Any educational institution has an image.

That image is not necessarily one concise, cohesive, clear idea. More accurately, an institution's total image consists of many individual sets of perceptions in the minds of its constituents. . .

How an institution is seen can make the difference between its success and failure. And careful attention to institutional image uill reap immediate and long-range rewards. (Topor, 1986, p. vii)

Topor further defines image as the "aggregate, or sum, of feelings, beliefs, attitudes, impressions, thoughts, perceptions, ideas, recollections, conclusions, and mind sets someone has about an institution, its components, or its products" (p. 60). He outlines several steps toward building a strong image, ties image-making to marketing, and explains that research should undergird the entire process. Topor's plan is explored more fully in chapter seven of this study, "Marketing and Public Relations."

Kotler and Fox (1985) point out that some researchers believe images are "object determined," meaning people perceive the reality of a subject. Other researchers feel - that images are "person determined," therefore, the same 
subjects are perceived differently by different people. The truth, according to Kotler and Fox, lies in between. They say that image is influenced by both objective reality and the subjective characteristics of the perceiver, however, the connection between image and any causal behavior is not as close as some persons believe. Nevertheless, Kotler and Pox do stress that one should not dismiss the importance of image, for monitoring it is useful in understanding what is happening to an object, and in identifying desirable changes .

For example, Ashby (1983) reports that the process of defining a new image at Pine Manor college, a two-year women's college in the Boston area, led to changes in the college's charter that eventually permitted it to grant the bachelor's degree. The process of image-building, according to Ashby, is circular.

Awareness of the need to project a strong image leads an institution to take a hard look at the realities of its programs and services and to make changes that strengthen the college at every level. This in turn enhances the college"s image, which reflects an improved reality. (p. 47)

While concerns about its image led to self-examination, Pine Manor was careful to set goals and objectives consistent 
with its mission before concentrating on public relations. Lauer (1985) also stresses the importance of clarifying institutional mission before beginning strategic planning that affects institutional image.

Pelletier states that "an effective marketing plan is based on the university"s statement of mission" (Pelletier \& McNamara, 1985, p. 57). It is the responsibility of administrative leaders to convey the sense of mission to those in admissions, development, public relations, and publications who are responsible for presenting the institution's image to its various constituents. Raley (1986) suggests that plans be formal and written.

$$
\text { Image and Marketing }
$$

One of the most systematic ways of influencing institutional image is through marketing. Marketing, according to Brooker and Nobel (1985), is part of the exchange process between organizations and society. Good marketing ensures that these exchanges are carried out in the most efficient manner. In today's complex world, marketing is a necessary tool of management.

In the past, when exchange processes were far simpler, a management philosophy of letting "exchange" take care of itself may have been reasonably successful. However, we no longer live in the past, and organizations cannot 
rely on their traditional ways of doing

business. (Brooker \& Noble, 1985, p. 192)

Marketing concepts can be adapted to the needs of higher education, according to Brooker and Noble. Colleges and universities, like business organizations, are concerned with their products and services, price, methods of promotion, and place of operation. These components, called the "marketing mix," are the areas of an organization addressed by a marketing plan. Hughes (1980) says, The goals served by marketing are not new to colleges. All schools recruit students. raise money, and--aibeit in a less organized fashion--cultivate an image. What is new is that economic and demographic forces are challenging an institution ${ }^{-} s$ ability to accomplish these old tasks in the traditional ways. (p. 92)

In an interview with Harper, Kotler states that there are three basic types of marketing approaches. The first is the product-oriented approach, in which people will recognize the inherent worth of the product. Second is the hard-sell approach that is highly sales oriented. Third is the professional approach, which "focuses on building satisfaction in a long-term clientele. It's professional marketing" (Kotler in Harper, 1984, p. 30). This approach 
should be the aim of marketing in higher education. Kotler explains, "it entails quite consciously doing a good job of consumer and market research, market definition and cultivation, product and service design and development, distribution, planning, pricing, and promotion" ( $p .30$ ).

Kotler and Fox (1985) use the term "marketing" to describe the effective management of institutions exchanges with various constituents, including students, faculty, donors, and others. The authors translate the elements of marketing identified and studied by the business comunity for several years into concepts familiar and useful to educators. Their book demonstrates that a closer connection between higher education and business is imminent, for increasingly, educational institutions are finding themselves in the midst of the marketplace--not in an ivory tower.

\section{Resistance to Marketing}

While many college and university administrators acknowledge the need for marketing in higher education today, some feel that marketing has no place in academe. Marshall and Delman (1984) report that a significant number of administrators are reluctant to develop marketing strategies. "More surprisingly, according to a recent report of the Association of Governing Boards, most leaders in higher education are remarkably complacent or do not 
recognize the significance of this overall situation" ( $p$. $317)$.

If CNamara (1985) strongly feels that marketing does not belong on the college campus, insisting instead that an institution of higher education should be a community of scholars, a place that focuses on the traditional values of learning and teaching. He says

The recent rush of educators into the arena of marketing, alien territory just a few years ago, will go down as one of the most rash decisions and saddest days in the history of American higher education. It is leading us down a primrose path to nowhere. And, on the way, we shall experience anprecedented delusion, discord, and enmity that will divide and diminish us as educators. (Pelletier \& McNanara, 1985, pp. $54,62)$

Don Sider of Virginia Polytechnic Institute and state University maintains a different view. Sider acknowledges the competitive environment that higher education now faces, and advises institutions not to withdraw from the challenges therein. He says "there is constant competition for the best students, best faculty, more grants, and corporate support. If you re not in there competing, then you're 
going to be left by the wayside" (Sider in Callaghan, 1986, p. 40).

Eowler (1983) admits that using marketing concepts in colleges and universities may attract criticism from "idealistic academics," however, he believes that a successful marketing program can bring about dramatic results that overshadow negative opinions.

Evergreen [State College] is proof that this criticism can be largely overcome. Through its coordinated marketing program, the college has achieved three important goals-en rollment growth, increased student retention, and greater public awareness-without having to sacrifice its founding principles. (p. 20)

Resistance to marketing by college and university administrators, faculty, and others has been noted by many authors (Brooker and Noble, 1985; Druck, 1986; and Taylor, 1984). A better understanding of marketing concepts by the higher education community would help alleviate apprehension. Druck sees marketing as an integral part of higher education's mission. He questions why institutions have neglected this function.

Why is it that people who are smart enough to produce such a fabulous educational system 
don't understand that they need to produce an equally fabulous system to build public understanding and support for their institutions--and for education in general?

Such a system is essential to an institution's survival. Yet it is almost totally neglected. It doesn't appear prominently on organizational charts. CEOs don't cite it in their speeches. Boards aren't structured to represent or pursue the function. In short, there's nothing to indicate that the administration understands the vital necessity of creating favorable public opinion. (Druck, 1986, p. 18)

In Academic Strategy (1983) Keller confirms the need for marketing in higher education. A sophisticated process, Keller cautions that true marketing should not be confused with simple advertising or "selling."

In marketing, the effort is a more scholarly one of systematically understanding who it is your university is serving, why they come, why they don't come, and how you might serve your students better and position yourself more self-consciously in the complex network of 3,100 colleges and universities. (Keller. 
1983, p. 159)

Keller implies that marketing is part of the academic strategic planning process. This is an important connection that is pursued in the course of this study.

Involving the College Community and Others

There are many ways, both direct and indirect, that colleges and universities promote themselves. The most successful image-building efforts are ones involving the whole academic community (Ashby, 1983; Litten, 1981; and others). Callaghan (1986) found that many institutions are setting up advisory boards to help them tackle marketing issues. Others are forming media relations comittees of friends, alumni, and parents to provide help and advice on public relations, fund-raising, and admissions projects. Jones (1986) suggests that university relations personnel develop contacts at major wire services to widen the scope of an institution's audiènces.

Landers (1986) advocates sending videotapes to prospective students as a new recruiting tool for admissions officers. Zimmer (1986) suggests choosing media geared to particular groups of people, such as specialized magazines, so that institutions can reach target markets with their messages. Milo (1986) says "admissions directors have found that increased involvement on the part of faculty can foster appreciation of admissions department efforts and create the 
mutual cooperation and support necessary for survival in these competitive times" ( $p .180$ ).

Pray (1981) advises using trustees as communicators to external audiences but notes that few colleges take advantage of this opportunity. Nagel (1980) studied public two-year institutions and found that their presidents believe that students are major image-makers for these schools.

Of course, the presidents, themselves, are crucial to the success and image of an institution (Ashby, 1983; Fisher, 1980; Gilley et al., 1986; Mahn, 1981; and Perkins, 1983). Perkins says we should take a lesson from Chrysler and Iacocca and market our institutions by using presidents as top public relations people. He identifies several schools such as Carnegie-Mellon, Notre Dame, and the University of Richmond that have received good "media mileage" from their presidents.

In spite of their "usual brief" terms of office, Mahn asserts that today"s presidents can positively influence their institutions. Mahn lists three broad areas of concern for presidents interested in advancing their institutions; "enhancing responsiveness to university needs, enhancing conditions for employment and retention of exceptional personnel, and enhancing respect for the university" (Mahn, 1981, p. 2273. He points out several tips for effective 
leadership, such as making moves early in the tenure period; devising comprehensive educational and budget plans that reflect personal philosophies; and developing loyal corps of alumni, friends, and admirers of the institution. One way to measure the esteem in which presidents are held, Mahn suggests, is to observe the number of invitations they receive to serve as consultants and members of associations, boards, and foundations (p. 231 ).

According to Kenneth Shaw, president of Southern Illinois University at Edwardsuille, there are five important public relations functions for the president.

(1) to communicate the institution's mission and be an honest conscience in judging how well the mission is being fulfilled; (2) to see that all support units with pr [public relations] responsibilities are coordinated and working toward a common goal; (3) to recognize that "legislative relations" is too limited a term for what is needed today to achieve success with political constituents-governmental relations better explains the challenge; (4) to pay close attention to internal university relations in order to maintain policy credibility and sustain morale, especially in times of stress; and 
(5) to communicate to members of the institutional community their role in interpreting the image of campus life to external audiences. (Shaw in Fisher, 1980, p. 17)

The successful completion of these tasks requires a close relationship between the president and university relations personnel.

perkins (1983) believes that the top university advancement or public relations official should have direct access to the president. Gehrung (1980) states this director should be an educational leader as well as a public relations person. He or she should be able to understand and articulate the institution's mission, be knowledgeable about institutional politics and policies, and stay in touch with the institution's many audiences.

The publications director is very important, too, because certain publications such as catalogs or viewbooks often represent the first contact people have with an institution. Zerby and Manning (1983) state that publications at Elizabethtown College were the starting point for adopting new marketing strategies. Because of the importance of publications, Bennett (1986) says a publications manager must educate campus clients about what his or her office does. This can result in better working 
relationships and in better products. Newfarmer (1981) says good communication within the university leads to better public relations with external audiences.

Several authors (Goldgehn, 1985; Hollister, 1985; and Litten, 1981) stress the importance of evaluating programs and processes. A good way to identify and confront iostitutional problems is to audit marketing procedures according to Goldgehn (1985). She developed a marketing audit instrument tailored specifically to education. She states, "Even the healthiest institutions should conduct marketing audits regularly, in response to the constantly changing market environment" (p. 36). Similarly, Hollister (1985) contends that evaluation programs should be in place to demonstrate the impact of institutional relations activities on the institution. Taylor (1984) says Periodically the university should normally investigate its image as held by various audiences including: alumni, the local business community, high school and junior college students, and its own students. For the university to change its image effectively, if that is deemed necessary, it nust first establish what it is that needs changing. Moreover, periodic investigations of image are needed to monitor progress and 
to locate emerging image patterns. (p. I56)

Conclusions

Despite a heightened awareness of the role of imagemaking in higher education, as demonstrated by the number of recent articles on the subject, few formal studies of the topic have been conducted. The literature demonstrates the broad scope of image-making, but individual articles and studies mostly are confined to one aspect, such as the importance of image to recruiting procedures or fundraising. Marshall and Delman (1984), for example, designed a study "to explore general research questions regarding the image of Potsdam College," but focused specifically on the college"s image with respect to prospective students. Other efforts have resulted in models that cannot be implemented readily by institutions. Taylor (1984), for example, created an extensive theoretical model of strategic marketing for urban universities, but it would be impossible to test it without a large commitment of money and energy.

This study contributes to the existing literature by providing an in-depth examination of one institution that is engaged in the process of image-building in an increasingly competitive environment that makes the task difficult. A challenge exists today for an institution to carve a niche for itself and to present a distinctive institutional image. Certain schools, such as George Mason University, vigorously 
are seeking ways to meet this challenge. Will these institutions become serious rivals of the long-standing, prestigious research universities? Perhaps, if they are successful in defining and projecting the right image to the right people. 
CHAPTER THREE

The Mission

Every institution has an intrinsic mission, a purpose for being. That this mission is distinctive, well-defined, and actively considered in institutional planning, however, is not always the case. What is "mission" and how is it related to image-making? A Carnegie Council policy study on the role of institutional mission in curricular development stated that the function of mission is to:

1. Guide the academic leadership of a college in determining what educational programs are appropriate for accommodation in the institution's curriculum

2. Provide students with information about the institution"s intentions so that they can compare them with their own interests and needs

3. Provide the college's governing board, accrediting agencies, and others having a legitimate reason to evaluate the performance of the college with the criteria by which the institution chooses, at least in curricular matters, to be governed. ("Missions," 1980 , p. 133) 
Just as those persons planning academic programs must have a basis for decision-making, those responsible for shaping an institution ${ }^{\prime} s$ image must have a foundation on which to build. As such, an institution's mission will have an impact upon all subsequent efforts, providing consistency and coherence to institutional image. Moreover, the resulting image will be true to and will promote the institutions mission.

The concept of "mission" is discussed in key literature on institutional image-making. For example, in each of the twenty noteworthy institutions studied by Gilley et al. (1986), the authors identified the presence of a welldefined strategic mission; "a strong and deliberate declaration that is the basis for institutional planning and operating" (p. 96). Gilley et al. (1986) urge institutions to reduce their strategic missions to brief, written, coherent statements that address relevant issues. They advise colleges and universities to discuss their missions frequently and to disseminate them widely, both within and outside of the institution.

Mayhew (1979) notes the connection between mission and image-making. He says:

In order to attract the kinds of students

they wish to serve, institutions are frequently urged to develop a unique mission 
and statements of purpose consistent with that mission. Such urgings are reinforced by examples of institutions that have succeeded because they were able to find a clear-cut and unique purpose. ( $p$. 135)

Generally, one would assume that marketing strategies should be based on an institution's established mission rather than the other way áround, however, Mayhew's observation may hold true for institutions lacking distinctive missions. At any rate, the process of image-making is a circular one, as noted in the last chapter, and missions should be reviewed periodically to ensure their relevancy.

\section{Changes in Mission}

Lynton and Elman (1987) suggest that many economic, societal and technological changes occurring since world war II have changed the model for the modern university. They discuss the importance of broadening objectives and realigning institutional missions to meet the challenges of the next century. They point out that missions need not be changed dramatically, however, they advise institutions to acknowledge new methods of knowledge transformation and consider how these affect institutional mission.

According to Iynton and Elman, universities should reflect the "mutually interdependent combination of research, instruction, and extension that characterized the 
traditional land-grant college" (p. 29) in a manner that addresses the complexities of today"s environment. For example, they compare the "pull versus push" systems of university research. After World War II, they say, ideas were "pushed" into the marketplace by lab researchers. Today, however, ideas rnust be "pulled" from university labs to meet the needs of the marketplace. A trend toward more applied research within the university has come about as a . result of efforts to meet marketplace demands. GMU has embraced this need in Northern Virginia with its current focus on high technology.

Being aware of new demands and broadening objectives to meet them should help colleğes and universities strengthen their place in an educational environment that is becoming more diverse and competitive. Colleges and universities must give ongoing attention to how they can meet society ${ }^{-}$ needs while remaining loyal to their missions in the face of new challenges from diverse institutions. Lynton and Elman review a growing list of higher education's rivals; churches, libraries, museums, professional organizations, the armed forces, and the corporate sector. Lynton says, "-the reluctance and lack of urgency with which academic institutions by and large have reacted to these opportunities [for meeting market needs] are striking indications of the gap between external societal needs and 
the internal priorities of higher education-" (Lynton and Rlman, 1987, p. 103).

Lynton and Elman emphasize, however, that institutions should not make changes randorly, but should base decisions about change on thoughtful consideration of their individual missions. They admit that perhaps some forms of learning are better left to nonacademic sources. Boyer predicts the consequences of overzealous ambition. He says, "in a bid for survival, higher education will imitate its rivals. . as colleges pursue the marketplace goals of corporate education. If that happens, higher learning may discover that, having abandoned its own special mission, it will find itself in a contest it cannot win"" (Boyer in Lynton and Elman, 1987, p. 105). Boyer's warning confirms the need for frequent evaluation of strategic planning and marketing efforts.

\section{Mission and Marketing}

Topor (1983) suggests that the mission statement represents a logical place to begin planning a marketing program. The best statements, he says, are ones that position an institution within the marketplace. The statement should describe:

1. the academic identity of the institution and its curricular programs 2 . the institution in relation to other 
institutions

3. the educational philosophy maintained by

the institution

4. [the] specific educational aims in

relation to target markets

5. [the] educational purpose of the

institution. (pp. 73-74)

An institution that has addressed these concerns in writing is more likely to convey a clear image to its constituents than one that has not considered these details fully.

Finding the best way of meeting market needs while maintaining academic integrity is a challenge that can be assisted by a current, well-defined strategic mission. $\mathrm{GMU}^{\circ} \mathrm{s}$ mission has broadened over the years to address the evolving priorities of the unjuersity. The two-year branch of the University of Virginia, designed to serve the needs of Iocal students who could not afford to go away to college, opened in 1957. Thirty-two years later, GMU is an independent university striving to provide more distinctive, higher quality educational opportunities that meet the needs of an increasingly sophisticated environment.

Gilley et al. (1986) describe GHU's four-pronged strategic plan:

high quality undergraduate liberal arts education, a reflection of its beginning as 
an undergraduate liberal branch of the University of Virginia: policy studies, because of its location adjacent to the nation's capital; fine and performing arts, resulting from the university's desire to be a cultural focal point in an emerging commity; and high technology, reflecting the region's primary business and industrial community. (p. 139)

Chapter six of this study, "The Plan," discusses specific curricular programs and activities that have been implemented to fulfill $\mathrm{GMU}^{-5}$ expanding mission.

The Mission Statement

$\mathrm{GMU}^{*} \mathrm{~s}$ mission statement, revised in 1980 and adopted by the Board of Visitors, says:

"George Mason University will provide superior, traditional education enabling students to develop critical and analytical modes of thought and to make rigorous, honorable decisions. . . The University seeks to prepare students to interpret the complex questions facing them and society. It further seeks to meet the needs of students by providing the opportunity for innovative educational methods and programs; 
and it will enhance these programs with undergraduate, graduate, and professional courses of study that are cross-disciplinary.

"The University will support a faculty which is excellent in teaching, active in pure and applied research and responsive to the needs of the comounity.

"The University will strive to be a resource of the Commonwealth serving government and private enterprise, and to be the intellectual and cultural focus of Northern Virginia." GGeorge Mason University Undergraduate Catalog, 1987-88, p. 11)

Key words and phrases from this statement are significant: superior, traditional education; meet the needs of students; innovative educational methods and programs; undergraduate, graduate, and professional courses of study that are cross-disciplinary: pure and applied research; serving Government and private enterprise; and, of course, the intellectual and cultural focus of Northern Virginia.

While the undergraduate curriculum at GMU is rooted in the traditional liberal arts, there also is a growing emphasis on the high technology needs of the future

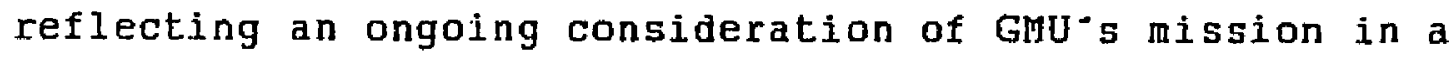


changing society. Many sophisticated programs have been developed to meet the needs of both students and the surrounding governmental and corporate environment. And recently, the fine arts have received increasing attention as the university strives to become the cultural focus of Northern Virginia. All of these changes, while each stands alone, are consistent with GMU*s evolving mission.

Beliefs and Values: The Root of Mission

An institution"s mission should both reflect and shape the beliefs and values of those who are part of the college or university. In the corporate world, Deal and Kennedy (1982) state that successful organizations enghasize their fundamental beliefs and values. "As the essence of a companys philosophy for achieving success, values provide a sense of common direction for all employees and guidelines for their day-to-day behavior" ( $p .21$ ). Deal and Kennedy identify three value-related characteristics shared by successful companies:

* They stand for something--that is, they have a clear and explicit philosophy about how they aim to conduct their business.

* Management pays a great deal of attention to shaping and fine-tuning these values to conform to the economic and business environment of the company and to 
communicating them to the organization.

* These values are known and shared by all

the people who work for the company--from the

lowliest production worker right through to

the ranks of senior management. ( $p .22$ )

Institutional beliefs and values should be considered by those attempting to create a distinctive image. The role of beliefs and values in image-making at GMU is discussed more fully in chapter nine, "The Cultural Campus." These characteristics are noted here, however, because they embody many of the same elements found in Topor's definition of a good mission statement; organizational identity, philosophy, aims in relation to market needs, and common purpoise.

Although Deal and Kennedy state that corporate values are not "rhard, like organizational structures, policies and procedures, strategies, or budgets" (p. 2l), and, in fact, often are not even written down, higher education provides a good vehicle for expressing values in the mission statement. Mission statements are found routinely at colleges and universities, however, their value in creating a strong image varies a great deal among institutions. The difference between broad, ambiguous statements and distinctive, relevant statements is determined in part by how well the statement reflects the values and beljefs of those persons within the institutional community and relates 
to current organizational plans and activities. The mission statement offers an appropriate, though often underused, means of communicating beliefs and values clearly to an institution's audiences.

\section{Beyond the Mission Statement}

Mayhew (1979) says that often one can learn more about an institution's true mission by scrutinizing the institution than by studying the formal statement. He suggests looking at particulars such as students and faculty to see who comes to an institution and, more importantly, who stays. He also advises talking with alumni; asking what they value from their college experience, and observing whether or not they continue to participate in the life of the institution. He says, "such information should be interpreted prudently, of course, because slavish adherence to the past could prove to be foolish. However, not to consider the past could be even more unwise" (p. 149).

The author met with many persons and studied numerous articles and documents to learn about GMU's emerging image, which is influenced, in part, by its mission. The following chapters discuss many curricular, technological, and personnel changes found at GMU that have led to a rising calibre of students, faculty, and staff, broader curricular programs, increasing technological sophistication, and more spectacular architecture. These changes demonstrate that 
GMU`s evolving mission considers the complexities of today's environment, as advised by Lynton and Elman (1987). The following chapter on GMU's history provides a brief look at how the institution has grown to the position it now enjoys, a position of actively seeking new challenges in order to establish its unique character. 
CHAPTER POUR

The History

As Thelin (1982) said in Higher Education and Its Useful Past. "Colleges and universities are fascinating places. Their charm and complexity come, in large measure, from the fact that they are historic institutions" (p. 1). George Mason University, in comparison to many familiar colleges and universities, is a fledgling institution whose history is "in the making." Nevertheless, specific events and people in GMU's short lifespan have contributed a great deal to its emerging image.

Although neither Topor (1986) nor Deal and Kennedy (1982) emphasize the importance of history to institutional image, each addresses it indirectly. For example, Topor says, "Few institutions have analyzed what their images are, how they got those images, or more important, how the images can be modified or changed" (p. $x$ ). Many authors have noted the value of examining institutional traditions and values before instituting change (Deal and Kennedy, 1982; Keller, 1983; and Thelin, 1982.) Learning about an institution-s history provides useful information about how traditions and values have evolved.

The purpose of this chapter is to provide an overview of some inportant historical events revealed through an 
examination of archival artifacts and documents that have shaped the growth, development and stature of GidU. Some events were planned and executed thoughtfully by those with power to persuade and influence. Other experiences, as Gilley et al. (1986) would say, are the result of an "exploitation of opportunities."

George Mason, the Man

Pirst, one might ask, who was George Mason? Born in 1725. George Mason was a patriot and gentleman. He was the author of the Virginia Bill of Rights and a vehement supporter of the Bill of Rights of the federal Constitution. Pacheco contends Mason "has never received the acclaim he deserves. - . because, as an intensely private man, he preferred to do much of his political work behind the scenes, rather than on the public stage" (George Mason: The Man and the University, 1976, p. 2).

Mason built his plantation and Georgian home, Gunston Hall, on land overlooking the Potomac river, not far from where GMU now is located. Two centuries later, the Board of Visitors of the University of Virginia (UVA) selected the name "George Mason College of the University of Virginia" for its branch campus "in honor of the virginia patriot and statesman. That same year the City of Fairfax purchased 150 acres just south of the city as a permanent site for the college and donated it to the Iniversity of Virginia" 
(George Mason: The Man and the University, 1976, p. 15).

The Name

Topor (1986) discusses the importance of an institution"s name in Institutional Image. He says that a name often is taken for granted, even though it is what delineates an institution from its competition. He says, "The name is the identifier. It communicates identity. It contributes to an institution's image" (p. 13).

George Mason's name was chosen to honor a Virginia patriot. At the time the selection was made, the college was still a part of UVA. Its name revealed both its affiliation and its separate identity. Thus, "George Mason College" distinguished it from the university at Charlottesville, while "of the University of Virginia" provided a ready sense of prestige, history, and guality for the new institution.

George Mason, The University

Much of the early history of GMU is recorded in the archival papers of C. Harrison Mann, a former Arlington delegate and friend of the university, who played a large part in the politics of establishing the embryonic institution. Mann began working on a history of the university that, unfortunately, never was completed. Excerpts included in this paper are taken from Mann*s revised working draft, therefore, some quotes may not appear 
as he might have finalized them. In Mann's intended preface he wrote:

George Mason University was not, as in the case of some other institutions, the creation of one man. Nor was it the product of farsighted vision. It was sired by many men and was the offspring of competition and evolution. Its birth was not easy, but turbulent in the clash of many midwives; but in retrospect [it was] a fascinating way to be born.

The genesis of George Mason is a rewarding story of how things "happen" and it is desirable. to get down the facts while still in the recollection of living mèn before someone begins to fictionalize events based on legend and memory, and call it "history." (Mann, 1976, p. 1)

The Beginning

George Mason University was spawned from the idea of extension centers, a movement begun in the late 19th century "at such places as Columbia, Hisconsin, Chicago, Brown, Indiana, and Illinois" that represented "an effort to extend the influence and the popularity of the university into communities beyond the immediate vicinity of the campus" 
(Rudolph, 1962, p. 363). Mann (1976) says, "In 1919 the College of William and Mary established extension courses in Richmond, Norfolk and Newport News" (p. 1). One year later. the University of Virginia started its own extension programs. As time progressed, UVA began to expand its influence throughout the state including the growing area of Northern Virginia. "By 1953-57," Mann continues, "the

- University of Virginia Extension Division had 74 so-called extension "Centers" around the state, with 6,145 course registrations, even tho [ $\underline{\underline{s i c}]}$ in some areas these "centers" only conducted one class" ( $p$ p. 1-2).

According to Mann, Colgate Darden, President of the University of Virginia, and George Zehmer, Dean of the Extension Division, soon determined that a more ambitious project was needed in Northern Virginia. Mann (1976) says:

In implementing this decision they had a long range objective, that of establishing some kind of school of higher learning under the aegis of the University in the area at some future date. Neither Zehmer nor Darden or anyone else had at that time any clear idea what form this institution would take, altho [sic] the Division of dillian and Mary in Richmond (RPI) [Richmond Professional Institute] and in Norfolk provided an example 
for the project. (p. 2)

The University Center of Northern Virginia

Mann explains that while Darden and Zehmer were making their plans, the people of Northern Virginia were beginning to realize a need for local adult education although they were unsure about what specific form it should take. Mann, who then was president of the UVA Alumni Association. remembered receiving a telephone call "sometime in 1949" from Colgate Darden who said "Hank, the people of Northern Virginia need higher education, but they don ${ }^{-t}$ know it yet" (Mann, 1976, p. 3). William McParlane, Professor Emeritus of GMU, says, "So the university tried to start a school without seeming to. That's the way things are done in Virginia" (personal communication, July 13, 1988).

Mann continues, "Then Darden told of the decision to send J. N. G. Finley [a professor who had been involved in the University"s adult education programs] to Northern Virginia to establish an extension center, and the need for public support by the local population" (Mann, 1976, p. 3). This "entrepreneurial spirit," characteristic of many key persons in $\mathrm{GMU}^{-} \mathrm{s}$ brief history (and notably apparent in its current president, George W. Johnson), largely is responsible for its rapid growth. Gilley et al. (1986) note that "opportunity consciousness" is a salient characteristic among presidents, board and faculty members in each of the 
schools they examined.

Mann worked with Finley and local citizens to organize an extension center that was housed in Washington and Lee High School, Arlington, Virginia. An Advisory Council of twenty citizens from Arlington, Alexandria and Falls Church was formed, chaired by Mr. Clarence A. Steele, that both advised the center and solicited support for it. Although the center was distinct from the University College, which opened in 1957, the center is important to GMU's history for it paved the way for the birth of the University College which evolved eventually into GMU.

Initially, as Finley began assessing the educational needs of the local communities and devising plans to meet those needs, he commuted between Arlington and Charlottesville, where his wife taught psychology at UVA. "During this time efforts were directed to establishing the office, getting together mailing lists, appearances at meetings of service clubs, civic organizations, and other groups, which had been arranged largely by the Advisory Committee [Council], to explore and promote the work of the future Center" (Mann, 1976, p. 4). In February, 1950, the Northern Virginia Center of the University of Virginia Extension Division offered its first classes in economics, English, engineering, history, and math. There were 55 students registered for six classes. Enrollments at the 
center grew rapidly, however.

In the two semesters of 1950-51, 44 classes were organized with a registration of 665 . In 1951 a summer program was organized with 26 classes and 368 registrations. In the fall and spring semesters of 1951-52 89 classes were organized with 1,192 registrants, an increase of 798 . Most of the classes were held in Arlington"s Washington \& Lee High School, altho [sic] some classes uere held in Alexandria, Fairfax, Prince william and as far away as Quantico. Perhaps Northern Virginians really were aware of their need for higher education. Mann, 1976, p. 6)

\section{A New Institution}

Mann states that once the success of the center was apparent, Finley began promoting the idea of a new full-time institution. Although some Northern Virginians were intrigued by the notion of an independent community college, that idea soon was abandoned by Steele and the Advisory Cauncil who felt "it was highly desirable to have a college sheltered by the University of Virginia, whose prestige would assure accreditation for courses taken" (Mann, 1976. p. 6). This decision was critically important, for had 
Finley and the others opted for a community college, George Mason would have become part of Virginia's community college system, and could not have developed into the university it is today.

Darden was optimistic about UVA"s further growth into Northern Virginia, however, he pointed out that the University first had to receive the countenance of the local communities. Acknowledgments of support and promises of financial subsidization quickly were garnered from the localities of Arlington, Alexandria, Fairfax, and Falls Church. Thus, "the stage was set in 1953 for the University to crystalize action in the Northern Virginia community" (Mann, 1976, p. 8).

The next step was to obtain the General Assemblys endorsement. Mann says that in January 1954 the local delegation to the General Assembly had proceeded with very little legislative action. Mann was a new delegate, however, he realized the need to create favorable opinion concerning the establishment of local colleges. He cosponsored House Joint Resolution No. 46 which recommended a study by the Virginia Advisory Legislation Council of "the educational opportunity offered by the extension services of the various universities and colleges, with the view of determining whether such extension services can and should be developed to meet the higher education needs of those who 
Cannot afford to attend the state universities and colleges" (House Joint Resolution No. 46 in Mann, 1976, insert between pp. $9 \& 10$ ). The resolution was passed unanimously by both the House and Senate. The Virginia Advisory Legislation Council formed the Committee on Extension Services, to which Mann was named, to execute the study.

The Need for a Local CoIlege

The Committee on Extension Services was to submit a report on its findings to the council, who in turn would report to the Governor and General Assembly. The minutes of the committee's first meeting show that Resolution No. 46 was drafted with two major considerations in mind. First. . there was concern that many capable high school graduates were not attending colleges and universities in Virginia largely due to financial barriers. Second, studies forecasted that the number of students wishing to attend colleges and universities was to increase dramatically and that higher education facilities in place at that time would not be adequate ("Minutes," Committee on Extension Services, December 15, 1954).

Mann opposed the creation of independent community colleges. He realized that most college presidents did not favor the commity college concept. He writes that, "in the eyes of most college presidents "community colleges" did not carry at that time a connotation of higher education, 
but merely an extension of high school. They [the presidents] saw transfer of credits problems. They regarded such a system as very expensive, which could jeopardize needed appropriations for their institutions. They could not see themselves operating such colleges" (Mann, 1976, p. 11).

Mann, himself, preferred a plan of building extensions or branches of existing colleges and universities. In a Statement on the Objectives of Resolution 46, Mann urged the committee to consider the term "extension" in a broad sense, "not in terms of correspondence courses or limited classes for groups seeking specialized instruction" ("Minutes," Committee on Extension Services, December 15, 1954 , attachment). In striving to gain support for the branch college concept, Mann writes that he continually referred to the needs of the Northern Virginia commity. As ballast For his case, he supplied data about the growth and success of the University Center that he received from Finley (Mann, 1976).

Mann's efforts did not go unnoticed and support for a Northern Virginia college was established within the comittee. The comittee's final report to the Virginia Advisory Legislative Council recommended development of mbranches of existing institutions offering the first two years of college education." It stipulated further that 
"-the present university center in Arlington County be developed into a branch of the University of Virginia offering two-year courses, both in the field of liberal arts and other subjects for which there is sufficient denand in that area-" (Mann, 1976, p. 15).

House Joint Resolution No. 5, which both acknowledged "a great need for the establishment of facilities for higher learning in Northern Virginia" and recommended that a branch of UVA be established there, was presented to the General Assembly in January 1956 (House Joint Resolution No. 5 in Mann. 1976, insert between pp. $17 \& 18)$. Mann argued persuasively for the resolution, emphasizing the anticipated increase in college attendance, the high college attendance rate of students from the Northern virginia area, the benefits to those persons who could not afford to send their children away to school, and the advantages of establishing an accredited branch over the center that was already in place. The resolution was favorably received. The resolution sailed thru the [Education] Comittee, the Bouse and the Senate, with only one hurdle. T'he Education Committee was suspicious that the branch might turn into a full blown college, and that the resolution was but the camel's nose under the tent. Having rade it plain that the resolution was 
in possible jeopardy. Mann agreed to add a section to the resolution which stated "offering two years of collegiate instruction, which branch shall provide instructional facilities only." Later events at George Mason proved the Education Committee-s suspicions were well founded. (Mann, 1976, p. 19)

Mann writes that following acceptance of House Joint Resolution No. 5, Senator Penuick, Delegate Magruder, and Mann, himself, envisioned the possibility of a four-year college, however, they kept their thoughts to themselves, so as not to jeopardize the new branch.

Shortly thereafter, a "Board of Control" with representatives from each of four localities--Alexandria, Arlington, Pairfax, and Palls Church--was established, not to govern the new college, but to be "the vehicle for obtaining and holding title to the property of the branch. It was thus early and clearly established that the branch college was the property of the localities, a fact which was very quickly forgotten by the Board of Visitors of the University and subsequently ignored by that body" (Mann. 1976. p. 20). Mann served as the Board of Control's first chairman. The Site 
Meanuhile, the local Advisory Council began to consider sites for the new branch. A letter from the chairman of the council, Clarence Steele, to the members of the City Council of Alexandria stated the Advisory Council hoped to announce the college's permanent location by mid-June 1956. They expected it to open, either in permanent or temporary quarters, in October of that year. Also in the letter. Steele indicated the importance of obtaining funds for the college so as not to delay its opening. An attached budget listed estimated expenses for salaries, books, furniture, supplies, athletic equipment, custodial supplies, utilities, and repairs as $\$ 161,000$ for $1956-57$ and $\$ 222,000$ for 1957-58 (C. A. Steele, personal communication, June 1, 1956). Despite the good intentions of the council, however, the college did not open that fall.

Mann writes, "The future looked like clear sailing. It wasn-t. Immediately in front of the Northern Virginians was a totally unexpected and unpleasant experience.. . like being asked to a party and being met at the front door by [a] cold bucket of water in the face" (Mann, 1976, p. 22). A controversy erupted over where to permanently locate the new branch of UVA. The location had to be approved by the Advisory Council to the center, the Board of Control of the college, the localities, the Board of Visitors of UVA, the State Council of Higher Education, the Governor, and the 
General Assembly. The decision was made neither quickly nor easily.

\section{The Fight}

The controversy escalated rapidly and was played out at every level. of decision-making, as well as in the media. In a petition to the UVA Board of Visitors by the "students for a CONVENIENTLY LOCATED COLLEGE," students of the University Center who anticipated enrolling in the new branch college, outlined the problem.

A University of Virginia Advisory Council. after passage of the legislation, was directed to select a site for the Branch from among a number of tracts which were offered in the Northern Virginia area as locations for the University. This council . . devoted more than two years of study, many miles of travel, on-site visits, and lengthy deliberations, to the advantages and disadvantages of the various sites. Its membership voted unanimously to recommend a tract which had been offered at Ravensworth, near Springfield. . . Yet, after its unanimous report favoring the Ravensworth tract had been made, a three-man subcomittee was named by the University, headed by Judge 
Bryan of Alexandria with a gentleman from Richmond and a gentleman from Lynchburg.

This subcomittee, after but a few weeks of consideration, and with complete disregard for the unanimous opinion of 19 Northern Virginia political, business, and educational leaders, brought in a report recommending a site near Herndon, which:

1. Is 23 miles from Alexandria and considerably farther from the Southern Eairfax County developments in the Mount Vernon area.

2. Is about. 18 miles from the center of Arlington.

3. Is without water, sewer, or many people. ("This is Your University," no date, pp. 2-4)

Mann vehemently opposed establishing the college at the Herndon site. He protested the action of the Universityappointed subcomittee which overturned the Advisory Council-s unanimous recomendation of the Ravensworth tract.

"I shall oppose the establishment of the institution at the inaccessible location for the majority of our people," Mr. Mann said. "This opposition will be expressed to the board of visitors and, if necessary, to the 
General Assembly.

"I will protest expenditures of a single dollar of State funds for property that places the location of this branch so far from the population center of the area it is designed to serve." ("Mann Hits," 1956, no page number)

Mann had evidence that supported his position. Mileages from various Fairfax locations--Falls Church, Bailey“s Crossroads, Seven Corners, and washington and King Streets-to Herndon were recorded on a piece of Mrs. Mann's engraved stationery that is part of Mann's collection of papers.

A "Letter to the Editor" echoing Mann"s sentiments was distributed to the Northern Virginia newspapers by Uilliam Simms, Chairman of the Springfield Comittee for the Northern Virginia University Center. This committee was composed of many local organizations such as the Annandale Kiwanis Club, the Franconia Civic Association, the Garfield Parent-Teacher Association, the Springfield Lions Club and Cub Scouts Pack 856, to name a few. Simms also wrote to alumni of UVA living in Fairfax County urging them to express their concerns to both the Board of Visitors of UVA and President Darden (ti. C. Simms, personal communications, September 24,1956$)$. The localities in this instance clearly favored the recommendation of the Advisory Council 
(Ravensworth) over that of $\mathrm{UVA}^{-} \mathrm{s}$ subcommittee (Herndon), however, as is later to be seen, there was not unanimous agreement on a site among the various localities, themselves.

Minutes from the Board of Visitors meetings during the spring of 1957 show that the University requested its subcommittee to negotiate with the Board of Control in determining a site ("B.0.V. Minutes," March 9, 1957). Minutes from the June meeting, however, acknowledge the "lack of progress" in establishing a permanent location ("B.O.V. Minutes," June 7, 1957). President Darden then requested, and authority was granted, to house the college in temporary quarters until a permanent site could be found. The University College Opens

Although the controversy over a permanent site for the new branch continued to brew, the college opened its doors in temporary quarters that fall. "The University College, a two-year, coeducational institution, was opened in 1957. Its campus was an abandoned schoolhouse at Bailey's Crossroads with 17 students and three full-time faculty" (George Mason: The Man and the University, 1976, p. 15). The University College was distinct from the University Center that remained part of the Extension pivision of the University of Virginia, however, both shared one director; J. N. G. Pinley. 
A published profile on Finley, part of Mann's special collection in the archives of GMU, states that the opening of the University College was an enlargement of Finley-s mission from Darden, eight years prior, to establish a community college in Northern Virginia. The new college and the old center had some similar, but many distinct, features. Although Pinley acknowledged that he was to head both entities, he stressed that "for the time being, the two will operate separately and that all facilities for the older facility will continue to be provided" (Monk, no date, no page number). A letter to Finley from Dean Zehmer of the Extension Division emphasized the importance of making "a sharp distinction between courses that will be offered within the college organization and those which will fall in extension" (G. B. Zehmer, personal communication, May 3 , 1956).

Although some students from the center planned to enroll in the new branch, the University College was created for another student population; more traditional-age students who were not leaving home to attend college.

The Extension [center] deals mainly with persons out of the category of recent high school graduates, it was pointed out, and is principally an evening institution. The pressing need now, wet in a small measure by 
the two year University college which opened

this week at Baileys Crossroads, is for

facilities for the high school graduates of

the coming years. ("Outlook Brightens," 1957,

p. 2)

The centers Advisory Council continued to play an active role in the affairs of the new college. Chairman Steele urged civic leaders in Alexandria, Arlington, Fairfax, and Falls Church to show support to both the Governor and the General Assembly for operating funds for the 1958-59 biennium. The council created a Committee on Public Information to inform local citizens and civic organizations of the college's activities. The new college was under way, however, the debate over its permanent home continued.

\section{A Site is Chosen}

In November 1957, the Board of Control approved and recommended three sites for the college branch to the Board of Visitors. Rejected by the Board of Control was the Herndon property, for despite the fact that it was offered as a gift, it was considered too far from the majority of people it would serve. The state Council of Higher Education urged the four Northern Virginia localities of Alexandria, Arlington, Fairfax, and Falls Church to agree on a site so that it (the council) could request construction 
funds from the Governor. The localities unanimously agreed on the Ravensworth site.

Five days later, the UVA Board of Visitors selected the Herndon tract, rejecting the Ravensworth land favored by the Northern Virginia localities. The Board of Visitors decision prompted a great deal of controversy. "Mrs. Anne Hilkins suggested that the four nearby jurisdictions, which already had indorsed [sic] the Ravensworth location, buy the tract near Springfield and invite some other educational institution to locate there. Hers was among the shocked reactions that many Northern Virginia officials expressed at the board's decision" (Hope, 1958, p. A13).

Mann voiced his opinion that the State Council of Higher Education would not approve the Herndon site and declared his feelings about the board's decision in strong terms.

"In effect, the visitors have said to the four governing bodies and all the members of the Tenth district delegation to the General Assembly, You have nothing to do with your own college. The wishes of a small group near Herndon are more important than the convenience of 450,000 people near the center of population, " Mann said. (Bruns, 1958, p. 4D) 
Nevertheless, the Board of Visitors referred the Herndon property to Governor Lindsay Almond for approval. Although Almond did not reject their selection, he requested that other sites be considered. Senator Charles Fenuick of Arlington suggested a site adjoining the town of Fairfax which the board designated "suitable." (Orndorff, 1958, p. 2D). Finally, the many factions reached a compromise and in December 1958 the town of Fairfax purchased 150 acres of land for the college. One year later, the name "George Mason College of the University of Virginia" was selected by the University Board of Visitors to honor the patriot gentleman of Fairfax, George Mason.

The location of George Mason College obviously was an issue of considerable importance. Although Fairfax County now is so populous that it seems hard to imagine that twenty-some miles could cause the stir it did, one must remember that Herndon was much more rural thirty years ago. Without assured access to stuaents, George Mason would not have flourished as it has. Northern Virginia, once a "bedroom community" to dashington D.C., and now its own burgeoning hi-tech metropolis, has provided the students, and the students have required much from George Mason. Gilley et al. writes

Time and time again in our study of colleges on-the-move we found institutions whose 
location created a climate conducive to a great leap forward. In some cases general location and/or regional demographics created an adverse environment that prepared a college commuity for major changes, and sparked a desire for new leadership. In others, the community was a positive influence, growing and developing so rapidy that the particular school was forced to change--and fast--just to keep up. (1986. pp. 46-47)

George Mason has relied on its location to establish a position in the marketplace. This will be discussed further in chapter eight. "The Physical Campus."

Building a Campus

While plans for the college"s new location were being finalized, classes continued at Bailey's Crossroads. In June 1960 the college formally separated from the Northern Virginia Center and the college's first dean, Dr. Lee Potter, was selected. Pinley remained director of the college, however, until his retirement in 1963. Meanwhile, construction of the new campus began according to a plan that envisioned an enrollment of 2,500 full-time comater students. The college moved in August 1964 to a campus of four buildings--North, South, East, and West--where 356 
students enrolled that fall.

As the physical plant began to grow, so did the college's ambitions. In October 1965 the UVA Board of Visitors approved the college's expansion to four-year status. In December a "Higher Ecucation Study Commission recommended the establishment of a regional university in Northern Virginia and indicated that George Mason might become that university" ("Highlights," 1981, no page number).

The year 1966 was a turning point for George Mason College. In March the General Assembly authorized it to become a four-year, degree-granting institution "with a long-range mandate to extend into a university of major proportions" (George Mason: The Man and the University. 1976, p. 16). Three months later, Dr. Lorin Thompson of UVA-s Graduate School of Business was selected as the first chancellor of the four-year college. Projected enrollments for the college increased to between 12,500 and 15,000 students, and in November, the four localities of Alexandria, Arlington, Fairfax and Falls Church allotted funds to buy 422 additional acres for it.

Thompson presided over the development of the early campus: ten buildings were constructed during his sevenyear administration. Also, under his direction, the college awarded its first $B A$ and master's degrees and received 
separate accreditation from the Southern Association of Schools and Colleges. The time was ripe for legislation. enacted in March 1972, that separated GMC from UVA and elevated it to university status. The new "university" soon established the College of Arts and Sciences, College of Professional Studies, and Graduate School, and named Thompson its first president.

Thompson retired the following year and Dr. Vergil Dykstra became the university ${ }^{\circ}$ second president. Michael Bmsley, Chairman of the Department of Biology at that time, writes that Dykstra's style of leadership differed a great deal from Thompson"s. "During his term, Lorin Thompson honed his skills as a self-confessed "wily old buzzard," and successfully resisted all faculty incursions into the arena of administration. With the appointment of President Dykstra in 1973, there entered a breath of philosophy and a veritable blizzard of democracy. Committees sprang up like nushrooms for every conceivable activity" (Emsley, 1984, p. 8). Emsley implies that the tilt in democratic direction perhaps was too steep.

Since its origin in 1957, George Mason had been primarily a teaching institution, and the faculty of the mid-seventies was not strongly research-oriented. . . Many of the faculty were shy of scholarship, and the 
rules for promotion and tenure were couched in such nebulous phrases as ". . must have demonstrated his capacity and concern for research and scholarship. . ." cold Faculty Handbook, page 32). Notice that performance is not specifically required, just potential.

Movement toward traditional university requirements was resisted at every turn, and some faculty members seemed to turn their backs on scholarship by becoming full-time committeemen or standard-bearers for a wide variety of causes. (Ensley, 1984, p. 8)

The university was searching for direction, however, its top administrator was not a strong leader. Dykstra resigned in 1977 and Robert C. Krug, Vice-President of Academic Affairs, stepped in as Acting President on the condition that his appointment be temporary. Unlike some persons in an interim position who merely maintain the status quo, Krug worked with the Board of Visitors to achieve some significant accomplishments during his 14 months as president. A faculty member commented that Krug provided a sense of direction and built morale. The student government president praised him for both stabilizing the campus during "one of the worst periods in GMU's history," and acquiring "a far better budget from Richmond than GMU 
had obtained in previous years" (Cseplo, June 20, 1978, p. 3). Krug`s performance was considered so exceptional that the Board of Visitors named him George Mason*s third president one month before he resigned, retroactive to the beginning of his appointment.

\section{A New Direction}

Irug's successor, George $\mathrm{W}$. Johnson, provided the surge of energy that GMU required to catapult to the level of distinction it now enjoys. Although Johnson's ideas, strategies, and demeanor were, and are, not always accepted harmoniously, most persons credit him with building GMU into the university it is today. Johnson is a different type of adninistrator than were any of his predecessors. In addition to intensive strategic planning and reorganizing, Johnson has concerned himself with enhancing the university"s stature. "With the appointment of President Johnson, the winds of change swept through the University, bringing new goals, new ambitions, and a new style," wrote Emsley (1984, p. 8). From this point forward, most "significant events" at the university were either part of Johnson's organizational plan or a result of the university`s exploiting serendipitous opportunities. In fact, at GMU the latter is part of the former, and these will be discussed further in the following chapters.

\section{Conclusions}


GMU*s history, while not addressed specifically in the framework of image-making outlined by Topor, is an important consideration for this study. Although Topor (1986), Gilley et al. (1986) and Lynton and Elman (1987) tend to emphasize the present and future, Deal and Kennedy (1982), Keller (1983), and others remind us of the importance of considering beliefs, values, and traditions--historical dimensions--of an institution.

This chapter has touched on some noteworthy aspects of GMU`s history such as its initial tie to UVA, which brought it a certain automatic prestige; its link to the surrounding commuties it was established to serve, a part of its mission that continues to be important in decision-making: its neophyte status that has allowed it greater discretion in program planning than many institutions with more longstanding reputations enjoy; its leaders, individuals who have actively shaped the institution's course; and the political nature of public higher education, a factor that must be considered in institutional planning.

Gilley et al. (1986) identified three "movtivating forces" present in nearly all of the "on the move" institutions they studied. These are location, adversity, and leadership, with an emphasis on the latter attribute. This chapter, and the following two that focus on the people and plans of GMU, show how two of these forces, location and 
leadership, have been factors especially significant to GMU's rise in stature. 
CHAPTER FIVE

The Players

Although the names of colleges and universities often invoke images of bricks and mortar, it is people, not buildings, that form an institution's true essence. Deal and Kennedy (1982), Topor (1986), Gilley et al. (1986), and Lynton and Elman (1987) each proclain the importance of people to successful organizations. While presidents can impact upon colleges and universities greatly, many other persons-faculty, staff, students, and "heroes"--can make a difference, too. This certainIy is true at GMU.

\section{People and Culture}

Deal and Kennedy (1986) found that most employees in the "outstanding" corporations they studied held similar beliefs and values that contributed to a sense of strong culture. These organizations also had "heroes" who were role models for other employees and symbols to those outside the organizations.

The hero is the great motivator, the magician, the person everyone will count on when things get tough. They have unshakable character and style. They do things everyone else wants to do but is afraid to try. Heroes are symbolic figures whose deeds are 
out of the ordinary, but not too far out. They show-often dramatically--that the ideal of success lies within human capacity. (Deal and Kennedy, 1982, p. 37)

Deal and Kennedy make a distinction between "born" and "made" heroes. They define "born" heroes as "visionary heroes, the people whose influence lasts for generations," and they label situational heroes, or those who excel on particular occasions or in specific instances, "made" heroes (Deal and Kennedy, 1982, p. 43). Although heroes are inspiring individuals, not always are they charismatic, according to Deal and Kennedy. "In contrast to the warm. humane managers promoted by business publications today, . what businesses need are individuals concerned about building something of value and sensitive mostly to the needs of the organization they are trying to establish. Call it bastardly, but also call it heroic" (p. 56). In keeping with these descriptions, one might characterize President George Johnson as the born hero of GMU.

\section{George W. Johnson}

A national survey of 485 persons, including college and university presidents, association and foundation heads, and higher education scholars, denoted 100 college and university presidents the "most effective college leaders in - the country" ("Six Presidents," 1986, p. 7). Six presidents 
from Virginja were selected and George Johnson of GidU was one of those six.

Johnson came to GMU in 1978 from Temple University, where he had been Dean of Liberal Arts for ten years and Chairman of the English Department before that, He was selected for the position of president from a group of more than 280 persons. Shortly after his arrival, a reporter from the student newspaper, Broadside, interviewed Johnson about his plans for the university:

He feels that a major goal is the establishment of a distinguishing characteristic of the university. Areas of potential strength he feels, include, "the quality of academic programs and the experience available with the faculty. George Mason ought to become a cultural center. . .

"I don't believe public relations is something you add on to a university [he said]. It has to grow out of the center. First a university has to have distinguishing features. Then you can get somebody to publicize." (Kreitler, 1978, p. 1)

Johnson was guick to identify "distinguishing features" at GMU. During his first year in office. GMU acquired a law 
school through a merger with the International School of Law, despite a recommendation against the merger by the State Council of Higher Education and the state-s bar associations. GMU also received approval of two doctoral programs. Johnson saw these programs as "first steps in the race to make George Mason a full-scale university" (Sanders, April 5, 1979, p. F-X5).

During a speech in 1984, Johnson predicted that Washington D.C. would become the Paris of the next century and GMU would be comparable to Stanford University. This statement was met with skepticism by students, faculty, and the community, however Johnson stuck by his vision. In a 1987 address to the general faculty, Johnson urged them to press ahead for the next five years, again, comparing GMU's ambitions to those of more well-known universities.

"We have to resist the temptation to pause and rest," he said. "I have a theory that most great universities, incluaing Harvard and Stanford, achieved their stature in a short period of time. I think if we pause at GMU, we pause for a long time," he continued. "I think we can stand the strain, and that in four years we will have crested the hill." (Ackerman, 1987, p. 3)

Some of Johnson"s critics accuse him of "selling" the 
university, however, that charge probably would please him as long as these critics acknowledge his success. Johnson and others at GMU use the term "exploit" freely when discussing their operating methods. Their "exploitation" of opportunites means, simply, that they take advantage of every resource available to them.

Johnson, known in Richmond as a master of hard-sell and a duke of cunning and selective diplomacy, . . has tapped nearly every outlet of power and influence in the state, cutting a path across the social, political, and economic landscapes that could serve as [a] road-map to power in Northern Virginia. $\Delta t$ the same time his slick and sometimes controversial lobbying on behalf of George Mason has led him into the political trenches, headlong into the fold of area businesses and sometimes straight into the scorn of his own university faculty and students.

But even his sharpest critics concede that Johnson has made things happen at what some students boastfully call "the other George university" in the washington area. (Feeney, 1983, Pp. CI, 4) 
Johnson readily will sacrifice decorum to advance university causes. He also expects a large degree of commitment from faculty and staff. Joan Fisher, former vice president of development at GMU, remarked that Johnson-s style of management was "clearly disruptive" sometimes. She says it has had "everyone from the president"s wife to the vice presidents doing things that would normally not be expected of them.- Fisher says she once had to pick up liquor for a university function and her secretary once had to vacuum an entire auditorium" (Feeney, 1983, p. C4). On another occasion, when Johnson appeared at a Faculty Senate meeting to address rumors that he held the faculty in contempt, he denied that charge, stating that he would not be at GMU if such rumors were true.

He reiterated a number of times, however, that if he considers a faculty position on something "a load of crap," he was going to Iabel it "a load of crap." . . In discussions later, a number of faculty members tried to visualize circumstances under which president [sic] Bok of Harvard or President Giamatti of Yale would tell their faculties that their positions were to be characterized in such a manner. (Cassara, 1984, p. 2) 
In an evaluation conducted by the GMU Faculty Senate"s Committee on Faculty Matters and the Senate-s staff in 1986 , Johnson scored high marks for improving the university"s finances and image, however, evaluations of his management style and internal communication skills were poor. Johnson focuses on advancing the university before placating the faculty. "As the place gets bigger and more complex," says Johnson, it demands more of everybody involved. That creates a certain amount of anxiety among people who wonder whether they can keep up. Not everyone can" (Peeney, 1983, p. $\{4\rangle$.

This picture of Johnson is consistent with Deal's and Kennedy's hero. They state that powerful leaders put their companies first. "They put business in their heart and thus crowd out softer sentiments. It's a lesson today's managers should learn as an antidote to the hype on business humaneness. Humaneness is important, but the goals of the culture are paramount" (Deal and Kennedy, 1982, p. 57).

Characteristics of a Good Leader

Gilley et al. (1986) observed presidents of "on the move" colleges and universities and determined that good presidential leadership is a leading factor in successful organizations. The qualities these presidents exhibited were an ability to shape the work environment. accessibility, compassion, far-ranging vision, intelligence 
and creativity, opportunity consciousness, persistence, skillfulness in public relations and team-building, and visibility. Gilley et al. also identified a trait they labeled "parallel perspective." The presidents they studied "came to their present jobs with a conceptual foundation on which they wished to build a plan for making major changes and for moving their school forward; usually a dramatic, wide-ranging, and detailed strategy with both general and specifjc applicability" (1986, p. 68). As an example of parallel perspective, Gilley et al. describe how the ideas Johnson brought to GMU were ones he had been pondering and forming for some time at Temple University. GMU provided the right place and the right time for expressing these ideas.

George Mason University president George Johnson told us of how he, as dean of the college of liberal arts at Temple University for 10 years, came to develop his own theory of what an urban university should be through pilot programs at the school. By observing Temple‘s successes and failures, and arguing with Temple president Marvin Wachman about Teaple's mission as an urban college, this perspective was well developed when Johnson accepted the presidency of George Mason--and, 
he had the opportunity to test his vision at a fledgling urban university. (1986, pp. 99100)

Determination, intelligence, persistence, skillfulness in public relations, vision, creativity and opportunity consciousness, qualities noted by Gilley et al., are characteristics Johnson displays. These traits, coupled with endless energy and a "just say yes" attitude, have taken Johnson and GMU far. Johnson believes there are tuo types of administrators:

the one who is always inclined to say "no" unless he or she can be overpowered, and the other administrator who will try to find ways to say "yes" and will only say "no" once all of the possibilities have been exhausted. And how does Johnson perceive his administrative technique? "Positive," he sailes, "is always better." (Hopkins, 1981, p. 5)

Although Johnson is optimistic about his administrative technique, his perceived lack of accessibility to many faculty and students is a problem. Misunderstandings about Johnson's priorities for GMU that occur in part because of poor communication have caused faculty discord. Johnson says that faculty were prepared for both a different pace 
and approach than the ones he brought to GMU. He admits that there have been many battles. "They [the faculty] went to the station to meet the president," Johnson says, "and the train went by." (personal communication, March 25 , 1988). On the other hand, as one dashington Post article explains, "If you put it to a vote on every campus in this country, you couldn't find a faculty that didn't feel it should have more influence than it does, nor would you lack at least one student on each campus who felt the president neglected the student point of view" (Ostar, 1983, no page number).

\section{The Administrative Team}

One of Johnson's strengths in image-making lies in his administrative team. One of his senior vice presidents is J. Wade Gilley, co-author of Searching for Academic Excellence, former president of three colleges and former Secretary of Education for Virginia. Gilley knows about "stature enhancement" and works with Johnson and others to ensure a coordinated institutional approach. As testimony to his ties to GMU (or perhaps Johnson's persuasiveness), Gilley recently withdrew his name from consideration as one of two finalists for the position of chancellor of the Oregon State System of Higher Education. Gilley says the job "would have been a great challenge in a beautiful state. . . But after weighing everything and listening to 
Dr. Johnson and Dan Bird, I decided to stay"" ("Gilley Withdraws," 1988, p. B5).

Gilley is coordinator of a five-member legislative lobbying team, which also includes the president, a government liaison officer, the financial vice president, and the budget officer, that meets throughout the year to set budget objectives for the institution. This team ensures that GMU has "distinguishing features" to promote.

Before the legislative session begins, the team gathers information, finding out where state revenues are going and how much is going to be available to higher education. Tean members talk with the staffs of the governor and legislators to learn their priorities. "Then we set our goals, which are achievable goals, and pursue them," Gilley says.

In late sumer--again, before the legislative session begins--George Mason"s president tours the state visiting 25 selected legislators in their home districts, seeking their input. He invites the legislators to tour the campus and meet some of the trustees. The trustees, in turn, also initiate other legislative contacts. "we try 
to put everybody to work," says Gilley.

The lobbying effort also draws

assistance from the George Mason Institute, a

non-profit research corporation. The

institute"s 42-member board of directors

includes business leaders. "They"re helpful

in dealing with the legislature, which is

interested in economic development," says

Gilley. Businesses involved in the Institute

also provide direct donations for favored

projects, thus persuading the legislature by

example. ("Legislative Lobbying," 1986, no

page number)

GMU's approach to lobbying the state legislature,

described above, reiterates the importance of coordinated administrative teamwork and also identifies two other groups--the university ${ }^{*} s$ Board of Visitors and the Northern Virginia business comunity--whose influence and importance to GiU's success extend beyond the lobbying area. Johnson has a good relationship with both the board and the business community.

The Board of Visitors

GMU's Board of Visitors, responsible far setting policies for the university, sees its major goals as "getting the programs, facilities, and faculty demanded by 
Mason's rising reputation. Related efforts. . involve boosting faculty salaries, building a strong base of alumi support, and developing a stronger residential campus" (Odin, September 27, 1985, p. 5). Most visitors are active in educational, economic, political, and social spheres beyond GMU. They provide a link to the external community and facilitate $\mathrm{GMU}^{-}$s growing reputation.

One of the board's past rectors and a prominent Pairfax businessman, John T. (Til). Hazel, is Johnson's own choice of persons most responsible for $\mathrm{GMU}^{-} \mathrm{s}$ growth. Hazel was a member of the search committee that recruited Johnson in 1978 and he also has been a major financial benefactor to GMU for many years. A history of GMU currently in progress will feature Hazel prominently, according to McParlane (personal communication, July 13, 1988).

\section{The Business Community}

The local business community has provided direction as well as great financial resources for GMU. Nevertheless, Johnson has been criticized for encouraging too close a connection with local businesswen and corporate leaders.

Some members of the faculty, students, and

financial contributors are worried that

George Mason is becoming nothing more than a

farm team for Pairfax County's business

commity and the federal government. In a 
way they"re right, and Johnson is proud of

it. "For a long time the greatest value of

the university was its distance from

society," he says. "These are not the

times." (Mundy, no date, no page number).

Despite this criticism, GMU realizes that without the patronage of the local business community, it could not begin to keep pace with schools like the University of Virginia and the College of William and Mary that have older, established, influential alumi from whom to draw both financial and political support.

Lynton and Elman (1987) would agree with Johnson that increasing interaction between the university and society is advantageous. They discard old metaphors of "ivory tower," "city on a hill," and "multiversity" as inaccurate for the modern university, choosing instead, a geographic metaphor of a metropolitan region, "with no single center but many points and concentrations of activity. The university is a network or web of many nodes, each closely connected to all the others, and it engages in continuous two-way interaction with its environment" (Lynton \& Elman, 1987, p. 161). Although the modern university still retains a traditional vertical structure of departments, schools, and colleges, there also exists horizontal organizational, budgetary, and procedural linkages that cut across boundaries, they say. 
Iohnson understands and uses these links at GMU. To some, in fact, his actions of ten seem more like those of a corporate chief executive officer than of the president of a state university. As one administrator said, Johnson is ready to "short-circuit the system" to get what he needs. For instance, when the opportunity arose to recruit James Buchanan from Virginia Polytechnic Institute and State University (UPI), Johnson "took five minutes to decide" to do so (Johnson, personal communication, March 25, 1988). The quick decision-making Johnson exhibited is not routine in the bulky, bureaucratic state system of education, but it has worked for him at GMU.

Buchanan came to GMU in 1983, bringing with him the Center for Study of Public Choice which he had established at VPI with Gordon Tullock and Charles Goetz. Three years later, Buchanan won the Nobel Prize for Economics. "An editorial in the Pairfax Journal read, The award nails down the university's credentials as an institution of growing national stature, of course, but beyond that it should dispose of any lingering doubt as to the good sense of the policies of GMU president George Johnson-" (Roebuck, 1986, p. 8).

\section{The New Faculty}

Buchanan is one member of the "new faculty" at GMU. This term is used loosely--several "new" faculty have 
actually been at GMU for quite some time, however, the term characterizes an expanding role for faculty members. Although the tension between "old" and "new," or "teaching" and "research" faculty began before Johnson came to Fairfax, the rift has been exacerbated by his demands upon the university. The complete problem cannot be labeled accurately as "old versus new" or "teaching versus research" because people are complex, multi-dimensional individuals and the university is not striving in one direction to the exclusion of another. It is correct to state, however, that GMO's comitment to growing quality is requiring more from faculty than ever before. This is an appropriate response to new challenges, according to Lynton and Elman (1987).

All this is asking a great deal of faculty and shows that if universities are to respond more systematically to external knowledge needs, they must raise, rather than diminish, the intellectual standards and challenges both for their institutions as a whole and for participating faculty members. (Lynton and Elman, 1987, p. 134)

\section{The Robinson Professors}

GMU has established one way of both challenging faculty and raising standards through the Clarence $J$. Robinson Professor program. In 1984 GMU received $\$ 5$ million from the 
estate of Mr. Clarence Robinson, a local businessman, to attract notable faculty to the school and to finance lectures unavailable without such funds. The gift qualified for dollar-for-dollar matching from the Virginia Eminent Scholars Program, and thus, became the foundation for a program of diverse named professorships that attracted, and continues to attract, several distinguished scholars to GMU. The Robinson Professors are quite distinct from other faculty. Shortly after an advertisement about the program appeared in The Chronicle of Higher Education, Johnson announced to faculty that for the first few years, scholars invited to apply for these positions would be chosen from outside the institution. Johnson explained that this was necessary to protect the integrity of Robinson's bequest and its tie to the Virginia Eminent Scholars Program.

Participation in the Virginia Erinent Scholars program is often contested... since it requires both enlarging and splitting a pie of money with the other virginia universities-and it is important that the university be very careful to preserve the legality of our claim on the state treasury. . .

We cannot afford to jeopardize the validity of the bequest by any subterfuge 
which would use the money internally for the benefit of faculty already here. (Johnson, April 3, 1984, p. 10)

One Robinson professor implied that Johnson had his own agenda. "When schools get large sums of money, normally they will spread it around the departments. George Johnson decided not to do this. He wanted to get people from the outside. He [Johnson] feels that departments are a hinderance to universities as educational facilities, although they are okay for research universities." This professor sajd that although the Robinson professors are affiliated with departments at GMU, they were promised more flexibility than at their previous institutions. They were to fill a role nestled somewhere between faculty and administrators. "Johnson wanted to "see what happens, " he said, "and now we are trying to decide what to do now that we"re here" (Robinson Professor, personal communication, March 23, 1988). This sense of experiment was part of what attracted this professor to GMU.

The Robinson Professors offices are located in an enclave on the second floor of one of the original four canpus buildings. They meet together every other week to discuss educational and philosophical ideas. They maintain contact with other faculty through comittee work, however, "there is a very clear difference between the regular 
faculty and these [Robinson] professors. One of our main functions is to be an instant senior faculty," one Robinson Professor explained. "At every university, there is a core of older faculty to advise the administration. This was lacking here because the university hasn't had time to develop" (Robinson Professor, personal communication, March 23, 1988). Johnson was aware of the need for more mature faculty even before the Rohinson Professorships were established. In a 1981 interview Johnson said, "-In an emerging institution that is developing dramaticaliy in programs, you ve got to provide senior faculty role models for junior faculty. It gives those deserving people already here a chance to become the senior faculty of the future-" (Hopkins, 1981, p. 5).

Although GMU may be in a developmental state, it appears to be progressing in the right direction. One of Topor's characteristics of institutional quality concerns the ability of faculty, staff, and administrators to achieve the objectives of the institution ${ }^{-5}$ mission. Johnson is ensuring that those persons responsible for expanding and fulfilling the mission are the best he can find. Some academic "stars" at GMU include Andrew Sage, "considered the world's leading expert on artificial intelligence" (Intress, 1987. p. Al); anthropologist Mary Catherine Bateson. daughter of Margaret Mead and Gregory Bateson; Roberto 
Marquez, specialist in Caribbean and Hispanic literature; and Roger wilkins, Pulitzer Prize-winning author.

When one Robinson Professor was asked his perception of peer institutions" thoughts on GMU, he replied, "there are no peer institutions. George Mason is unique. There is no sense yet of how it will work finally, but the slope is positive. The university is up and coming, but it hasn't arrived yet." This professor admitted that before he accepted his position, he had to consider whether he could handle GMU's relative anonymity. "I had my own professional reputation to go on, GMU or no," he said. "Also I realized that many professors west of the Appalachians have a loose perception of the distinction of individual state universities. They don't know VPI from UVA" (Robinson Professor, persional communication, March 23, 1988).

Is this professor happy with his decision to come to GMU? "We are being treated pretty well. It's hard not to be happy. There are some of the same problems here as there are at other places--such as the physical plant. It's a frontier atmosphere, but with benefits such as more money and status, it is easier to cope with these problems," he said. "It is harder for others. Among the faculty, there is a bit of jealousy, but not as much as $I^{-d}$ imagined. When I arrived, I met with a geology professor who said how's it going?- I told him my air conditioner didn't work, and he 
said -good. - "

While some faculty have little to complain about, morale problems that extend beyond pseudo jealousies over air conditioners have prevailed at GMU for the past few years. For example, many faculty feel that the College of Arts and Sciences is losing its place as the central core of the university. "Problems in George Mason's College of Arts and Sciences range $f$ rom a high turnover in the dean's position to a feeling among faculty members that Johnson is sacrificing quality in arts and sciences to build flashy new schools and programs" (Natale, July 6, 1988, p. Al0).

The New Provost

Johnson is looking to Provost Clara $M$. Lovett, who was recruited by GMU in 1988, for help in defining GMU's character. Johnson said, "She is a scholar, a proven administrator, and she brings with her exactly the talents that we need at George Mason" ( $p$. Al0). Lovett came from George Washington University (GWU) where she was credited with "binding a college of disjointed departments" ( $p$. AlO). "There"s no question that my greatest contribution [to GWU] has been to strengthen and unify the faculty of arts and sciences-to give them a sense that the whole is more than the sum of the parts." said Lovett, who sees herself as a risk-taker with good 
management instincts. (Natale, July 6, 1988 , p. Al0)

In Natale-s article, Lovett implied she would address complaints by GMU's arts and sciences faculty, however, she simultaneously noted that a university "gearing toward reality and the area it serves" has to extend beyond the arts and sciences, a point made often by Johnson.

\section{The Students}

The student population at GMU is much less "traditional" than those found at several other state universities. For example, one professor who recently came to GMU spoke of the pleasure he found in teaching a larger number of adult students than he taught at his previous institution. "The joy is they"re here because they want to be. They aren't intimidated. It's very rewarding. still, one-half the students are "traditional undergraduates." Some are very good, some are not so good," he said. The Scholastic Aptitude Test scores of his previous students were better generally than the scores of GMU students, yet, he has not noticed much difference in the quality of students. In fact, he said, "students at GMU are more interested in what's going on. I get stopped here by students who ask questions about the theory of evolution, for example. This never happened at [his previous institution]" (personal communication, March 23, 1988). 
Deal and Kennedy (1982) recommend observing and talking with people to gather clues about an organization. Several students willingly offered their views about GMU. Most noted the school's convenience, low tuition, and growing reputation as reasons for their choosing GMU. One adult student, John, said he selected GMU because it was "close, cheap, and good." A classical music student, he enjoys a good rapport with his professors, however, he finds most students young and inexperienced. Because GMU is so large, and because there are many part-time students, John says one easily can "get lost in the cracks." Nevertheless, he quit his job to attend GMU full-time and he plans to continue his graduate education there upon finishing his bachelor ${ }^{-}$ degree (personal communication, March 14, 1988).

A communications major in her senior year, Sara selected GMU over Baylor University in Texas because "I ve lived in this area my whole life and $I$ am very close with my family." Her brother-in-law received both his bachelor"s and master ${ }^{*} s$ degrees in economics from GMU several years ago. When Sara was debating where to go, he told her that GMU was a great school then and was destined to become even better. Sara agrees wholeheartedly. Although her family lives nearby, Sara elected to live on-campus during her first two years, a decision that helped her feel part of the school. "There is a big controversy now about giving 
freshmen priority to Iimited dorm space. More dorms would help dispel the view of GMU as a commuter school," she sajd. "I have always been impressed with the faculty here," she continued, "but it is time for GMU to focus on campus life, activities, and tradition. I would like to see more sports involvement, more participation by the students. Apathy occurs here because lots of students work and go to school and they aren't around for activities. Now that I am graduating. I wish Mason had a football team to draw support from alumi. Basketball is nice, but there is something special about football" (personal comunication, March 23, 1988).

It is difficult to measure the effect students have had on the global image of GMU. It is easier to see the effect that $\mathrm{GMU}^{-} \mathrm{s}$ expanding stature is having on its students. Snatches of student conversations such as "When I was at T'ech," and "I didn't like Harrisonburg [home of James Madison University] at all. There was nothing to do there," are consistent both with information from the admissions office that students are transferring to GMU from other good schools, and with Gilley et al.'s (1986) observation that good location is a major benefit.

Student enroliments have increased steadily over the past five years culminating in an all time high of more than 18,900 students in the fall of 1988 ("Enrollment Up," 1988). 
While there was a 14 percent increase in the number of students from the Northern Virginia area from 1983 to 1987. there also was a 142 percent increase in the number of Virginia students from outside the area, and a 78 percent increase in the number of students from out-of-state ("Factbook," 1987-88, p. 30). This supports the theory that GMU`s reputation is spreading geographically.

Conclusions

This chapter has shown the importance of people to an institution"s image. It also has shown that individuals do make a difference. Just as Gilley et al. (1986) found that presidents of "institutions on the move" are significant to their progress, this study found that Johnson is a key factor in the forward movement of GMU.

Johnson clearly is committed to GMU. He represents the institution to the world outside its walls, even though he is not as accessible to those within them as he could be. He came to GMU with a "parallel perspective" and visionary intelligence, even though he disputes the latter (Johnson says he isn't visionary--his business simply is to bring in good people who will bring about changes). As part of Johnson's plan, he has brought others to GMU that have added to its stature--most notably, the Robinson and other eminent professors--but also the business and corporate comunity. of whom one prominent figure is John T. Hazel. 
Johnson fits Deal's and Kennedy"s description of "born hero," that is, a motivating individual of unshakable character. He has helped define the institution according to Topor's characteristics of quality, by expanding and refining the mission, upgrading the teaching and learning experiences, understanding and responding to the needs of the community and the university"s constituents, and increasing the attitudes and self-perception of the university's personnel and students.

This chapter has examined some of $\mathrm{GMU}^{-} \mathrm{s}$ principal "players." Although it appears that Johnson is the primary player at GMU, his administrative team, which includes Gilley, among others, has been critical to his success. As stated above, prominent faculty and business and corporate leaders also have braught prestige to GMU, however, neither eminent alumni, "by far the most common method of ranking undergraduate colleges" according to Webster (1986), nor students have been major factors in shaping GMU-s image. These sources may become more influential, however, as time progresses and the university matures. 


\section{CHAPTER SIX}

The Plan

This chapter initially sought to focus on specific adninistrative plans for the university that have enhanced GMU`s image. In the course of this study, however, that focus broadened as two things became apparent with respect to administrative planning and institutional image-making at GMU.

Pirst, there is no single overarching plan instituted by Johnson. Instead, there is a philosophy of innovation and optimism, shared by Johnson, the Board of Visitors, and the majority of administrators and faculty, that undergirds decision-making at GMU. Second, the line between organizational planning and pronotional planning increasingly is blurred. Success in one area reinforces planning in the other and growth occurs in each through the "snowball effect."

This chapter examines some plans, activities, and changes that have attracted significant attention to GMU, manifestations of the administrative philosophy discussed above. Included in this examination are both the specific plans on which this chapter originally intended to focus, and also less tangible influences that became apparent as the study progressed. The university`s specific marketing 
strategies are discussed in the next chapter.

The Changing Environment

In New Priorities for the University, Lynton and Elman (1987) point out that many societal, technological, and economic changes occurring over the past few years now require a "broadening of scholarly responsibilities" for the university. Universities must realize that knowledge is transferred in new ways and make appropriate adjustments in their teaching and research methods. For example, they say that, "until recently, American universities have placed excessive emphasis on basic, nondirected research. On the whole, most academic institutions have neglected the next step--applying research findings in ways that would benefit the overall economy" (p. 18).

Applied research is emphasized at GMU. In a 1981 report to the Board of Visitors, Johnson spoke of his desire for GMU to become the "academic center" for Northern Virginia. Responding to the needs of the local economy was one way of facilitating Johnson's desire, however, this required expanding the university*s traditional mission. "We have an enormously dynamic "big league" economy burgeoning right under our feet, driven primarily by the high technology industry" said Johnson. Rurther, "most universities are not responding to the implications of the Information Age and the move by American industry to high 
technology" (Thomas, 1982, p. I). GMU recognized a need and moved to meet it in part by fostering a liaison with business and industry.

Strategic Planning

Gilley et al. (1986) found strategic planning a characteristic of "on the move" institutions. A GMU faculty member once said that Johnson was a "-strategic planner who has his finger on the pulse of the commonwealth-" (Hancock, 1985, p. 5). How do his planning methods and attitudes compare to the strategic planning characteristics described in Keller"s Academic Strategy, one of the few books on higher education that Johnson admits he has read? Keller (1983) identifies six distinguishing features of strategic planning:

1. Academic strategic decision making means that a college, school, or university and its leaders are active rather than passive about their position in history.

2. Strategic planning looks outward and is focused on keeping the institution in step with the changing environment.

3. Academic strategy making is competitive, recognizing that higher education is subject to economic market conditions and to increasingly strong competition. 
4. Strategic planning concentrates on

decisions, not on documented plans, analyses, forecasts, and goals.

5. Strategy making is a blend of rational and economic analysis, political maneuvering, and psychological interplay. It is therefore participatory and highly tolerant of controversy.

6. Strategic planning concentrates on the fate of the institution above everything else. (pp. 143-151)

Johnson's interviews, speeches, and messages to the GMU community over the past several years reveal an optimistic theme of change and leadership for GMU. For example, in a 1981 speech to the Board of Visitors. Johnson spoke of his desire for the university to "adjust to accommodate the high-tech industry in the area," an area in which "there are more high-tech employees that in the entire state of Plorida" (Thomas, 1981, p. 1).

Faced with "recurrent misunderstanding, and some conseguent resentment" from faculty. Johnson elaborated on what such an adjustment would mean.

A high technology business is one depending on the continual application of the state of the art to a product or a service. It is a 
firm whose whole being depends on a faster and faster transfer of new findings and new ideas to matters of the marketplace. Such firms depend upon creativity and innovation.

\footnotetext{
When I have stressed the University"s responsibility to develop close ties with high technology, I have therefore really been using "high tech" as a metaphor for change, for the need to create an atmosphere within our academic community which is truly conducive to unconventional thinking. (Johnson, 1983, p. 2)

Johnson and others at GMU emphasize the university`s boldness and individuality. "Our situation is one in which we dare to be different. . we must present ourselves as an institution of significant difference, $\cdots$ he said. "of all the colleges and universities in Virginia, GMU is clearly the best situated to seize tomorrow-" (Hancock,
} 1985, p. 1).

Johnson and others realize it would not be advantageous to try to become another University of Virginia or William and Mary. "We had to become an other-centered institution. not centered on ourselves, but centered on outside, " he said. "We could not hope to make our way if we were going 
to duplicate any of the established institutions"" (Audet, 1987, p. 2). George Gangloff, Senior Associate Director of Adnissions agreed. "UVA used to be our goal. We wanted to be better. Now we don t care about that because we are different than UVA," said Gangloff (personal communication. March 24, 1988).

\section{Multiple Initiatives}

As a part of strategic planning, some institutions, including Glu, are coordinating individual initiatives to attract resources, gain publicity, build morale, and stimulate creativity, according to Gilley et al. (1986). "Time and time again, we saw well-defined projects being initiated to advance an institution as a unified whole. The type of initiatives we observed were ones that executed a strong pull on an entire institution," they said (p. 82).

GMU is involved simultaneously in many creative enterprises. Some, such as its link with business and industry, and a new center to train commity college teachers, benefit the state as well as the university. Other initiatives, such as the law school's recent focus on economics, and the new Center for Conflict Analysis and Resolution benefit GMU by attracting national and international attention to the university.

Shenandoah College and Conservatory in uinchester. Virginia, received $\$ 15,000$ in October 1988 from the state 
Council of Higher Education to help finance a program that would bring GMU students to its performing arts program (Nalker, October 23, 1988). This joint venture between the Conservatory and GMU reflects GMU's current emphasis on arts and humanities. GMU also is building a multimillion dollar humanities complex as part of its effort to become "the" cultural center of Northern Virginia.

"An emerging community, such as Northern Virginia, needs focal points," said George Mason president George U. Johnson. "A university is one such focal point. That university should provide the arts as a living experience, a part of the community.".

Developing the arts and humanities means building centers, broadening course offerings, raising money for endowed professorships and making art part of the envi ronment, said Dr. Johnson. "Sculpture on our grounds, music in our halls, art on our walls--and all of it of top quality," he said. (Miller, 1984, p. 12)

The new arts center is expected to be completed next year. The center's advocates hope it will put to rest GMU's j.mage as an institution devoted solely to high technology. 
"-The coming of the arts is the maturing of this university and it will mature in a glorious way," said Nancy Hirst, a member of George Mason's board of visitors and a strong advocate of the humanities complex" (Neuberger, 1988, p. E1). The center also will help meet the needs of its growing surroundings. "With Northern Virginia emerging as a community in itself with its own cultural needs, the university has been serving as a hub of activity. Now it's taking the next step to meet the social and cultural needs, said Dwight Schar, president of NVRyan, the area"s largest home builder" (Neuberger, 1988, p. E9).

While GMU's Pairfax campus is growing, the university recently introduced plans to the State Council of Higher Education for opening a branch campus in nearby Prince William County. The council rejected $\mathrm{GMU}^{-} \mathrm{s}$ plans for the time being, nevertheless, Senator Charles D. Colgan of Prince dilliam said he would introduce a measure to the General Assembly to appropriate funds to study putting a GMU branch there anyway. Ten years ago GMU acquired its law school without the State Council's support, and Johnson seemed unruffled by its decision to reject the proposed expansion.

"George Mason represents discontinuity and instability," Dr. Johnson said, "so we-re a troublemaker by nature, and there's no way to 
disguise it. I have a great deal of sympathy for the state council and its staff.

"It seems to me their assignment almost has been to try to create relatively smooth, easy transitions, to maintain equilibrium, to concentrate on equitable distribution of resources, and to concentrate on stability and continuity.

"But $I$ 'm afraid that kind of linear planning is futile," he said. "I don"t think it works. Planning on the basis of continuity of trends is a good way to go bankrupt." (Nalker, October 16, 1988, p. A12).

Gilley et al. (1986) determined that state bureaus such as the State Council of Higher Education for Virginia often are obstacles for public institutions. "Federal and, especially, state authorities must abandon the view that initiative and even self-interest on the part of bright and entrepreneurial people are somehou bad. In fact, our only hope as a nation is to ensure that this creative energy is not only unfettered but encouraged!" (p. 116).

\section{Curricular Innovations}

Much creative energy at GMU has been applied to building strong academic programs. According to Gilley et 
al (1986), the curricular "developmental thrusts" of GMU`s strategic plan are:

high quality undergraduate liberal arts education, a reflection of its beginning as an undergraduate liberal branch of the University of Virginia; policy studies, because of its location adjacent to the nation's capital; fine and performing arts, resulting from the university's desire to be a cultural focal point in an emerging community; and high technology, reflecting the region's primary business and industrial community. (p. 139)

Topor (1986). states that an institution's academic programs a re the foundation upon which its image depends. "In order to change an institution"s image," he says, "actions must precede or accompany words" ( $p, 37$ ). Some unique programs that are helping form the foundation for $\mathrm{GMU}^{-} \mathrm{s}$ emerging inage include the George Mason Plan for Alternative General Education (PAGE); the Center for Conflict Analysis and Resolution; the law school's law and economics curriculum; George Mason Institute (GMI); and the School of Information Technology and Engineering (SITE).

PAGE

Lynton and Elman (1987) extol the virtues of 
multidisciplinary endeavors, despite the fact they sometimes are viewed as anti-departmental and consequently are difficult to fund. GMU has initiated an optional undergraduate program, PAGE, designed to fulfill general education requirements while at the same time allowing students to sample a wide range of academic fields.

The program emphasizes both breadth of knowledge and the acquisition of skills and provides opportunities for students to integrate and apply both knowledge and skills in order to prepare themselves better for living and working in contemporary society. Augmenting the interdisciplinary thrust of the various courses in PAGE will be two weekly lecture series (one credit each) by PAGE faculty and guest lecturers during each of the first three semesters. (George Mason University Undergraduate Catalog, 1987-88, p. 81)

PAGE grew out of a request by Johnson in 1982 to Jan Cohn, Chairman of GMU"s English Department, to "write a rationale and form a faculty committee to create an alternative general education place [program] that would be uniquely Mason"s" (Odin, Pebruary 15, 1985, p. 4). With funds from the State Council of Higher Education, Cohn and 
three other faculty members designed a new curriculum that considered technological, social, economic, and political issues and integrated general education with the outside world. "Replacing the introductory courses traditionally designed for majors in a discipline, PAGE would provide several interdisciplinary approaches to specific problems in each subject, and different learning environments offering the skills, information, and critical abilities that lead to productive Iives" (Odin, Rebruary 15, 1985, p. 4).

As PAGE was being initiated at GMU, severaI institutions nationwide were evaluating their approaches to general education. The creators of PAGE avoided networking, however, in order to achieve a unique perspective and approach. Although some faculty have reservations about the program, it has helped bring recognition to GMU, with the university co-winning a national award for innovation and qualifying for funding through the Virginia Punds for Excellence program (Johnson, September 19, 1986). The Center for Conflict Analysis and Resolution Hugh Megarry is blind, but he sees problems every day in his native Northern Ireland-unemployment, poverty and prejudice. So the 36-year-old shooting victim traveled to Pairfax County to try to see solutions, too. Megarry, a Protestant who works in a Belfast 
community center, was one of 20 Irish

Catholics and Protestants who took conflict

resolution lessons offered by George Mason

University in March. (Natale, April 1988, p.

\section{Al)}

GMU's Center for Conflict Analysis and Resolution is new. In fact, the discipline itself is only 20 years old, which is appealing to GMU. "The program's newness fits into university President George Johnson's plan to make George Mason non-traditional--a university offering what students can't get elsewhere. In September, George Mason will offer what George Mason officials say is the country's only doctorate program in conflict resolution" (Natale, April 1988, p. A5).

The center has four components: teaching, research, a clinical service program, and an outreach program. It has attracted noted faculty, organizational support, and endowment funds (Townsend, 1988). In its academic program, students analyze the nature of conflict and identify ways of solving problems that avoid aggression and violence. GMU is an appropriate home for the center because of the university ${ }^{*}$ proximity to Washington, B.C. and its penchant for new and different programs.

Law and Economics

- GMU merged with the International School of Law (ISL), 
opening a satelite campus in Arlington in 1978, after two previous unsuccessful attempts to start a law school. John Hazel, then Rector of the Board of Visitors, explained GMU's rationale for providing a law school in Northern Virginia. "The interest among people is there, and he [Hazel] considered it to be a realistic goal for GMU. It can be an aid for people already in government, for those who want a law background to aid them in business, or for those who are contemplating a change in careers, he [Hazel] continued" (Cseplo, July 12, 1978, p. 3).

Although some persons questioned how a merger with "a second-rate law school" ("Viewpoint," 1978, p. 4) would affect GMU's reputation, others saw the long-term benefits to the institution. One student wrote, "One of the criticisms leveled by opponents of the acquisition is that ISL is a second-rate law school and therefore unworthy of a nerger with GMU. The issue, however, should not be what ISL, is, but rather what it can become" (Bedell, 1978, p. 4).

During the last ten years, a span in which many other initiatives at GMU have been launched, the law school has made remarkable progress. Beginning with the 1986 appointment of law Dean Henry Manne, the administration moved in a new, albeit controversial, direction to "transform the traditional curriculum into one with a highly debated, sharply defined focus on law and economics" 
(Chiacu, 1987, p. Bl). In an address to students, Manne said, "the big, bustling university wanted something different than a program that mostly trained lawyers for local practice. The administration started looking for someone provocative, outspoken and controversial, and they found that in me, - he said." Manne stated further that the new focus would move the institution "to the top of the law school world"" (Townsend, 1987, p. 5).

The law school is not the only edifice Manne wants moved. A recent article said that Manne "wants to lure Northern Virginia's new federal courthouse out of Alexandria and onto his campus. . . We have got a great law school here. But if you want the world to know it, put a federal court right next door," he said" (Einucane, 1988, p. Al5). A new location for the Alexandria courthouse is being sought because of a space shortage, however, the feasibility of roving it to GMU's law campus has not been examined in detail. While the idea may seem far-fetched, lofty goals are routine in $\mathrm{GHU}^{-}$s recent history.

The goal of establishing GMU as a hallmark institution in law and economics is one of Manne-s dreams. Law and economics are a major part of the curriculum at some schools such as the University of Chicago and the University of Virginia, however, Manne wishes to make George Mason`s law school the first to specialize solely in this movement. 
according to Chiacu (1987).

Law and economics considers how the law works

in society: Are the goals of a particular

law being met? what is the likely result of

a legal decision? whom does it help and whom

does it hurt?

In the same way an economist considers

the behavior of the market under. certain

conditions, the lawyer-economist considers

the effect of certain rules, or laws, on

future behavior. (Chiacu, 1987, p. B5)

Although Manne planned to phase in the program

gradually, controversy arose when several professors, some with tenure, were asked to resign to make room for new faculty with strong economic backgrounds. "The dean concedes he would like to cull from the faculty those who do not support the movement. - I wish we could force them to leave,- he [Manne] said. We don't want anyone who isn't enthusiastic"" (Chiacu, 1987, p. B5).

While some faculty who remained at GMU agreed to Manne's suggestion that they obtain advanced degrees in economics, others complained that the economics focus is too narrow and does not apply to all facets of law. Students, in particular, were unenthusiastic about Manne*s changes. One student credited Manne with looking toward the future, 
but expressed concern about "somewhat of a disregard toward the students and faculty that were [a]ready at the law school] when this transition began" (Townsend, 1987, p. 5). When a Washington Post article entitled "Dean Brings Upheaval to Mason Law School: Special Program Pocuses on Economics" appeared in November 1987, stating that two professors had filed a complaint with the American Bar Association because Manne had not consulted with faculty before making curriculum and personnel changes, Manne responded quickly. He denied that faculty had not been involved in changes at the law school and he asserted that "-the overwhelming majority of this faculty are extremely happy with what's happening here-" (Collins, 1987, p. 29).

The main point is, you got a story like that is [sic] because they're looking for something that is juicy and gossipy and no, the big story here is how remarkably well this law school is progressing to a substantially, [sic] different new program. Almost everyone is solidly behind it. (Collins, 1987, p. 29)

Pour months later, the lau school was the subject of another Post article, "GMU Taps Judge Ginsburg to Boost Law School Prestige."

Judge Douglas H. Ginsburg, who withdrew his 
nomination to the Supreme Court in November after his admission that he had sooked marijuana, has been hired as a part-time visiting professor by the George Mason University Law School in its quest to transform itself from an obscure state-run institution into a center of the controversial law and economics movement. (Cohn, 1988, p. Cl).

The article stated that changes at GMU had received much attention from the local legal comunity, as well as from prospective students. After Manne arrived at GMU, applications doubled, and Manne predicted that Ginsburg would attract even more interest.

Not all of the interest Ginsburg attracted has been favorable, however. His hiring brought the school's decision to promote law and economics sharply into focus. Some local legislators objected to a state-supported law school moving in such a narrow direction and others were concerned that too many big-name scholars with strong conservative views had been hired. One legislator, who also is an attorney, stated that it is the Board of Visitors' job to shape the direction of the university. "And the current board, he said, is not strong enough, "especially in contrast with George Johnson, who is a strong individual . . 
- and [who] wants to make it a first-class university *" ("Lawmakers," 1988, p. Bl).

Johnson defended GMU's actions stating that GMU "is trying to give the law school a balance of practicality and intellectual creativity. 'It's got its feet rooted in the ground and its head in the clouds, a position the entire university should be in, he said" ("Lawmakers," 1988, p. B1).

Local citizens responded to the issue in support of both sides. One letter to The Journal said that "packing" GMU"s law school with "spokesmen for controversial and very dubious constitutional, legal and economic theories" went beyond academic freedom and, as a "mouthpiece for the promotion of notions championed by its leadership," was a cause for concern (Lowerre, 1988, no page number). Another letter expressed qualms about government interference in acaderne.

GMU broke away from the University of Virginia 14 years ago. Its image has changed to that of a first-rate university. There has been steady growth and a rise in quality. GMU is a case study in how a college can change for the better. Its ability to lure top scholars such as James Buchanan, Roger dilkins and Judge Ginsburg is a prime 
indicator of its success.

President George 4 . Johnson has almost single-handedly propelled GMU into the acadenic big leagues in parallel with changes in Northern Virginia.

Hopefully, the large private contributors and Northern Virginia corporations will have something to say about this unwarranted intrusion by disgruntled politicos whose objections are grounded in leftist ideology. (Gilmore, 1988, no page nusber)

The above discussions highlight aspects of $\mathrm{GMU}^{-3}$ law school that have allowed it, like the rest of the university, to attract substantial attention. The basis for the attention is grounded in change. Although changes at the law school have garnered attention, not all of it has been positive. Deal and Kennedy (1982) outline a plan for successful organizational change. They offer the following advice:

- place a "hero" in charge of the process

- have a good reason for mounting change

- create "transition rituals" for the change process

- provide "transition training" for new expectations

- bring in "experts" to give direction and credence to 
change

- establish tangible symbols of new directions

- provide security for persons during transition (pp. 175176)

Manne, key spokesperson for the law school's transformation, does not have the "hero" status that Johnson has established over time, and certainly the security of the law school faculty has been put in question. Better communication and following some of Deal's and Kennedy's suggestions such as involving personnel in change rituals, providing transition training, and establishing tangible symbols of the new direction may have eased the transition. The George Mason Institute

The Institute for Science and Technology at George Mason, Inc., or George Mason Institute (GMI) was established through a cooperative effort between the university and some of Northern Virginia`s businesses and industries. Gilley, senior vice president of the university, also is director of GMI .

GMU officials began conversing with Northern Virginia*s high technology industries in 1981. By the spring of 1982 , GIU had developed an Induscrial Policy Advisory Board consisting of top executives from 20 of these industries including AT\&T, BDM International, and TRW. Members of the board helped win approval of high technology legislative 
budget proposals and assisted in GMU's design of GMI as an "innovative model for University-industry-government liaison" (Johnson, 1982, p. 5). In 1982 Johnson wrote:

In the past twenty-five years, American high technology industries have accounted for $75 \%$ of exployment growth in the nation's manufacturing sector. This trend will accelerate for the foreseeable future. No longer will the proximity of raw materials, cheap labor, or railheads be crucial to America's economy. What will matter will be the availability of highly trained professional, skilled technicians and the proximity of educational facilities capable of providing the people and ideas on which this kind of industry depends.

High technology industrial leaders in Northern Virginia have identified a major university presence as one of the major factors that Virginia must address if the Commonuealth is to take advantage of the opportunity to enhance and advance the nascent high technology concentration in this area. . .

High technology leaders, along with 
influential political and business leaders, look to the full development of George Mason University as one part of the necessary response to a Commonwealth need. (Johnson, 1982. P. 1)

Johnson said that GMU had been working for several years to position itself to respond to the needs of the high tech community (1982, p. 5). "Positioning" is a key concept of strategic marketing outlined by Keller (1983), Ries and Trout (1981), and Topor (1986). GMI, "conceived as an innovative model for industrial liaison which could serve as a model for the nation" (Johnson, 1982, p. 7), helped GMU position itself to serve the needs of business and industry, the state, and the university, itself.

Some of $\mathrm{GMI}^{-5}$ programs include the Center for High Tech Manpower Research and Curriculum Development, which researches the need for high tech employees and disseminates the resulting data to educational institutions across the state; the Virginia Faculty Research Data Bank, an agent that connects faculty experts state-wide with high tech industries; and university faculty/executive exchange programs, which provide opportunities for university faculty to gain new experiences, as well as new resources for the university. Another project, the Industrial Affiliates Program, began in 1984 when the TRW corporation of Mclean, 
Virginia, engaged in an agreement with GMI that provided "money, company employees to help with adrinistrative work and teaching, cooperative jobs for students, free seminars, and occasional use of company equipment that may be too expensive for the university to purchase" in exchange for students for jobs and faculty for consulting and joint research (Dorsey, 1984, no page number).

Gilley (1985) reports that although there were high hopes for GMI's success, the initial few months of the program were difficult. "Then, in early 1982," he wrote, "George Mason President George Johnson had a heart-to-heart talk with a few supportive irdustry leaders. We learned a good lesson: Business executives were interested in helping accelerate the university ${ }^{-}$s development--but only as partners" (p. 30). These executives articulated their needs to GMU and GMU addressed these concerns. Gilley remarked that many long-term goals of business and industry--"such as using and advancing the state of the art in a discipline"-are not so different from those of a university ( $\mathrm{p}$. 3I). In addition to helping design GMI, the corporate community also played a large part in forming GMU's School of Information Technology and Engineering (SITE).

The School of Information Technology and Engineering

The School of Information Technology and Engineering (SITE), composed of three departments--computer and 
information sciences, electrical and computer engineering, and systems engineering--opened at GMU in 1985, the first such school in the United States. "Intended to bypass the conventional arrangements of oid-line engineering schools, GMU's newest academic unit is a direct response to the needs of high tech business and the information age" ("New School," 1985, p. 7).

Local business and industry leaders welcomed the new school and donated more than $\$ 500,000$, which supported five endowed chairs.

"This is a great step forward for the University and for the business and industrial community," said Earle Williams, president of BDM International, Inc. "In my view, none of the goals of our industry or of Virginia-s economic development can be achieved without the steady development of GMU as a special world-class educational institution," said Williams. ("New School," 1985, P. 6)

SITE has attracted international attention. In 1985 a group of computer scientists from China visited three U. S. schools chosen for their innovative technology programs-Stanford University, Massachusetts Institute of Technology, and George Mason University. 
You might think George Mason would be ecstatic to be in the company of stanford and MIT, but such occasions are actually becoming commonplace. The visit by the Chinese is just one more indication of George Mason's stature in high-technology education, and further substantiation of the Wall street Journal"s description of the university as "a giant . . growing just outside Washington in Virginia"s thriving Pairfax County." ("Advances," 1985, no page number)

The success of SITE has helped overshadow disappointment concerning GMU's attempts to establish an active relationship with Virginia-s Center for Innovative Technology (CIT), a nonprofit corporation designed to foster a relationship between the state's universities and businesses and industries, and to encourage research and employment opportunities. In $1983 \mathrm{GMU}$ offered 180 acres of its campus to house CIT, however, the offer was rejected despite Governor Charles Robb`s endorsement of Northern Virginia as a site and the support of several area high technology corporations who favored GMU.

Three other universities, the University of Virginia (UVA), Virginia Commonwealth University (VCU), and Virginia Polytechnic Institute and state University (VPI) were made 
host institutions for four CIT-sponsored institutes, a decision which Gilley said was made partly due to opposition f rom other institutions concerned about $\mathrm{GMU}^{-5}$ rapid grouth. A CIT official disagreed with Gilley, however, claining that UUA, VPI, and VCU were the true research institutions of Virginia, determined by the amounts of graduate programs, graduates, and research funds they had (Hancock, 1986). Despite a tenuous relationship with CIT, however, GMU continues to flourish in high technology education.

\section{Technological Innovations}

In addition to teaching about high technology, GMU uses sophisticated communication systems to meet the growing needs of students, faculty, and others. Lynton and Elman (1987) suggest two important areas to consider in maximizing the educational potential of technology: telecommunications as a delivery mechanism, and computers as instructional tools.

Telecommunications

On December 16, 1981, George Hason University ${ }^{*}$ microwave television station-The Capitol Connection--conpleted its first year on the air, broadcasting live gavel-togavel coverage of the House of Representatives, as well as Senate and House comittee hearings, National Press Club 
luncheon speeches, and public policy debates to offices, hotels, and apartments in Washington, D.C., and in Northern Virginia. On its first broadcast day, the closed circuit service, which can only be received with a special antenna and decoder box, had only one viewer--the Assistant Secretary of Commerce. Before the end of the year, however, the public relations firm of Bob Gray and Company, as well as Atlantic Richfield, and the Republican National Committee had signed up for the service. On its first anniversary. The Capitol Connection could count over 140 offices, apartments and hotels among its patrons, in a list that continues to grow daily and reads like a "Who"s Who" of Washington... . Probably George Mason Television's most wellknown viewer is President Reagan, who watches faithfully. . .

"When you think about it, George Mason"s television system reaches the most powerful and influential audience in the world, the movers and shakers, the decision makers of America," said Dr. Michael Kelley, English 
professor and now Director of

Telecommications at George Mason. Two

years ago, University President George

Johnson, [sic] asked Kelley to think through

the various things George Mason might do to

carve out a unique niche for itself in the

new and expanding field of

telecommunications. (Jenkins, 1983, p. 4)

In addition to the Capitol Connection channel, another channel provides a link via satellite to anywhere in the world. Studio facilities on campus allow faculty to videotape courses to be transmitted or distributed to libraries or other universities. GMU produced its first televised courses in 1985, a step that aided both students with full schedules and the university, which had a shortage of classroom space.

GMU established a committee to determine guidelines for university television courses. Nine policy guidelines that addressed issues such as faculty work-load credits for taped courses, repeated use of tapes, lifespan of taped courses, student counselling, and examinations were adopted and approved by the committee, the vice president of academic affairs, and the president (Moshos, 1985). GMU`s advanced telecommunications system is another example of how it anticipates and meets community needs in a way that reflects 
positively on its image.

\section{Computers}

Increasingly it is accepted in this society that computers are essential tools. A few universities now require that students own computers and almost all schools make them available to students and faculty, according to Lynton and Elman (1987). GMU does not require students to purchase computers, but offers a wide range of facilities that include a main state-of-the-art computer system, several microcomputer laboratories, graphics and artificial intelligence laboratories, and extensive software. The systems are connected through a local computer network, MasonNet, which allows cross-campus and off-campus access.

One model of automation success is Fenwick Library. GMU requested funds from the state in 1985 to implement a plan to become Virginia"s first electronic library, "a project that could one day allow users to find and read books and magazines off a computer screen" (Beyers, 1985, p. Al).

"He want to be a model for the rest of the state," said Charlene Hurt, director of Iibraries at GMU. "We think we have the experience and expertise to make it work."

To make it work, George Mason is proposing to merge its library operations 
with its computer staff. Such a "radical" departure from existing administrative schemes has been "widely discussed in the world of information technology, but few academic institutions have implemented the idea," states a GMU budget request. (Beyer, 1985, P. Al)

Presently, the library provides "computerized circulation, public catalog, and in-house processing services," as well as access to more than 300 data bases in many different fields (GMU Undergraduate Catalog, 1987-88, p. 15). Recently, three CD-ROM (Compact Disc-Read Only Nemory) systems were installed that provide unlimited access to ERIC, ABI/Inform, Dissertation Abstracts, and the Electronic Encyclopedia by subscription rather than through the conventional dial-up on-line system ("Puture Comes," 1988). GMU is using technology as both a teaching and learning tool as well as a frontier for exploration.

\section{Administrative Support}

As stated in the last chapter, administrative teamwork is a valuable asset to image-making. Gilley et al. (1986) found that a cooperative administrative team facilitates effective strategic planning.

We found that the efficient and harmonious functioning of an administration is an 
important corollary to the guiding of a college toward strategic goals. At all of our colleges on the move we found a significant emphasis on teamwork and the creation of strong administrative teams. ( $p$. 29)

While Johnson may "guide the administrative boat" at GMU, there are many hands pulling the oars. For example, David King, past Vice President of Academic Affairs, was given credit by one administrator as being more successful than anyone else at GMU in recruiting high quality faculty (personal communication, March 24, 1988). Predictably, top. level administrators close to the president are helping form GMU`s image. There are other groups, however, whose contributions should be considered. Admissions

One notable team at GMU is the admissions staff, one of the new campus "power brokers" that Gilley et al. (1986) identified. "By power brokers, we mean individuals or division heads who have become extremely important on campus because of changing demographic and environmental conditions affecting higher education today" (p. 84).

Lynton and Elman (1987) discuss new challenges for admissions personnel. For example, there is increasing student interest in career-oriented and professional 
degrees. There are larger numbers of students delaying or interrupting their studies, as well as more adults enrolling in courses, which result in greater, albeit more disconnected, attendance patterns. These changes require greater flexibility in adoissions procedures than in the past.

Topor suggests that one measure of institutional quality is access: "Can constituents approach and contact the institution through readily available channeIs?" he asks (1986, p. ix). Dr. Patricia Riordan, Dean of Admissions, heads a stafi of nine who ensure that GMU is very a pproachable. Riordan is aware that student recruitment today is "big business" and she has explored many avenues to spread the word about GMU. "-Recruitment is not what it nsed to be, she says. - It requires a long comitment of tige on the part of the university ${ }^{-"}$ (Moshos, 1984, p. 4). GMU sponsored its first "open house" for 1200 students in 1984. Faculty, students, and staff from more than 30 departments and offices were on hand to assist. George Gangloff, Senior Associate Director of Admissions, remarked that initially faculty were reluctant to participate in open houses, but now they are enthusiastic. According to Gangloff, "research has shown that scholarship aid is helpful, but not as important as faculty" in influencing students to attend a particular institution (personal 
Conmunication, March 24,1988 ).

In $1985 \mathrm{GMU}$ was the first school in its area to participate in a computerized application program in which students taking the Scholastic Aptitude Test (SAT) could simultaneously apply for admission by listing GMU's code on the SAT registration form. In this program, called the "5827 Plan," pertinent information is transferred from the SAT to a GMU admissions application, sent to the student for verification, taken to the high school guidance counselor, and forwarded with appropriate transcripts to GMU.

"The advantage of the $5827 \mathrm{Plan,"} \mathrm{according}$ to George Gangloff, associate director of Admissions, "is that students that qualify for admission will be notified earlier of their acceptance. They will then be eligible for special programs, such as the honors program, and they will also get first priority in course selections, housing and financial aid." ("SAT Test," I985, p. 28)

For the past five years, GMU has drawn students with increasingly stronger acadenic records. Gilley et al. (1986) state, predictably, that increases in the number and quality of students are a sure sign of institutional wellbeing. At GMU, the average SAT score for entering firsttime freshmen was 1024 in 1983. In 1987, the score was 
1061. Grade-point averages for the same two groups were 2.89 in 1983 and 3.04 in 1987 ("Factbook," 1987-88). The number of undergraduate applications rose $25 \%$ from 1986 to 1987 .

George Mason University attributes its success to the large applicant pool it received for the Fall 1987 semester and to the overall positive image that the school re[f]lects. . .

"George Mason is no longer seen as a backup school as it was seven years ago and thus, we are now receiving applications from the best students in Virginia as does William and Mary or the University of Virginia" said Phyllis Percorak, Assistant Director of Admissions. (Dean, 1987, p. 4)

Gangloff said that GMU now is viewed by prospective students as a viable alternative institution. He said that the percentage of entering students for whom GMU was their first choice has increased from $20 \%$ in 1980 to 508 currently (personal communication, March 24, 1988).

Attracting top students to GMU is important, but as significant is the challenge of keeping them there. With a large number of part-time students in a transient area such as Northern Virginia, student retention at GMU must be 
thoughtfully considered. In 1987 GMU began examining its student support services under the direction of Arthur Chickering, visiting professor of higher education, and an expert on student developmental theory.

Chickering has begun meeting this month with members of student support offices such as the Registrar, Career Services, Academic Advising, Financial Aid, Student Activities and others to become familiar with the range of student services at George Mason. He is guiding offices in developing mission statements to maintain internal consistency and provide direction for diverse entities under the student services umbrella. (Turner, December 11, 1987, p. 8)

Donald Mash, Executive Vice President for Administration, remarked that GMU was prepared to make prompt changes where needed. "George Mason must keep pace with rapid change, notes Mash, ensuring that the student services offered is [sic] relevant to the student. -The ongoing support of our students is essential, " he said" (Turner, December 11, 1987. p. 8). The fact that Chickering is administering this project is noteworthy. As a visiting professor, the practical application of his expertise is strategically beneficial. 


\section{Development}

Another administrative branch of GMU that impacts and is impacted by the university ${ }^{-5}$ image is the fund-raising or development function. The George Mason University Development office solicits gifts from alumi, faculty, students, friends, corporations, and others that supplement funds provided by the state. In addition, the George Mason University Foundation, a private non-profit corporation, receives gifts that "largely provide for eninent scholars, academic and athletic scholarships, resources for the libraries, equipment for research, assistance for various departments, as well as gifts in memory of faculty[,] alumi, or stuđents" ("Factbook," 1987-88, p. 84).

that is unique about $\mathrm{GMU}^{-} s$ private gift support is that the largest percentage comes from businesses and corporations. In 1986-87, $35 \%$ of total gifts to the GMU Poundation came from these sources. That same year alumi giving, a traditional source of revenue at many institutions, increased 48.58 , representing 98 of all individual giving and $2.6 \%$ of the Foundation's gifts ("Factbook," 1987-88).

Gilley et al. (1986) state that increasing financial resources are a good indication of institutional well-being. GMU currently is planning a major fund drive with a possible goal of $\$ 100$ million. 
The capital campaign would signal a new era for George Mason, which despite national ambitions, climbing standards and a 1986 Nobel laureate--economics professor James M. Buchanan--depends largely on a paltry endownent of $\$ 20$ million and the largesse of the state. . .

Founded three decades ago, George Mason has a comparatively small pool of alumni. But officials are counting on Northern Virginia`s explosive economic growth and prosperous business community for a large chunk of the fund-raising effort.

The growth and development of Northern Virginia has expanded a lot of people s horizons of what's possible," said J. Wade Gilley, senior vice president of George Mason. "We"re in the midst of a booming business community with an immense amount of uealth" (Hockstader, 1987, pp. Cl-2).

The funds raised, according to Gilley, will be targeted first toward the endowment, more professorships, and scholarships, with buildings and facilities being a second priority. The success of the capital campaign will be a telling sign for GMU. 
Alumni Relations

A key planning strategy for GMU has been selective targeting of attention, energy, and resources. As a young school, alumi relations have not been a top priority at GMU. Joe D-Agostino, Director of Alumni Relations at GMU since 1984, feels that GMU alumni do not have a great deal of influence within the university yet, but they are gaining clout. Topor suggests that a strong collective image can be enhanced by attention to alumni relations as well as other areas. "Coordination of admissions, development, alumni, public information, publications, and a news service will become more important as an institution works to communicate an image to its publics" (Topor, 1983, p. 58).

The Alumi Association of George Mason College was organized by a group of its first alumi who graduated in 1968. In 1977 the GMU Board of Visitors authorized the establishment of a campus alumi relations office headed by a director, chosen by the association and the university administration, who would work with the alumi association. "Fron 1982 until the present, the University and the Board of Visitors have had an agreement with the Association to provide a home for the Alumni Association on campus in a new interdependent relationship" ("Alumni Association," no date, no page number). The office is located, along with the development office, in a large home on the edge of campus 
that used to house GMU's president.

$D$ Agostino, who had twenty years of experience in alumi relations prior to coming to $\mathrm{GMU}$, has instituted changes to provide more opportunities for alumni participation in GMU activities. Eighty-five percent of the nore than 25,000 association members live within two hours of GMU. "The proximity of alumni to the campus is both a benefit and a curse," said $D$-Agostino. "Nostalgia brings al umi back, but nostalgia daesn't build up when you drive by campus twenty times a week" (personal communication, Aarch 24,1988 ). Communication is the key to success, he said. "The best program in the world won't make a difference if the alumi don't know about it " ${ }^{-}$〈Hill, 1986 , p. 6).

D-Agostino has tried to identify programs and activities that appeal to GMU's diverse alumni. "Traditionally, it's always been thought that you reach alumni through sports, but that hasn't been the case here. We have a good turnout at basketball games and other sporting events, but nowhere near the response we get for the cultural events" said D'Agostino (Hill, 1986, p. 6). The wealth of cultural opportunities available in the Washington, D.C. area assists planning. For example, an alumi dinner and tour of the Smithsonian"s "Treasure Houses of Britain" exhibit for which Dªgostino expected 40-50 
persons attracted more than 500 responses.

A strong alumi group can be a source of prospective students, employment opportunities for graduates, and financial strength for the university. DAAgostino says that 6MU"s recent publicity, its Nobel prize-winning faculty member, Robinson professors and other prominent faculty have brought attention to the school and inquiries to his office. "We now get calls every two weeks from people who want to be on our mailing list," he said. "Graduates are beginning to perceive that the image of the university is growing and they are proud. Most of the success can be attributed to the efforts of the president". (personal communication. March 24,1988 ).

\section{Conclusions}

This chapter has shown that a strong link between administrative planning and image-making exists at GMU. This link is supported by Johnson"s "philosophy of innovation and optimisw," shared by many at the university, that guides decision-making.

Lynton and Elman (1987) point out that the changing environment requires new approaches by universities. GMU considers demographic, economic, social, and technological trends in its strategic planning. The university uses a tactic of multiple initiatives that include PAGE, the Center for Conflict Analysis and Resolution, the law and econorics 
focus, and the School of Information Technology and Engineering in meeting new needs. GMU also has experimented with technological "waves of the future" such as sophisticated telecommunications and computer systems that will set them apart from other institutions.

Although critics propose that some of $\mathrm{GMU}^{-} \mathrm{s}$ initiatives are too risky or narrow, Johnson uses challenges presented by the changing environment as opportunities for growth. He relies on a practice he calls the "smoke and mirrors" approach, a strategy for changing perceptions to reality, to gain support for his plans.

Continual focusing on the future--that is, on performance and quality levels above those of the present--appears to influence faculty. behavior positively. Self-interest and institutional reinforcement cause movement toward that future ideal, through present action and the belief that goals are closer than they seem. This attitude changes internal procedures and attracts a higher caliber of faculty and students. (Gilley et a1., 1986, p. 42)

While lofty ambitions and a positive attitude have taken GMU far, even the best-made plans occasionally go awry. For example, Johnson"s "smoke and mirrors" system of 
bringing new faculty to the university was disrupted in the early 1980 s by then Governor Robb“s state hiring freeze. "We had a plan to swamp faculty uith new faculty, then the Robb administration stopped [the hiring of new faculty]. It was almost tne death knell," he said (personal communication, March 25, 1988).

While GMU continues planning for growth, the State Council of Higher Education currently is trying to. "hold onto the reins. . . In particular, the council agreed informally it intends to send a message to George Mason University and other state universities that now is not the time to begin planning expansion on their own" (Walker, September 7, 1988, p. B3). Council director Gordon Davies said he felt GMU should be allowed to go ahead with planning, but ather council members disagreed, fearing this step right indicate their favoritism to one institution. Northern Virginia now is exhibiting an increasing need for educational facilities just as it did 32 years ago when 6MU first began. A Commission on the University of the 2lst Century has been mandated by the legislature to study how growth should be handled in Virginia.

Projections of growth in Virginia's collegeage population indicate thousands of new students will be pressing for space in state schools by the mid- to late 1990s. Most of 
them will be in Northern Virginia. . . The commission may recommend expanding existing colleges and universities, creating a new institution of higher learning or both. But expansion is likely to come in Northern Virginia. (Nalker, September 7, 1988, p. B3)

With this prediction, GMU's past history, its increasing stature and strength, and Johnson as its president, it is unlikely that GMU will sit idly on this subject, despite contrary advice from the state council.

Finally, GMU benefits from strong administrative teamwork, a positive characteristic of "on the move" institutions noted by Gilley et al. (1986). The value to Jahnson of individuals such as Gilley, Lovett, and the Robinson Professors was indicated in last chapter. The growing importance of groups such as the admissions, development, and alumni relations offices to institutional image-making was discussed in this chapter.

The next chapter concerns marketing and public relations at GMU. Gilley et al. (1986) state that "one of the things that appears to be sweeping through the American higher education system currently is the desire for positive feelings and beliefs about individual institutions" (p. 87). The following chapter focuses more specifically on how GMU seeks to address this concern. 
CHAPTER SEVEN

Marketing and Public Relations

In Marketing Higher Education (1983), Topor discusses how institutions sophisticated in marketing strategy not only plan programs to meet their constituents needs, but promote these programs as well. "Doing the good deed isn"t enough," he says. "People need to know about it" (p. 21). Marketing is a planning tool that can help institutions form strong comprehensive images and increase visibility. The Public Relations Services Office at GMU is responsible for coardinating the marketing effort.

What is marketing? Topor (1983) says, "marketing is an exchange process. In the commercial world, consumers exchange money for products. In the nonprofit sector of higher education, clients exchange tuition for services" ( $p$. 21). For the purpose of this study, marketing is the process of identifying consumer needs, planning to meet those needs, establishing and pronoting programs and activities, and evaluating the overall effort. Colleges and universities with active marketing programs operate differently from the way colleges and universities customarily have operated. Instead of simply providing traditional programs for students, institutions research consumer needs, carefully design curricula that relate to 
these needs, communicate information about programs to target audiences, encourage feedback, and evaluate results, making adjustments where necessary. This circular process encourages a close connection between product image and reality.

Established areas of specialization and marketing are two common elements of strategic planning found in "on the move" institutions, according to Gilley et al. (1986). At GMU, Johnson began early both to identify consumer needs, and to plan programs to meet those needs. A more aggressive narketing strategy developed, however, after administrators realized that GMU was "undervalued" by the public. Gilley and Belen Ackerman, Director of Public Relations at GMU, tell of how a note sent to them from one of GMU's professors ignited the spark that initiated planning and lit a fire of publicity about GMU four years ago.

In January 1985, an economics professor at George Mason University sent the University's

Senior Vice President and the Director of Public Relations a book and a note. The book was Blaug's The 100 Greatest Economists Since Keynes and the note said, "We have three of the 51 active economists in this book. Can't we get some publicity?" The note served as a catalyst which led 
to an unprecedented flood of publicity at the national and local level for the 12-year-old university. Coverage included a lead front. page story in the kall Street Journal, major stories in the dashington Post, inclusion in a Time magazine review of universities, an article in the New York Times, and the appearance of those stories in major dailies across the country.

The note also drew attention to a fact that administrators, too close to the action, had failed to register. With the success of President George Johnson's game plan for University development, including building an outstanding faculty and innovative programs, the reality of George Mason's stature had far outstripped the public perception of the school as a small, insignificant liberal arts college. (Gilley \& Ackerman, 1988, p. 2)

Marketing and Inage

Topor says that using marketing concepts such as market research and planning, audience segmentation, demographics, and product differentiation is one way that higher education institutions can form and promote effective images. To those attempting to implement such programs, however, Topor 
varns that resistance to such efforts is to be expected. "Some people argue that marketing and development are superfluous to the basic mission of a nonprofit institution. The successful marketer should not overlook these objections," he advises. "Rather, he or she should listen carefully to these arguments and work cautiously to change attitudes" (1986, p. 20).

Those persons with reservations about marketing of ten are members of institutions that do not concern themselves with details of image-making. Topor (1986) says:

This passive approach reflects an institution without comprehensive, coordinated marketing objectives. Actions and events are unrelated; each is an end in itself, designed to reach a specific goal, rather than to contribute to an overali plan. ...

Conversely, in an active approach, inage comes about through activities that relate to a unified marketing plan. Institutional actions support each other, and their combined impact contributes to a specific immediate and long-term positive institutional image. ( $p . x$ )

The events and activities at GMU related in the previous chapter, combined with the administration's mindset of being 
"the first, the best, and/or the only," are indicative of the open and active attitude toward marketing at GMU. This kind of attitude also satisfies Keller's first "distinguishing feature" of strategic planning, that is, "a college, school, or university and $i$ ts leaders are active rather than passive about their position in history" (1983, p. 143).

Who is Involved in Image-Making?

The process of image-making or stature enhancement, as it is called at GMU, begins with people. "Marketing techniques, materials, and plans do not by themselves produce successful institutional image programs. People do" says Topor (1986, p. 19). Because an institutional image is formed by so many activities, events, and people, a coordinated strategy is needed. While the public relations office certainly is crucial to this process, Topor suggests involving many persons. "The board of trustees, president, faculty, alumni, students, and staff all play roles [in developing institutional identity]. The challenge is to combine information from these many sources into a concise, coherent image" (p. 19).

The President

Gilley et al. (1986) found that the presidents of the institutions profiled in Searching for Academic Excellence were very involved in institutional image-making. 
Public relations is crucial to success for any president, and it is an area of great interest to these 20 presidents. These leaders clearly define their external community. Upon assuming the presidency, they take every opportunity to speak to outside groups, discerning the community power structure and taking advantage of it, and creating a particular image for therselves and their institutions that is consistent with their plan for the future. External relations are a team affair for these men and women, and they make fuIl use of the resources of their administration and faculty. (p. 15)

It should be evident by now that Johnson is concerned, even obsessed, with $\mathrm{GMU}^{-} \mathrm{s}$ image. Johnson says that his own particular "game plan" highlights meeting the needs of the community. He incorporates these needs into his overall administrative plans. "We use a lot of strategic planning. You make a wish Iist, assess the situation and seize a position. You start with what is logical to others and you build a box with only one place to go." he said (personal comunication, March 25, 1988).

A slide show about GMU, funded by local corporations, 
is a tool that Johnson uses to focus attention on, and gain support for, GMU's plans for meeting the needs of a changing environment. The professional quality slides begin with recent flattering quotes from the dall Street Journal and the New York Times. The slides identify growth in the Northern Virginia area and in GMU's enrollments; outline the university“s master plan; and comment on new levels of faculty excellence, all of which present a convincing argument for supporting GMU.

Johnson says that GMU is beginning to be viewed by community leaders as the glue that holds the community together. And with the 1988 legislative session "we came over the edge of the hill" with the General Assembly, too, said Johnson. "Richmond had decreed us to be second.tier," he said, "and we had to break out of that. The vicious ci rcle had to be turned into a self-sustaining circle. We picked law, engineering, high tech, and the performing arts [on which to focus]. He did only what was crucial, and we did it all the way to a level of national excellence. We began slowly to build a reputation, but then went in a rush. That is one of my contributions," said Johnson. "I don"t nibble, I slam into things" (personal communication, March 25,1988 ).

Johnson's "slamming style" has accomplished a great deal, but also has created some tensions within the campus 
comnunity. Faculty surveys show a need for better communication between the president and faculty. "The faculty thinks,- Professor Sinith said, -Johnson does a fine job representing the institution to groups off campus--to the Governor, the Legislature, local groups and industry. But he does not deal well within the campus. His relations with the faculty are not very strong-" (llerner, 1986, no page number>.

The Faculty

Johnson is committed to enhancing GMU's image and expects the same of others at the university. Of course, James Buchanan, winner of the Nobel prize, was a key element in bringing recognition to GMU. "The media attention and public recognition of Buchanan's award yielded concrete benefits to the University. Endowments grew from $\$ 800,000$ in 1982 to more than $\$ 25$ million in 1987 , including endowments for 39 named professorships" (Gilley \& Ackerman, 1988, p. 5). As publicity about the school grew, "George Mason also defied one of American higher education's primary sociological laws as full professors, many in endowed chairs, began to migrate to the University from such established research institutions as Harvard, Northwestern, Emory, Vanderbilt, Virginia, Virginia Tech, and Johns Hopkins" (Gilley and Ackerman, 1988, p. 5).

Professors such as these also have brought recognition to 
GMU. A December 1986 article in The Mason Gazette. proclaimed that "George Mason has arrived. With its prestigious faculty and its skyrocketing academic reputation, George Mason has suddenly been "discovered" by the print and broadcast media as a valuable resource for innovative research, creative arts programs, and scholarly analyses of world events" (Crandall, 1986, p. 3). The article noted GMU's inclusion in many feature news articles and local news programs as well as faculty participation on talk shows such as $\mathrm{CNN}^{-} s$ "Crossfire," "The MacNeil-Lehrer News Hour," the Christian Science Monitor's "Monitor Radio," and $\mathrm{ABC}^{-5}$ "Nightline." An accompanying article told of a GMU professor's first appearance on national television (an impromptu interview with London's BBC television news), and offered tips for preparing for interviews that included advice on what one should wear (Crandall, 1986).

The Administration

The senior vice president's office prepares news sunmaries bi-monthly for the Board of Visitors that contain copies of articles published about the university, its personnel and/or students. These serve to keep board members apprised of the university ${ }^{*} s$ image as it is presented by the media, and also keeps them familiar with the priority of coordinating activities and image-building. The senior vice president also supervises Public Relations 
Services and Design and Publications, two other offices that greatly influence the university ${ }^{-}$image.

Public Relations Services

Public Relations Services is the office at GMU "whose purpose it is to procure publicity, recognition and a positive image for George Mason University" (Essman, 1986, p. 17). Helen Ackerman, Director of Public Relations since 1982, actually has worked in the public relations office 5ince 1978. Ackerman says that recognition for the university was a big problem when she arrived. "A lot of people didn't even know George Mason existed. If they knew it existed, they did not know what it was," she said (Essman, 1986, p. 17). Although educating people about GMU continues to be one of the office's responsibilities, that part of the job is somewhat easier since GMU has received increasing recognition.

Ackerman works closely with the administration, campus commity, media, and others to coordinate publicity about university activities and news.

It is Dr. George w. Johnson, president of Guo, who sets the goals and tone of the university, but Ackerman, to a large extent, is responsible for implementing that tone. "I+m very fortunate. A lot of PR directors don't get to talk to the people who are in 
charge of their organization, whether it be a university, a business or any other kind of organization," said Ackerman. "That makes it very hard for them to reflect what they are trying to achieve for the institution. . .

"This office is a service to the whole university community, so while we work to promote the university as a whole, we also do an enormous amount of work for individuals on canpus," said Ackerman. "lue support the admissions office; we work with them on their admissions materials and their recruitment materials and work with them to develop slide shows. We work with the personnel office to help then develop orientation side shows for new people coming on board, as well as the development office, to do the publicity they need to do their job." (Essman, 1986, p. 17)

Design and Publications

Design and Publications is the office responsible for coordinating GMU*s printed image. Dan Skripkar, director, says that his office relies on a Visual Standards Handbook to ensure that its productions conform to a certain style. "All of the work coming from us shares certain standards making it easy to recognize work from George Mason, be it a 
brochure or business card.- He continues, the work to provide the image the University wants to present to itself and others"" ("Design," 1987, p. 12). Business and Industry

GMU also has gained the assistance of business and industry in its public relations cause. According to Gilley and Ackerman (1988), several corporate members of the George Uason Institute agreed to sponsor advertisements in the Sunday editorial sections of The Washington Post, the Richmond Times-Dispatch, and the Roanoke Times. These pieces, published during the spring of 1985, focused individually on public policy and economics, high technology, and arts and hunanities.

Written from the corporations perspective, the advertisements ran under the headings, "What do Harvard, Chicago, UCLA, MIT, Colunbia, and George Mason have in common?" [sic]; "The Nation"s Newest Engineering School Focuses on the 2lst Century"; and "At George Mason University, the Humanities Make a Difference."

Presented as low-key, informative articles, the advertisements had an immediate impact and provoked considerable discussion throughout the state. They also caught the 
attention of a Hashington-based Wall Street

Journal reporter and stimulated him to

investigate the possibility of a story on

George Mason's development, particularly in

the area of economic science. The result was

a front page, 44-column-inch [sic] Wall

Street Journal article published on September

30, 1986, headlined "University in Virginia

Creates a Niche, Aims to Reach Pop Ranks."

(Gilley \& Ackerman, 1988, p. 4)

Alumi and Students

Two groups that Topor (1986) advocates using in imagebuilding are alumi and students. There is not much evidence that GMU relies on these groups for public relations purposes. Student representatives from the admissions office do participate in leading campus tours for prospective students, however, this is common practice at nany institutions.

One explanation may be that because the university-s student and alumi bodies generally are young, without much financial and political strength, they are not a major part of the marketing plan. Johnson says lack of organized alumi is a problem that must be considered in the future, but for now, he is leaving it alone. With the large numbers of students and alumi that live locally and could. 
therefore, be a ready source of various kinds of support, including these groups in planning, sooner than later, would seen logical.

\section{Steps for Building an Image}

Topor (1986) advocates an "additive process" of creating a positive institutional image. He suggests that one:

1. Use research to measure target

audience image perceptions and attitudes.

2. Understand your institution.

3. Establish compative differential advantage.

4. Make and carry out an image/marketing plan, involving many people as you go.

5. Measure, evaluate, and maintain your image, and refine your image program as necessary . ( $p .29$ )

The process of image-making at GMU follows these steps. Gilley et al. (1986) recommend many ways to assess growing external recognition including reviewing newspaper articles and independent reports, conducting comaunity surveys, and noting interest in the institution displayed by foundations and organizations ( $p, 97$ ). The Board of Visitors news sumaries prepared by Gilley's office already have been 
described. Another source of information is business and industry leaders who have expressed their beliefs about how GMU can help meet their needs and vice versa.

Understanding the institution means reviewing its aims and objectives--and its mission--and ensuring that marketing efforts are compatible with these. And always, says Topor. market reality. "An institution that engages in false image creation will pay the price in the long run" (1986, P. 32). Keller (1983) suggests looking both inside the organization-at programs, faculty, location, and size--and also at the external world--the econony, demographics, competitors, and opportunities (p. 153). The knowledge gained through this process forms the basis for an academic strategy and paves the way for a marketing strategy as well.

GMU has received nuch more recognition since it has refined its mission to focus on undergraduate liberal arts, econorics and public policy, high technology, and arts and humanities, and tailored its marketing strategies to emphasize these strengths. This kind of focusing by GMU, or positioning, explains how the university is establishing its "differential advantage." As Topor explains, it is the differences, not the similarities, that distinguish products.

In 1985 administrators at GMU realized, after receiving a request for publicity about its economists, that they 
needed to display GMU`s strengths and advantages to the public in a nore systematic way. Gilley says that GMU quickly began to focus on public relations (personal Communication, March 14, 1988). "President Johnson called together a group of University faculty, deans, vice presidents, and staff to help him define the 'new' George Mason in a way which would enable the University's goals and accomplishments to be easily communicated externally and internally." (Gilley and Ackerman, 1988, pp. 2-3)

Their new warketing strategy was based on the institution's academic strategy and it involved several persons who could provide both ideas and support for the plan. Its success is evident through $\mathrm{GMU}^{-} \mathrm{s}$ increased media coverage, increased student applications and enrollments, better qualified applicants, improving faculty quality, and increasing financial resources. Nevertheless, administrators continue to review and evaluate their strategies as the institution develops.

The Global Image

The collective image of your institution, or global institutional image, is the total of nany audience members perceptions. This global image should contain some recurring components, the key ideas you want to communicate to each target audience. An 
institution cannot change images as an actor changes costumes to play different roles. The institution can, however, project image variations that have common key ideas. These variations allow you to develop and deliver custom information to each target audience. The key ideas, as the conmon threads binding your global image into a cohesive whole, wiIl help position your institution in relation to others in the competitive marketplace.

(Topor, 1986, p. 5)

The key ideas identified by the administration at GMU are evident in the university*s outreach materials as well as in the language of personnel at the institution. The university־s slide show, its admissions prospectus, even the "I987-88 Pactbook," each open with recent quotes that express GMU's growth, location, and quality. Parts of the mission statement are reprinted often, a strategy advised by Gilley et al. (1986): "Outside the college walls, the mission should appear in publications and speeches, forming the basis for institutional image building" (p. 96).

The president, an admissions officer, the director of financial aid, the public relations director, and the director of university activities each used several of the following terms during interviews about the university: 


\begin{abstract}
"dynamic," "exciting," "ever-changing," "on the threshold of becoming great," "fast-paced," and "fascinating." The repeated use of these terms demonstrates communication of a particular mindset about the university among these indivi duals.
\end{abstract}

\title{
Communications
}

One of the signs of institutional quality is a good commications system, according to Topor (1983). Effective communications involve both outreach and feedback:

We may be producing communications to create awareness, describe educational opportunities, or indicate where services are offered. We also need to evaluate feedback to ensure that our audiences understand our messages. The communications function is not simple. It requires sophisticated skills and abilities. Most of all it requires a comprehensive understanding of organizational services, objectives, and goals. (p. 87)

Establishing good communications involves using tools such as advertising, publicity, and personal contact. It also requires realizing that "everything about an organization talks" (p. 89). To create a strong identity, institutions must coordinate images portrayed through activities, the school logo, news articles, publications. 
reports, stationery, and more. At GMU, the persons responsible for these things are in touch with the president's goals, objectives and plans for the university.

Lynton and Elman (1987) state that faculty provide a good means of communication and suggest that outside professional activities for faculty be encouraged. Easy access to faculty expertise must be provided, they say: "Appropriate marketing techniques and strategies for informing various constituencies must be carefully developed and coordinated in cooperation with key individuals in designated campusuide offices as well as with organizations and agencies in the external community" (p. 34).

At GMU, faculty participation in outside activities is one stroing avenue of external comounication. In fact. Iynton and Elman (1987) note: "A recent survey of collaborative activities of universities with industry and public and private agencies turned up the names of such schools as the University of Texas at San Antonio, San Jose State University, and George Mason University" (p. 38). Paculty participation in external activities, awareness of the university ${ }^{-} s$ plans and priorities by key individuals responsible for portraying the university to external audiences, and coordinated outreach materials demonstrate the benefits of $\mathrm{GMU}^{-} \mathrm{s}$ good public relations comanications system . 


\section{The Pour $\mathrm{R}^{-} \mathrm{s}$ of Image-Making}

Topor (1986) describes how Philip Kotler created a "Four P" approach to marketing for nonprofit organizations that requires consideration of an institution's product, price, promotion, and place. "With homage to Kotler," Topor created a "Four $\mathrm{R}$ " approach to image-naking that involves research, recognition, repetition, and recollection (p. 39). Resea rch

Topor says that nonprofit agencies traditionally have used a passive approach to image-making that involves informing people of their strengths without considering the value of the strength to the external conmunity. He says

It is important to consider what services you are best at providing (Kotler's Product).

But that alone is not sufficient. You must augment this -inside-out- approach with an "outside-in" approach. Institutions must start with the audience. They must first assess consumer needs, identify demands, and then generate or adapt products targeted to neet those demands. (1986, pp. 39-40)

Of course, a controversial issue in higher education concerns how far colleges and universities should go to meet market needs. Topor states that the answer to this question will vary among institutions depending upon their individual 
wissions. What about the integrity of the institution? Johnson implies that education today is not about protection of a sacred curriculum. "dho"s calling the shots?" he asked. "The factory system of education isn"t working anymore. We are going through a period of transition and the next 20 years will be very different." As a means of establishing direction for the university, Johnson wants "to reconnect the academy with the community," so GMU has organized an active marketing strategy that depends on assessing consumer needs ipersonal comunication, March 25. 1988).

Recognition

Topor (1986) suggests that institutions continually question what sets then apart from their competition and establish means of recognition consistent with their findings.

Recognition is the glue that binds your institution and its prograns and activities to a target audience member ${ }^{-s}$ mind. It requires the development of a carefully orchestrated image based on your institution"s strengths. The best way to improve recognition is to present a clear. unified total image. Consumers will find it easier to focus on and recognize an 
institution if they can associate a clear

image with the institution's name. (p. 42)

GMU has strengthened its recognition by focusing on

particular aspects of its academic plan and seejng these priorities through to "a level of national excellence" (Johnson, personal communication, March 24, 1988). By striving to provide the "first" or "only" or "best" program to meet certain consumer needs, GMU has achieved recognition in particular areas such as the high technology field. GMU has used some unique methods to increase its recognition such as persuading business and industry leaders to sponsor the aforementioned advertisements that linked $\mathrm{GMU}^{\prime} \mathrm{s}$ name with other, more prestigious institutions.

Dorcas Goodwin, Director of University Activities, explained that Johnson takes advantage of every opportunity for publicity about the school. GMU gets more mileage out of media events by planning other activities around them, Goodwin said. For exanple, once when the governor was visiting the canpus, Johnson arranged to have a building*s cornerstone dedicated, an event that probably would not have received media coverage on its own. The governor brought attention to this event and increased recognition for the institution .

Evidence of GMU's growing recognition can be found in its increasing appearances in such well-known publications 
as the Chronicle of Higher Education, in which it was noted three issues in a row in 1985 (Grubisich, 1985). Also that year the Wall Street Journal's front-page story and spin-off stories appeared, and GMU was noted in Eduard Piske's The Best Buys in College Education. In 1986. Time magazine included GHU as one of nine schools featured in an article, mhose Hot Colleges on the Climb." A Hashington Times endof-the-year review of things "in and out" of vogue, designated GMU "in," and the University of Maryland "out" (December 31, 1986, p. B1).

More importantly, in 1985 GHU ranked fifth in the Southern and Border States comprehensive schools category of the U.S. News \& World Report's survey on America's Best Colleges (fuscatine, 1985). In 1987, the next survey, GMU was sixth in the same category. GMU was not included in the 1988 survey, however. The nethod of determining the institutions included was changed for the I988 survey. In the first three surveys (1983, 1985, and 1987) college presidents were asked to make the selections. In 1988. however, academic deans and college admissions officers helped, and also, objective data such as financial resources, retention rates, and selectivity were included in the determinations. In addition, the school categories were combined into five rather than the previous year-s nine.

Despite their exclusion from U.S. News \& World Report ${ }^{-}$ 
most recent survey, GMU still is making itself known. In The Chronicle of Higher Education"s "Almanac" for 1988, GMU is mentioned in Virginia"s section of the report.

The improving reputations of Virginia"s colleges and the economic health of its populous Northern Virginia area are generating a new set of problens. Both William and Mary and the University of Virginia have come under criticism fron some communities for failing to accept enough instate students. Thus far, the legislature has not imposed limits on the number of outof-state students at public universities. In Northern Virginia, George Mason University, which was established in 1957, has mounted an ambitious program of expansion and is competing with older institutions for both state money and prestigious professors. (pp. 75-76)

Gilley et al. (1986) state that growing external recognition is a sign of an institution on the move. GMU certainly is showing that it deserves to be included in this category. Repetition

"One of the best ways to learn something is to repeat it," according to Topor (1986, p. 43). He stresses using 
every opportunity to identify and promote an institution "in good taste with a sensitivity for the ideals that are important to education, the institution, and its audiences" (p. 43). Gilley and Ackerman (1988) agree that "consistent and repeated printing of the University's message is crucial" (p. 5).

Consistency in the images and messages that are communicated is important, Topor stresses. GMU displays "George Mason University" in a particular typeface in virtually all publications and materials that bear its name, from applications, brochures, and bumperstickers, to catalogs, letterhead, and postcards. This provides a visual sense of unity among the many elements of the university.

Specific messages about $\mathrm{GMU}^{-} \mathrm{s}$ mission are repeated through many media such as catalogs and viewbooks; the slide show and speeches; news articles and press releases; and, at a basic level, through the language of many personnel at the institution. Repeating themes through these many vehicles enphasizes important messages the institution is trying to relay .

Recollection

Topor (1986) explains that corporate marketers and public relations personnel have studied for many years the capacity of humans to classify information in their memory systems. Why is this process important to colleges and 
universities? Just as one has many cars or airlines or soft drinks from which to choose, one may also select from many educational institutions that each offer different programs and services. An institution must strive to create an image that will trigger people's mental processes and will bring its name to the forefront.

In building an image for your institution, your goal is to encourage audience members to think of your institution as representing a particular positive type.

There is great power in the idea of recollection. The degree to which your audiences recall your institution and its programs and activities, as well as how accurately these images relate to reality, and how they compare with competitors, are measures of the effectiveness of your institution ${ }^{-}$s image-building program. (Topor, 1986, P. 44)

Topor says that the best way to achieve recollection is to deliver products that best meet consumers needs. GMU has expanded its mission to consider these needs in its academic planning, therefore, it can rely on its curriculum and faculty to support the images it is seeking to convey. GMU's location, desire for innovative programs, and 
presidential persona help reinforce its place in the minds of its audiences.

Although GMU existed in relative obscurity just a few years ago, it is undergoing a major transition, according to Johnson. By consistently highlighting the institution's strengths--its programs, faculty, location, and zeitgeist-GMU's administration is enhancing the dall Street Journal's picture of "the giant" growing outside of Washington.

\section{Conclusions}

It is important today for colleges and universities not only to plan their academic programs thoughtfully, but to promote them, as well. In 1983 Topor said, "as higher education continues into the 1980s, it will be under increasing pressures. Creative marketing techniques can help, not as a panacea, but as a new way of looking at higher education" (p. 99).

GMU uses an active marketing approach that involves many people from the president to the public relations director to local business and industry leaders. GMU's practices are similar to the "additive process" that Topor advocates, a process that involves using research; obtaining knowledge of the institution's mission, goals and objectives; positioning to emphasize the institution's differences; establishing a marketing plan; evaluating its effectiveness and refining it. 
GMU takes advantage of every opportunity to promote its strengths, a strategy that is enhanced by a good communications system among specific administrators and faculty members close to the president. Internal communication lines between the president and other faculty. however, need attention. Nevertheless, the fact that GMU's public relations strategy is based so strongly on its academic strategy provides a greater liklihood that perceptions and reality eventually will merge. 


\section{CHAPTER EIGHT}

The Physical Campus

The discussion of institutional image-making at GMU has encompased thus far institutional mission, history, leaders and heroes, academic planning, and marketing and public relations. Another important consideration in image-making is the campus itself--both the physical setting and the cultural milieu of the institution. As Gilley et al. (1986) remarked, the current concern with institutional reputation has fostered "a new emphasis on image, on the appearance of buildings and grounds, and on generally improving the ạtmosphere in which students live and learn" (p. 87).

Topor (1986) suggests that the campus atmosphere evoked by facilities, personnel, and buildings and grounds, are visible indications of institutional quality. How has GMU developed and used its physical setting to enhance its image? What impressions about the university does the physical plant create? This chapter focuses on these questions.

\section{Location}

The importance of an institution's location was noted earlier in this study. Gilley et al. (1986) postulated that location, along with adversity and leadership, is a characteristic that has motivated "on the move" institutions 
to greater aspirations. Location has been a prime benefit to GMU. The growth of GMU's physical campus has corresponded to the growth of the surrounding community. The availability of jobs has brought people to Northern Virginia, and the nature of those jobs has created a market for GMU to tap. A Washington Post article described this phenomenon .

George Mason's rise is a textbook example of how a once-obscure university can push itself toward prominence by finding a need and filling it. It became situated in a fast growing region that did not have a major state university, and it tailored its economics and engineering programs to the Washington area's booming high-tech industry. ("What They're Saying," 1985-86, p. 2) The Master Plans

The university ${ }^{-}$master plans for 1968,1979 , and 1987 reveal a consciousiy drawn connection between the physical evolution of the campus and its evolving mission. The prevailing constant throughout the years, reflected in both nission and physical evolution, has been growth; growth in numbers of students, faculty, programs, and facilities. Unfortunately, the financial means for supporting such growth has not come easily. nevertheless, university 
administrators, faculty, and friends have juggled resources and pulled strings to accomplish objectives. 1968.

Although George Mason College had been operating as a four-year institution for only two years in 1968, the master plan of 1968 recognized that the college probably would become a regional university serving approximately 15,000 students by 1985. The first four buildings on the Pairfax campus, North, East, South, and West, had been completed since 1964 and the Charles R. Fenwick Library, named for a member of the General Assembly who was instrumental in locating GMC in. Pairfax County, was dedicated in 1967.

The recommendations of the 1968 plan called for a division of facilities into six separate "Cluster Colleges," an experimental concept of the 1960 s and 1970s in which each "college" of 2,500 students woula contain its own academic and residential space, and student center. Other facilities such as administrative buildings, the library, laboratories, and gymasium would be shared. This concept, popular on the west coast, was supposed to form "the basis of intellectual and social community" for students (Grant and Riesman, 1978, p. 369).

The most significant factor in the development of George Mason will be the unique educational plan which has been 
developed by the University. Briefly sumarized, it provides for the decentralization of the capus into a series of six Colleges, each of which will have a distinct physical as well as intellectual identity. ("Master Plan," 1968, p. 13)

Each new college was to have centered around its own quadrangle which then would have served as "a focal point to identify and express the unique character of each individual College" ("Master Plan," 1968, p. 3). Residential space was intended to accommodate only 40 percent of the students, however, a student center was to be erected in each college, to "strengthen the cluster College Concept at George Mason and help the non-resident student to develop a deeper sense of identity with the institution" (p. 13). By the time the next waster plan was developed, however, things had changed at GMU.

1979.

By 1979, George Mason no longer was a college of the University of virginia, but was a regional university with a greater agenda. President Johnson had arrived and a feeling of change was pervasive. The master plan states that the university"s "perception of self and its mission in serving the region have changed considerably" (1979, p. 1).

Fiscal constraints were salient and the policy of 
prioritizing building projects was emphasized. The cluster college concept had been abandoned after planners realized that it required duplication of facilities and programs. A new plan was introduced that reflected the growing concern with defining the institution's image. Part of the plan focused on providing "a visual link with the community by creating two campus landmarks" (p. 3 ). It called for creating a "major open space" in the center of the campus that extended to a pond site by an adjoining road. Additionally, it recommended constructing a "community related facility" near the intersection of two nearby roads that would "establish the presence of the University" ( $p$. 3). The campus, heretofore, surrounded on several sides by woods, had been fairly obscured from view. A new strategy of using landscaping and architecture to reinforce the presence of the university was introduced.

Landscape and architecture can and should be complemented by forms which represent our culture. CuItural accouterments represent the achievements of man and their presence in the environment are spiritually uplifting. At selected points, the introduction of sculpture, gardens, and fountains will add interest to the campus. Specifically, it is suggested that a major sculpture be placed in 
Mason Square and that a fountain be constructed within the pond on the main campus. The sculpture would be a representation of the University ${ }^{-} s$ namesake. The fountain would be a dramatic and eyecatching water spire. Each of these elenents would serve as focal points in the campus landmark and make a lasting impression on all who view them. ("Master Plan," 1979, p. 36) This effort to establish the university's presence reflects GMU's active approach to image-making, about which Topor (1986) says "institutional actions support each other, and their combined impact contributes to a specific immediate and long-term positive institutional image" ( $p . x$ ). Even though specific plans have changed through the years, the effort to tie facilities planning to overall academic and marketing plans represents a unified approach to imagemaking that is consistent with Topor's theory. 1987 .

The 1987 master plan renewed an emphasis on the university as a community, a community that had expanded greatly over the past thirty years. With an anticipated enroliment of 30,000 students, plus faculty, administrators, and staff, the number of persons on campus each day had grown roughly to 100,000 . The plan expressed GMU's desire 
to be "the hub or a pole in the overall development of Northern Virginia, and the metropolitan washington, D.C. area" (1987, preface) and stressed the importance of interaction between the academic and surrounding communities.

George Mason University, through its Master Planning for both academic and physical growth, has set the task for the development of a Master Plan that will maintain the existing program and provide the adaptability to respond to the needs and change of both the academic and community at large and eliminate any artificial or insular barriers between the two. ("Master Plan," 1987, preface)

By 1987 several schools and colleges had been established at GMU, including the College of Arts and Sciences, the College of Education and Human Services, the School of Information Technology and Engineering, the School of Business Administration, the School of Nursing, the Graduate School, the Division of Continuing Education, and the School of Law, located on its own Metro Campus in Arlington. Construction of the Humanities Complex and the Science and Technology Building had begun, and plans for additional student housing (for 5,000 students), classrooms, parking spaces, and plant 
facilities were under way.

The Patriot Center, a 10,000-seat field house that opened in 1985, was constructed on the south end of the campus. It provided a forum for interaction between the university and the community.

Northern Virginia is talking about GMU

sports. No longer the newcomer, George

rason's athletic program became first-rate

faster than anyone expected. The GMU

Patriots- record shows that these are teams

to be reckoned with. Each season attracts

more and more spectators, discovering the

excitement of Division I collegiate athletics

in their own backyard. (Hill, 1984, p. 6)

The arena, along with the new Humanities Complex which reflects the current focus on the arts and humanities, will shift the location of the campus's main entrance to allow its community-oriented and more visually impressive buildings to be more accessible. Future plans include development of off-campus land and consideration of a satellite campus elsewhere in the region.

\section{Growing Pains}

As stated previously, growth has been a pervasive consideration in each of these three master plans. "The men and women who hold the reins of George Mason University 
foresee, within the next quarter-century, a major institution that is two-thirds again as large as it is now, more heavily flavored with out-of-state, graduate and fulltime students, and boasting three times as many dormitory rooms" ("What They"re Saying," Pebruary 28, 1986, p. 8). Rapid growth at GMU has not been without its problems, however.

George Mason University`s enrollment is growing as fast as its reputation, but as it pushes for prominence in American higher education, its resources-faculty, services and space--are not keeping pace.

There are too few professors to teach required courses in the popular departments, faculty members complain about a shortage of telephones and secretaries, and some dormitory conditions are a "disgrace," according to the student government. (Cohn. March 30,1987 , p. DI)

Some students in popular programs complain of overcrowding and failure to get classes needed to graduate. Johnson says that the university has tried to alleviate these situations by hiring professors instead of support staff whenever possible, however, this has caused other problems resulting from a shortage of secretaries and 
custodians. Overcrowded and deteriorating facilities have created tensions, too.

Paculty members complain about tiny

windowless offices, and university officials say every classroom is in use during peak hours. The school has only 57 percent of the space that state guidelines recommend for the size of its student body. . . .

When the heat went out in parts of the new dormitories during the winter, a number of students spent several days in chilly rooms while the university tried to find a repairman. "I was really ticked that our [maintenance] people didn ${ }^{-} t$ have the wit to go out to a hardware store and buy space heaters," Johnson said.

Faculty members sometimes fare little better. Psychology Professor Robert F. Smith estimated that there were 20 leaks 1 ast year in his building, one of the newest on campus. It was only after an article was published in the student newspaper about his plight--the dripping threatened his research--that the repairs were properly made, he said.

Some faculty members say they are better 
off in one of the dozens of offices in temporary trailers than in some of the permanent buildings. The university uses 85,000 square feet of temporary space in the form of a dozen office buildings and 15 housing structures, each made of several trailers. (Cohn, March 30, 1987, p. 07) Despite problems with GMO's physical plant such as these, Johnson says the university has "maintained its quality." explaining that every institution receives complaints. One trustee remarked that students might have been better served by lower enrollments during 1986-87, however, Johnson did not acquiesce, saying that "slowing down could spell doom" (Cohn, March 30, 1987, p. D7). One might question, however, whether refusing to slow down might bring about a similar fate.

\section{Conclusions}

Deal and Kennedy (1982) believe that "a company"s investment in bricks and mortar--its building--inevitably says something about its culture" (p. 129). They say, and GMU has shown, that leaders of strong culture organizations try to establish "a setting that makes a statement to the world about their company, both deliberate and otherwise" (p. 130). GMU is attempting to create an environment that will enhance its abilities to meet the goals and objectives 
of its mission which include being "-a resource of the Commonwealth serving government and private enterprise, and - . the intellectual and cultural focus of Northern Virginia"" ("Master Plan," 1987, p. 1). The university"s academic plan has guided its facilities planning as it has guided public relations planning, and all have remained flexible to accommodate changes in mission.

Deal and Kennedy suggest looking for consistency anong various building sites and among classes of employees. Strong culture companies, they say, "care about all of their people and take pains to see they are all treated appropriately. Discrepancies in the way physical sites are arranged for different classes of employees is one sure sign of a weak or fragmented culture" (1982, pp. 130-131).

Although $\mathrm{GMU}^{-} s$ new arts center is awesome and prestigious faculty are impressive, resources should be distributed in a manner that ensures adequate services and facilities for all students, faculty and staff. Focusing on the future is important: too often, colleges and universities plod along, mired in bureaucratic rituals that are difficult to escape. Nevertheless, consideration for the needs of those enrolled in or employed by GMU now must not be overlooked.

While the campus is bare of academe's traditional ivycovered halls, such trappings would be out of character for 
GMU were they available. Satellite dishes and bulldozers are more indicative of the present mood of GMU. The campus that began in a semi-rural location nearly 30 years ago, now is immersed in the growing metropolis of Northern Virginia. As Gilley et al. (1986) noted, location has been a major benefit for GMU. In The Best Buys in College Education, Edward Piske described GMU:

George Mason University's 600 acre campus, situated between the nation's capital and the Blue Ridge Mountains, offers students a Halden-like spot in which to immerse themselves in tough academics. ("Prospectus," 1996-87, p. I)

Encouraging good publicity, negotiating problems such as traffic and noise, and sharing facilities with the surrounding commity, a major source of students, are ways that GMU is using the physical campus to enhance its image. Attention to the details of physical comfort and convenience for students, faculty, and staff should not be overlooked, however, for as Topor (1986) points out, "everything about an institution talks" (p. 8). 


\section{CHAPTER NINE}

The Cultural Campus

The last chapter discussed the connection between GMU`s physical campus and its image. This chapter examines the cultural, social, human side of the campus--and how GHU uses the environment created by these elements to influence its image. Deal and Kennedy (1982) state that successfuI "strong culture" companies foster environments that instill a sense of shared values and beliefs among employees. These beliefs and values are expressed through rites, rituals, ceremonies, and traditions that depict acceptable attitudes and behaviors and, in turn, reinforce ideals.

Eospanies that have cultivated their

individual identities by shaping values, making heroes, spelling out rites and rituals, and acknowledging the cultural network have an edge. These corporations have values and beliefs to pass along--not just products. They have stories to tell-not just profits to make. They have heroes whom managers and workers can emulate--not just faceless bureaucrats. In short, they are human institutions that provide practical meaning for people, both on and off the job. 
Are the cultural characteristics found at "strong culture" corporations operative at colleges and universities? These characteristics have been discussed before with regard to higher education albeit using different terms. Thelin (1982) says:

Colleges and universities are special places, historic institutions whose elaborate internal life inspires strong feelings cof love and hate) among various groups. Campuses acquire distinctive images and reputations; Neither wholly rational nor efficient, their operations and affairs are determined in part by custom. Such traits bring to mind the concept of institutional saga--a mixture of legend and fact-- of enbellished and accurate history which colleges and universities cultivate over time. . A concept related to saga is that of institutional charter, the distinctive reputation, expertise, privileges, traditions, and legitimacies which insiders and outsiders associate with a particular campus. (p. 20)

Dr. Julianne Mahler of the public affairs department at GMU says that an organization's history and personality are 
related through stories shared among employees. These stories change and expand as they are retold, she says, of ten becoming mythic. "These myths often contain beliefs about an organization that are expressed symbolically, Mahler explains" ("Those Office Stories," 1988, p. 28).

Uhat kinds of rites, rituals, ceremonies, traditions and lore exist at GIU and how have they been used to contribute to its image? Although this question alone could serve as the basis for a dissertation, it is entertained herein in a somewhat abbreviated context limited to a discussion of $\mathrm{GMU}^{-} \mathrm{s}$ awareness of the role of saga, its deliberate use of the concept, and a few examples illustrating the types of events at Gmu that have given rise to cultural traditions.

A related point concerns the consequences of adninistrators" failure to consider an institution's cultural characteristics when planning change.

Unfortunately, it is precisely these abstract phenomena that too often are overlooked by rational planners and decision makers, however, forced change contrary to an institution-s character can be divisive and often unsuccessful. Thelin (1982) says:

Saga and charter, which are historical dimensions of an institutional personality, are serious considerations for presidents, 
deans, and planners who want to work with or alter a university. Effective intervention and administration require an understanding of the peculiar legends, lore, taboos, and traditions embraced by a campus`s constituents. (p. 21)

Recognizing the importance of these characteristics, Deal and Kennedy (1982) caution that lack of attention to cultural beliefs and values can upset plans for change.

A strategic review may launch a new business strategy or new acquisition, but may miss the fact that these new initiatives undermine important values that have guided a company for years and years. Unless something can be done to reduce such threats and provide 5 upport for transitions from the old to the new, the force of the old culture can neutralize and emasculate a proposed change. (p. 158)

Por those in higher education planning an academic strategy, Keller (1983) advocates examining institutional traditions, values, and aspirations as the first step. He says, "You need to have an intilnate knowledge of your organization, its values, and its leadership. You need to cone to know your campus as if for the first time" (p. 153). 
Deal and Kennedy (1982) adnit that it is easier for a "company insider" than an outsider to analyze a culture, for those who work inside a particular environment have greater access to company leaders, rites and rituals, and information networks. Nevertheless, they say, even an outsider can learn a surprising amount of information, perhaps more objectively, by interviewing, listening, observing and reading.

\section{Traditions}

Webster (1976) defines tradition as "I: the handing down of information, beliefs, and customs by word of mouth or by example from one generation to another without written instruction 2: an inherited pattern of thought or action (as a religious practice or a social custom) 3: cultural continuity in social attitudes and institutions" (p. 1238). "Tradition," as manifested in each of these ways, is an inherent part of the higher education setting.

Alhough Johnson, himself, has instituted new customs at the university, he implies that "tradition" is not endemic to GMU, however. "President Johnson perceives the University as being unfettered by the past and therefore able to respond to today's new America" (Hopkins, 1981, p. 5). A change in attitude, rather than continuity, seems to be what he has sought for the university. He focuses on the future, rather than the past. 
Johnson is very much a man of his time and place. Now that the last vestiges of his Philadelphia accent have been worn auay, he has cut his ties to the past; for him, only the present and the future exist. In these ways he resembles the area he's grown to love and embody: both have lots of northern urgency and not quite enough southern charm. (Mundy, no date, no page number) although there have been monumental gains at GMU during the past few years, there have been losses, too, according to history professor Josephine Pacheco. In 1986 she conducted an informal survey of several colleagues who had been at the university for twenty or more years, most of whon were menbers of the College of Arts and Sciences, about changes at GMU. She presented a speech to the faculty and staff that incorporated her colleagues- replies with her own impressions about the changing direction of the university. Although Pacheco praised new graduate programs, endowed professorships, higher salaries and increased institutional stature, she indicated that, indeed, there had been lamentable losses at GMU, too.

For example, Pacheco (1986) noted the denise of intensive, interactive faculty meetings. "The tension probably reached its peak when a small female faculty member 
punched a large male faculty member in the stomach. I guess when the Senate came into existence, the excitement went out of faculty meetings" (p. 8). She mourned the sacrifice of trees, for their own sake, and for the feelings about the campus they invoked.

I have a passion for trees, and I have

literally wept as I have seen them bulldozed.

I know that we can't have trees and buildings

in the same place, but we no longer have a

canpus that gives a rural feeling. I guess

one can argue that we are now true to the

Latin meaning of campus as an open field. (p.

8)

Pacheco also expressed regret over the departure of colleagues who had retired or left GMU, taking with them "a great sense of caring and concern for students and this institution. They were not always the greatest scholars in the country, but their sense of comitment to a new institution made students feel that they were getting a good education, even with all the shortconings of a school just starting out" (p. B). She and others commented on their perception of some faculty members lack of comitment to the university as a whole, noting that many of the "new stars in the George Mason firmament," foremost concerned with their own careers, were not "here to build a University 
but to build a reputation" (p. 8).

Pinally, she spoke of the dissatisfaction of many at GMU who believe that the College of Arts and Sciences has lost its place as the center or core of the University. The clearest message that I have received from my small survey is that faculty worry that we are becoming a technical school, where learning takes second place to training.

These faculty believe, rightly or wrongly, that in the rush to be up-to-date, to provide training for Northern Virginians, the Unjuersity has forgotten that training can take place in many places--true learning only in a university. Hence the decline in morale, the sense of being bypassed, of uselessness that come through so clearly in y unscientific study. (p. 8)

This sentiment was echoed later by another faculty nember who acknowledged the rationale for the university's experimenting in new directions, but who also believes that arts and sciences should remain the primary focus of education at GMU (personal conmunication, July 13, 1988). The new arts and humanities center has taken the edge of $f$ of some people-s disquietude, however, the relationship between 
Johnson and the arts and sciences faculty still is strained.

In the midst of all of the changes at GMU, a small group is ensuring that the past is not forgotten. The "George Mason College Club," faculty and staff members who became employed while George Mason was still part of the University of Virginia, was formed in 1987 in an effort to preserve information about GMU's past.

"We work at a University that seems to become a new institution almost yearly," points out [Robert] Hawkes [co-founder of the club], who joined Mason in 1969 as a history professor and assistant director of the University of Virginia Continuing Education Center. "This dedicated core of people has worked here through the University's years of dramatic change. . .

"Maybe eventually, we could have an exhibit case displayed in the library or in the Pinley Building to show the University ${ }^{*}$ past." says Hawkes. "The University has grown so rapidly that there hasn't been time to preserve its past. But when the time comes for someone to study how George Mason achieved such great success in such a short time we should have plenty of information on 
hand." (Roebuck, 1987, p. 8)

While Hawkes hopes that club members will provide documents and artifacts that reflect $\mathrm{GMU}^{*} \mathbf{s}$ history, and perhaps even put together an oral history of the university, the club also serves another purpose; providing cohesiveness for long-time university members. During the current period in which much attention has been focused on new "university stars." the College Club provides a sense of balance and comminity for those individuals who helped lay the university ${ }^{-}$s foundation. The club-s formation indicates that preserving GMU's "saga" is important to the university commity .

\section{Rites, Rituals, and Cerenonies}

Successful "strong culture" companies use rites and . rituals to establish values and appropriate standards of behavior, according to Deal and Kennedy (1982). Uithout rituals and ceremonies as means of expression, values have no impact, they say. "Strong culture companies create the rites and rituals of behavior in their corporate life--the rites and rituals that exercise the nost visible and pervasive influence on, as Bower says it, the way we do things around here" (p. 60). Ceremonies are opportunities to celebrate the extraordinary. "Ceremonies place the culture on display and provide experiences that are remembered by enployees. . . . Properly done, ceremonies 
keep values, beliefs, and heroes uppermost in employees* minds and hearts" (p. 63).

Although events such as GMU's groundbreaking and commencements had been observed prior to Johnson-s incumbency, new precendents have been set since his arrival at GIU. A nemorandun from the Office of the Director of George Mason College announcing the groundbreaking cerenony in 1963 simply said

T0: All members of the Faculty and Staff FROA1: J. N. G. Finley

There will be a brief ground breaking ceremony on the permanent sice at eleven $0^{-}$clock on Thursday morning, August first.

This announcenent of the birth of the physical campus hardly can be called inspiring. By the time Johnson arrived, the campus was ready for some changes. Johnson's was the first formal innaugural cerenony in GMU's history. The all-day cerenony marks more than a personal wilestone for the president, George Johnson, and even more than the acknouledgnent of neu directions that cone with all changes in comand.

It is, as Johnson, the board of visitors, students and faculty see it, the symbol of a new era for George Mason--a tine 
when the tremendous growth the school has undergone in academics, physical facilities and student body will continue and the school`s reputation will grow concurrently. .

As one student said, echoing a common sentiment on campus these days, "The days of the rinky-dink university are gone. we are moving into the big time." (Sanders, April 4, 1979, P. F-XI)

The enthusiastic response to innaugural activities which included a dinner for Johnson at George Mason's home, Gunston Hall, the ceremony and following reception, and a student-sponsored innaugural ball paved the way for other events.

An observance of ten years of university status, celebrated in April 1982, demonstrates how GMU employs such events to cultivate beliefs about the university. In this particular case, administrators used the anniversary celebration as a means of attracting attention to the university and of seeking financial comitments from political, corporate, and local communities needed to ensure completion of the campus according to plans.

A planning document for the event quotes the mission statement, revised in 1980 , that says "-the University will 
strive to be a resource of the Commonwealth serving government and private enterprise, and to be the intellectual and cultural focus of Northern Virginia-" ("Tenth Anniversary," 1982, p. 1). Goals and strategies outline a specific network of activities planned both to highlignt the university regionally, such as choral presentations, a pageant, and personal visits to commuity college and high school counselors, nedia resources, and sports personnel, and to gain support for GMU.

Another GMU ritual, established by Joanne Johnson, the president"s wife, is the annual Arts Gala. Founded in 1981, the gala began as a small reception for fewer than 100 people that raised $\$ 8,000$. Since that time, several hundred thousand dollars have been earned through the sale of itens such as an MG sports car replica and a hand-made tapestry of a seventeenth century map of virginia, each created by the Gala Committee, a group of women who gather in the presidential mansion to work on these special projects.

The Arts Gala is a dinner, dance, and auction to raise funds for the arts at GMU. Past proceeds have gone to a corporate art show. matching funds for a National Endownent for the Arts in Public Places grant, and support for the university's International Arts Festival, which each year brings musicians, 
dancers, artists and theatre productions to

GMU. (Koklanaris, 1987, p. 39)

DIthough the gala's fund-raising effort is noteworthy, raising consciousness about the arts at an institution known for its high technology expertise is equally important.

The president and his wife are not alone in establishing ceremonies and rituals. The students are initiating and refining their own programs and activities. As senior Sara Eduards said, "it is time for GMU to focus on campus life, activities, and tradition" (personal comunication, March 23, 1988).

One of the students" favorite rituals is "Mason Day," a "spring fling" that has evolved since 1968 from an outdoor barbecue and accompanying speech by then GMC chancellor Thompson, attended by a couple of hundred students, to a three-day celebration, culminating with a fund-raising frolic complete with bands, food, and beer, that now draws a few thousand students. "This goes back so far and marks as strong a tradition as we know," said Dorcas Goodwin, Director of University Activities (personal connunication, March 24, 1988). Mason Day provides an opportunity for play, an integral part of culture building, according to Deal and Kennedy (1982), that "releases tension and encourages innovation" (p. 62). Honeconing, a traditional "play" ritual on college and university campuses, has only 
been celebrated at GMU for a few years, according to Goodwin. With no football tea to provide the traditional focus for it, attendance has been low.

Johnson says that football at GMU is not a likely prospect, at least for the time being. Basketball, soccer, and track, featured sports at GHU, contribute to the cultural environment and bring visibility to the institution.

once upon a time in the not so long ago, there was a snall college nestled in the woods of Pairfax County. It was called George Mason College, and it was attached to the University of Virginia.

The college's basketball teans played "home" games in places like Port Belvoir and W. T. Woodson High School. The wife of the baseball coach would spend all morning making cheese sandwiches for her husband"s team to eat on road trips. The school fielded a cross country team but not a track and field team. . .

What a difference a few years can make. the school now has university status and renains Virginia"s fastest growing state institution. 


\begin{abstract}
George Mason University-s men ${ }^{-}$
basketball team now plays in a 10,000-seat

field house and has played and won its first

post-season tournanent game this past winter.

Menbers of its 1985 women's soccer tean wear

NCAA chanpionship rings. Its men's track

team boasts two individual NCAA champions.

Its wowen`s track team and its baseball tean

have claimed major conference titles within

the last two years.

The school has been featured in national publications like Time and Newsweek and made the front page of The Lall Street Journal. As GMU wonen"s soccer coach Hank Leung points out, the university has achieved a measure of national visibility. (McDouell. 1986, no page number)
\end{abstract}

While GuU may not have a football team, GMU*s athletic programs have attracted local, regional, and national attention, and have contributed to building a relationship with the surrounding connunity.

The Patriot Club, a group of sports boosters, raises funds for athletic scholarships and generates interaction between the university and the comsunity. "-people like to identify with sports. with teams, with a winner," said Alan 
Srebnick, director of the Patriot Club in 1984. "Athletics is that magnetic pole that draws people together," he continued (Hil1, 1984, p. 6). GMU sports have drawn both students and resources to the university and have contributed to its saga, both within and outside university wa11s.

\section{Conmunity}

Although Johnson has expressed interest in strengthening the relationship between the university and the external comouity, his comitment to building a sense of conmunity within the university is less salient. Johnson says that there is very little community in most higher education institutions because they largely are broken into factions governed by self-interest (personal conmunication, Harch 25, 1988). At GMU, as in most colleges and universities, there are many individual communities that each has its own agenda, nevertheless, concern for the university as a whole is evident. Two faculty "opinion" pieces in The Mason Gazette, "George Mason As A Community of Interests" and "The University as Commity." express conmitment to establishing a larger sense of commity within the university.

This sense of connunity needs good communication between all parties to flourish. Johnson often focuses so strongly on the future and on external relations that a 
perception of neglect has emerged anong some faculty and students. In spite of the sense of excitement and growth highlighted recently that has, in fact, contributed to $\mathrm{GMU}^{-5}$ own particular saga and mystique, many at the university feel GMU lacks cohesiveness, direction, and maturity. Mundy (no date) says:

The gap between George Johnson's dreams and George Mason's reality is no longer as wide as it used to be, but it's still a considerable distance. What Johnson needs to bridge that gap can't be bought, built, or recruited. It's a patina that comes only with age, and a university only gets it with tine. (no page number)

This patina may need time to form, but perhaps it can be assisted by establishing and nurturing a stronger culture. Deal and Kennedy (1982) believe that rites, rituals, traditions and lore are good means for expressing shared beliefs and values, a process that reinforces an institution's culture. Although many new avenues of cultural expression have been forned since Johnson arrived at GMU, perhaps more attention to past traditions and to communicating beliefs and values within the university would establish a basis for a stronger sense of shared culture and community at GMU. This, in turn, would contribute to a 
stronger institutional image. 
CHAPTER TEN

Conclusions

The Problem

This study concerns institutional image-making at George Mason University. The study examined both GMU's deliberate attempts to improve its image as well as the effects upon image of its inherent culture. Specifically, the two-part research question asks, first, how do GMU's efforts to improve its image compare and contrast to Topor's method of image-building outlined in Institutional Image (1986) and Marketing Higher Education (1983)? And second, to add a new perspective to image-making, how does $\mathrm{GMU}^{*} \mathrm{~s}$ "culture" as defined by Deal and Kennedy (1982) affect its image?

In addition to the primary resources noted above, two other books were particularly helpful to this study. These are Searching for Academic Excellence (1986), by Gilley, Fulmer, and Reithlingshoefer, and New Priorities for the University (1987), by Lynton and Elman. In both of these books that address changes confronting higher education today, the authors suggest unique and provocative ways of meeting new challenges that can set institutions apart from others that ignore such changes. These resources, along with Keller's Academic Strategy (1983). provided insight 
into how strategic planning is tied to image-making.

The Findings and Discussion

That successful image-making involves the intimate nexus of both academic planning and marketing is the major finding of this study. Topor (1986) advocates using an image-building process that involves, simply, using research to understand target audiences- views of the institution, fully understanding the institution and its mission, establishing and publicizing the institution's unique strengths, setting up a marketing plan that involves many individuals, and evaluating and refining the process as necessary. Keller's (1982) system of academic strategic planning involves many of the same steps; conducting research, targeting markets, and evaluating and refining plans.

Although some people consider the use of marketing techniques distasteful and antithetical to higher education"s aims, the economic, political, and social environmental changes noted by Lynton and Elman (1987) require a new approach to academic planning that includes the active incorporation of marketing strategies. GMO's president, George Johnson, keenly is aware of the importance of institutional image-making, and he strives to identify people, curricular programs, and projects that will contribute to $\mathrm{GMU}^{-}$s positive image. 
GHO has demonstrated in many ways that the process of strategic planning and image-making is interactive and evolutionary. Several of the university's pursuits such as their hiring outstanding personnel and establishing unique curricular programs have brought recognition to the institution. Although some of $\mathrm{GMU}^{-} \mathrm{s}$ methods of stature enhancement have been criticized, most seem to be working rather well.

Topor's (1986) treatise on how to improve institutional inage is designed for higher education. He acknowledges that institutions should respond differently in their approaches to meeting new needs in accordance with their individual missions, however, he urges colleges and universities to take an active role in controlling their images. Although Topor (1986) admits that "everything about an institution talks" (p. 8), he focuses more specifically on the process of image-building than on the substance of what is being built.

Deal and Kennedy (1982) probe the "substance" aspect of image-making in their book, Corporate Culture. They say that some early leaders of American businesses created strong cultures within their organizations that ultimately led to the success of those businesses. "These builders saw their role as creating an environment--in effect, a culture-in their companies in which employees could be secure and 
thereby do the work necessary to make the business a success" (p. 5). These "strong culture" companies were characterized by shared beliefs and values among employees, rituals, ceremonies, and heroes that reinforced the cultural environment.

Like these business organizations, GMU is establishing its own kind of culture, one of innovation, experimentation, and uniqueness. While GMU is striving to cultivate an identity, one that has its oun heroes, rites and rituals, its "culture" differs from those of the "strong culture companies" that Deal and Kennedy (1982) examined in one fundamental way. Although it may be naive to assume there is a consensus of beliefs and values among educators and students at all higher education institutions, if one believes that shared beliefs and values among a majority are to be found at successful "strong culture" corporatinns, one pight logically surmise that these also should be found at "strong culture" higher education institutions. A sense of shared beliefs and values and attention to traditions that create a mode of expression for these are not prominent at GMU. What does this mean to GMU in terms of image-making? Although GMU's administrators busily are creating a bold, innovative, future-directed image for GMU, wuch of the American population tends to equate quality with "tradition" in higher education. Rightly or wrongly, many people 
believe that the knowledge of western culture imparted through a traditional curriculum is best, as evidenced by the present concern about the direction of higher education noted in reports such as tilliam Bennett's To Reclaim a Legacy, and E.D. Hirsch"s book, Cultural Literacy: what Every American Needs to Know.

Johnson believes that higher education must seek and address new challenges in ways different $f$ rom the past, and he actively is pursuing this course at GMU. GMU now is enjoying the glamour and excitement that accompanies innovation and growth. Will GMU's image continually improve on this foundation?

Perhaps, but the author believes that acknowledging and nurturing the more abstract "cultural" aspects of the institution"s image would create a broader base upon which GMU could build. Strengthening GMU`s culture by identifying and cultivating shared beliefs and values, and by acknowledging and expanding the traditions, rituals, and ceremonies that exist, even though some are rudimentary, would provide more direction for the members of the GMU community. Even though decision-makers at GMU are focusing more intently on the future, neglecting the past surely will Iinit $\mathrm{GMU}^{-5}$ potential.

While one must acknowledge the changing environment and its implications for academic and public relations planning 
in higher education, one must also realize the importance of beliefs, values, and traditions that are evident at many higher education institutions. Keller (1982) notes the value of examining these things prior to building an academic strategy. Deal and Kennedy have shown culture-s importance to organizational success. As this study has shown that academic and image-making strategies are enhanced when each is considered by the other, it follows that institutions intent on forming strong public images should consider and promote institutional culture in their planning, thereby providing a stronger foundation upon which to build their images.

In sum, to ansuer the two-part research question specifically, GMU's image-making efforts conford to Topor ${ }^{*}$ marketing guidelines presented in Institutional Inage (1986) and Marketing Higher Education (1983) in that GMU researches consumer needs, carefully designs curricula that relate to these needs, communicates information about programs and personnel to target audiences, encourages feedback, evaluates results, and makes adjustments where necessary. GMU actively participates in controlling its image, however, in contrast to Topor's advice, it does not use a formal written marketing plan, according to Gilley. Another departure from Topor is that, while many people are involved in image-making, student and alusni participation in this 
endeavor is not salient. Johnson, the "born hero," and others presently are establishing a specific culture at GMU that reflects its innovation and uniqueness, however, this culture differs from those of the "strong culture" organizations described by Déal and Kennedy (1982) in that a sense of shared beliefs and values is not prominent at GMU, and many of the vehicles for communicating them--rites, rituals, ceremonies and traditions--are nascent.

The above discussion addresses the primary research question. The subsidiary questions, while discussed previously throughout the body of this study, are considered briefly below.

1. Is the image GMU seeks to project consistent with its ission?

As Lynton and Elman (1987) advise, GMU has expanded its mission to address the changing environment. GMU began as a two-year branch of the University of Virginia. This branch was established to meet the educational needs of Northern Virginia students, most of whom planned to enroll directly from high school, who could not afford to go away to school. In the 32 years since that time, GMU has become a major university with a four-pronged mission addressing the fine and performing arts, economics and public policy, high technology, and undergraduate liberal arts that is designed to meet the needs of a much larger, more diverse population. 
2. What significant events in GMU's history have influenced its present image?

Several events in GMU's brief history have been significant to its image-making, but none more than its locating in the heart of Fairfax County, one of the fastest growing areas in the United States. Initially, GMU's tie to the University of Virginia as well as its link to the surrounding communities contributed to its stature and growth. Later, the selection of George Johnson as president, more than any other recent event, greatly influenced GMU's course. Both location and leadership are primary characteristics of "on the move" institutions noted by Gilley et al. (1986).

3. How have the presidents, trustees, faculty, students, and others shaped GMU's image? who are GMU's "heroes" and what effect have they had on its image?

The presidents, most notably Johnson, and trustees have encouraged the university"s growing stature by taking an active role in controlling its image. They have taken an approach to directing the university that is more entrepreneurial than bureaucratic, a description that characterizes many state universities. Many faculty such as the Robinson Professors have played a significant role by bringing their expertise to the university and by involving themselves in external relations such as faculty exchanges 
or consultations with local businesses and industries, and media events. The students and alumi do not appear to have played a major role in image-naking at GMU thus far, however, the author feels this avenue should be explored further by the adrinistration. Finally, Johnson is the preeminent "hera" of GHU. Even his worst critics acknowledge his success in increasing $\mathrm{GHU}^{`}$ s stature. 4. What systematic methods such as strategic planning and narketing have been used by GHU to build and project its inage?

While administrators at GMU shy away fron "cookbook" approaches to image-making, strategic planning and marketing techniques are salient features of $\mathrm{GMU}^{-}$s stature enhancenent philosophy. When making decisions about activities, programs, and personnel at the university. Johnson considers their potential value to $\mathrm{GHU}^{-} \mathrm{s}$ image. He uses an approach comparable to the "managenent by objectives" technique described in Keller's (1982) book, Academic Strategy. This systen relies on a manager that "decides on realistic objectives, devises shrewd strategies, and defines long-tern goals toward which the meabers of the firm can agree to nork" (p. 44). Of course in GHU's case, objectives sometimes are viewed as unrealistic, nevertheless, Johnson-s "smoke and mirrors" approach to melding perceptions and reality has made believers out of many who doubted the 
university's abilities to reach its lofty goals.

5. Who largely bears the responsibility for planning how GMU`s image will be enhanced?

Because acaderic planning and image-making are so tightly connected at GMU, the major planners are Johnson and his top administrators. Johnson says that, over time, he has gotten comfortable with the dominant role he plays, however, he claims he simply has been a catalyst for the energing university, "a crystal in a supersaturated solution" (personal communication, March 25, 1988). Johnson notes, too, the importance of the partnership he formed with the business comnunity personified by John T. Hazel, past rector and board member.

J. Wade Gilley, Senior Vice Président, also is involved intimately in shaping the direction of the university. And the provost, formerly David king, and presently Clara Lovett, has a prime responsibility, too, according to Johnson, in determining "the character and shape of the university." (Natale, June 15, 1988, p. Al). Johnson says that he also relies on faculty such as the Robinson Professors to help guide the university (personal communication, March 25, 1988). One Robinson Professor acknowledged their part, however, he was quick to point out that it is Johnson who makes the final decisions. 6. What role does the public relations office have in this 
process?

Helen Ackerman, Director of Public Relations, has been at GMU since 1978, as long as Johnson. She says she is fortunate to have access to "the people in charge," a situation that results in her office"s ability to reflect the priorities and strengths of the institution more clearly. "It is Dr. George Johnson, president of GMU, who sets the goals and tone of the university, but Ackerman, to a large extent, is responsible for implementing that tone" (Essman, 1986, p. 17). Johnson's active involvement in promoting GMU's image helps the office in its role as a bridge to the external community.

7. How do $\mathrm{GMU}^{-} \mathrm{s}$ publications influence its image?

GMU, like most colleges and universities, uses many applications, brochures, catalogs, documents, letters, and other publications. The major publications that the author examined were those such as catalogs, viewbooks, and the al umni magazine, George Mason Magazine, that are directed toward GMU's major audiences.

GMU's undergraduate and graduate catalogs are professional, harmonious publications that reflect the institution's current mission, the foundation for imagebuilding according to Topor (1986). The viewbook, aimed at prospective students, includes flattering quotes from wellknown publications such as the wall Street Journal, which 
aid in recognition and recollection, two important " $\mathrm{R}^{-} \mathrm{s}$ " of image-making, according to Topor (1986).

Dan Skripkar, Director of Design and Publications

Services, explains the difference between his work at GMU and at Gallaudet University, where he previously was Director of Art and Photography. This explanation characterizes $\mathrm{GMU}^{-} s$ attitude toward image-making. "The thrust of work at Gallaudet was on educational materials, such as textbooks, for rany levels of students, from kindergarten to university. At George Mason, the thrust in publications is on recruitment." he says. . . "We work to provide the inage the University wants to present to itself and others." ("Design," 1987, p. 12)

While Gallaudet has a special nission to meet the needs of deaf students, a mission that perhaps guides the development of its publications, GMU's focus on establishing a particular image is indicative of its own character.

The establishment of the George Mason University Press is another example of how GMU's strategic planning has provided an opportunity for stature enhancement.

In April 1983, George Mason University Press came into existence by the signing of a menorandum of agreement with Associated 
University Presses. The accasion marked the nost recent of a series of acts through which George Mason University is fulfilling its goal of becoring the intellectual and cultural focus of Northern Virginia. ("Announcing the Establishment," 1983, p. 1)

The announcement also noted the university ${ }^{-}$hope that the press would both increase comprication between Giv faculty and other scholars and bring "steady thoughtful contact with what is new in all fields of investigation" to the people of Northern Virginia (p. 2).

8. How does the physical plant--the architecture, technology, library, dormitories, and sports facilities-affect $\mathrm{GHU}^{-5}$ image?

GMU's location is one of its most inportant features, a point emphasized by Gilley et aI. (1986). Another consideration contributing to its inage is that the physical plant planning has been systematic, conforming to the priorities of its acadenic planning. rather than occurring haphazardly.

Unfortunately, budget constraints and overcrowded conditions have contributed to poor maintenance, a fact that has resulted in sone substandard facilities such as student dormitories and faculty offices. Nevertheless, the overall impression created by the campus is favorable, as noted by 
Edward Fiske, author of The Best Buys in College Education, who described GHU as "a Halden-like spot" in which students could "imaerse thenselves in tough academics" ("Prospectus," 1986-87, p. 1).

9. What institutional rites, rituals, ceremonies, myths, and other expressions of institutional culture exist and how do they influence GMU's image?

The cultural environment of GMU is still somewhat "primitive," as one professor described it. The university has progressed a great deal during the past few years in terms of establishing rites, rituals, and ceremonies, all paxts of a strong culture according to Deal and Kennedy (1982), however, Iack of shared beliefs, values, and traditions still is evident. The author believes that addressing wore attention to the cultural environment would contribute positively to its emerging inage.

\section{Implications for Further Study}

Because an institution"s "image" is corprised of many factors, the author attempted to address several distinct phenowena that have contributed to $\mathrm{GMU}^{-}$s global image. These included GMU's mission, history, personnel, academic plan, public relations program, physical plant, and cultural environment. Each feature, itself, invites further study. The most important finding of this study, as previously stated, concerns the relationship between academic planning 
and public relations. Shile GHU offers a good example of an institution that has formed a close connection between these tasks to the benefit of its inage, one might wish to study the association between these functions at other institutions concerned with improving their inages.

At GHU in particular, examining the evolving culture and its affects on image would be a good follow up to this study. McParlane believes that a deeper analysis of how GMU's history has affected its image would be worthwhile (personal comanication, July 13, 1988). A study that focuses more specifically on George Johnson's influences on GMU's reputation would be fascinating, as well. Although one tends to think that the days of influential presidents such as Charles Eliot, Daniel Coit·Gilsan, or Andrew White are behind us; Johnson has demonstrated that one individual can make a real difference, a point noted by Gilley et al. (1986).

Additionally, a closer exanination of the role of "mission" in image-making would be worthwhile. Have institutions that are building their reputations used their missions as starting points in the image-building process. as Topor (1986) has suggested, or have they developed missions as a response to the need to attract particular students, as Mayhew (1979) indicated?

An interesting study might be of the effects of the 
physical campus on image. What are the physical

characteristics of the most well-known institutions? what role does location play in their distinction?

The author selected the case study method for exanining "inage" because the topic is complex and nebulous. The author wished to explore nany aspects of inage, rather than focusing on one area, such as how inage is used for recruiting students. Because this particular study is so broad, however, and also because it was linited by time and financial constraints, each of the topical areas invites further scrutiny.

Postscript

GMU's story reminds one of a children's book, Stone Soup, a folk tale retold by Marcia Brown (1975). In this story, three soldiers travelling home from the war came upon a small village where they tried to obtain food and shelter for the night. The village peasants, afraid of strangers, hid their food and turned the soldiers away. Putting their heads together, the soldiers invented a plan and said to the peasants:

"lle are three hungry soldiers in a strange land. We have asked you for food, and you have no food. Well then, we'll have to nake stone soup."

The peasants stared. 
Stone soup? That would be something to

know about.

"Pirst we`ll need a large iron pot," the soldiers said.

The peasants brought the largest pot

they could find. How else to cook enough?

"That's none too large," said the

soldiers. "But it will do. And now, water

to fill it and a fire to heat it." (Brown,

1975, no page nunber)

And so it went, the soldiers "suggesting" and the peasants adding bits and pieces until a hearty soup of carrots, cabbage, beef, and potatoes was ready. The soldiers and the peasants ate, drank and danced together late into the night. When the soldiers prepared to leave the next day, the villagers thanked then. "We shall never go hungry, now that we know how to make soup fron stones," they said. "Oh, it"s all in knowing how," said the soldiers, and off they went down the road" (no page number). Ingenuity, determination, and persistence paid of $f$ for the soldiers. Likewise, these characteristics are paying off for GMU. Ten years ago, Mayhew questioned whether or not it was possible for an institution without a well-established image to build one. George Mason University is denonstrating that "it"s all in knowing how." 


\section{BI BLIOGRAPHY}

Ackerman, H. (1987, May 8). Johnson reviews progress: Where we are now. The Mason Gazette, pp. 1,3 .

Advances in science: High-tech education promoted by partnerships between schools and corporations. (1985, December) Regardies, no page number.

Alberger, P. (1980, February). Stalking the elusive student: Publications that really recruit. CAsE Currents, $6(2)$, 12-15.

Almanac: Pacts about higher education in each of the 50 states and D.C. [Special Issue]. (1988, September I). The Chronicle of Higher Education.

Alumni Association of George Mason University, The. (no date). (Brochure available from the Alumi Relations Office, George Mason University, Pairfax, Virginia 22030).

american Studies Subcomittee for Bicentenial Activities. (1976). George Mason: The man and the university. (Available from Special Collections and Archives, George Mason University, Fairfax, Virginia 22030)

Announcing the establishment of the George Mason University Press. (1983). (Brochure available fron Special Collections and Archives, George Mason University. Pairfax, Virginia 22030)

Ashby, R. (1983). The public image of a small college. Management Techniques for Small and Specialized Institutions (New Directions for Higher Bducation No. 42, 41-47). San Prancisco: Jossey-Bass.

Audet, L. (1987, Sunmer). University looks for unconventional prograns. Broadside [Orientation Issue 1, p. 2 .

Baldridge, J. V., \& Deal, T. E. (1975). Managing change in educational organizations. Berkeley. CA: McCutchan publishing.

Barnes, B. (1979, April 5). Innauguration to syrbolize George Mason"s new status. The dashington Post, pp. 1. 6 . 
Bauer, B., Solorzano, L., \& Woltz, V. (1988, October 10). America-s best collegés. U.S. News \& Horid Report, pp. CI-32.

Bedell, C. (1978, July 12). GHu lau school needed. Broadside, p. 4 .

Bennett, A. G. (1986, May). Marketing begins at howe. Currents, $12(5), 30-33$.

Beyers, D. (1985, October 10). GMU wants library of the future. The Journal, pp. Al, 4.

Bolman, L. G., \& Deal, T. E. (1984). Modern approaches to understanding and managing organizations. San Francisco: Jossey-Bass.

Bowen E. (1986, April 22). Those hot colleges on the climb. Time, pp. 56-58.

Bowen, E. (1987, November 23). Raiders in the groves of acadewe. Time, p. 69.

Brooker, G., \& Noble, Y. (1985, Spring). The marketing of higher education. College and University, 60, 191-201.

B roun, A. (1975). Stone soup. New York: Charles Scribner's Sons.

Callaghan, M. (1986, May). Gearing up with good advice. Currents, 12(5), 34-40.

Cassara, E. (1984, April 2). Administration's attitude could spark faculty exodus. Broadside, p. 2.

Chiacu, D. (1987, July 20). Disputed legal viek to be focus at GHU. Richmond Times-Dispatch, pp. B1, 5 .

Clark, B. R. (1970). The distinctive college. Chicago: Aldine.

Cohn, D. (1985-86). Virginia`s George Mason University: A calculated clinb. Reprinted in that They re Saying About Us... A Year of the University in the News: George qason University. pp. 2,3 .

Cohn, D. (1987, March 30). GMU bursting at the seams: Faculty, facilities have not kept up with zooming enrolluent. The Hashington Post, pp. Dl, 7 . 
Cohn, D. (1987, July 30). George Hason hires a jewel for its crown: Anthropologist part of plan for status. The Washington Post, pp. Di-2.

Cohn, D. (1988, March 31). GUU lau school hires Judge Ginsburg as visiting professor. The Uashington Post. Pp. $\mathrm{Cl}-2$.

Cohn, H. (1985, May 10). The university as conmunity. The Máson Gazette, p. 12 .

Collins, L. (1987, Novenber 16). Law dean says faculty happy; complaints to ABA absurd.- Broadside, pp. $1,29$.

Cox, C. (1987, October 16). 8 state universities, colleges recognized. Richnond Times-Dispatch, pp. Bl, 3 .

Cox, C. (1987, Novenber 6). GMU to start center to train teachers. Richnond Times-Dispatch, p. 35 .

Crandall, C. (1986, December 5). Professor, BBC Neus is on the line.. . The Mason Gazette. p. 6.

Crandall, C. (I986, Decenber 5). University featured in Chronicle: Mason ${ }^{-5}$ experts sought by media. The Mason Gazette. pp. 3,6.

Cseplo, A. B. (1978, June 20). President Krug`s 454 days. Broadside, pp. I, 3 .

Cseplo, A. (1978, July 12). GHU, law school merger possible. Broadside, pp. 1, 3 .

Davies, J. L. \& Melchiori, G. S. (1982, July). Developing the inage and public reputation of universities: The managerial process. International Journal of Institutional Managenent in Higher Education, $6(2)$, 87-108.

Deal, T. E. \& Kennedy, A. A. (1982). Corporate cultures: The rites and rituals of corporate life. Reading, ha: Addison-liesley Publishing.

Dean, F. (1987, Novenber 16). Board raises standards for adnission. Broadside, p. 4.

Design and publications creates university image. (1987. October 30). The Mason Gazette. p. 12. 
Dorsey, K. (1984, March 5). TRL pledges time, money, jobs. Broadside, no page number.

Druck, K. B. (1986, January). Advancevent planning: An objectives view. Currents, 12, (1), 18-20.

Emsley, 1. (1984, Novenber 1). Looking backward and forward: a piea for toierance. The Mason Gazette, pp. 8,7 .

Enrollment up $4.7 \%$ at George Mason. (1988, October 25). Richmong Times-Dispatch, p. B4.

Essman, L. E. (1986, April 21). PR reaches out to enhance GMU image. Broadside, pp. 17, 26.

Peeney, S. (1983, August 16). Selling a university. The Hashington Post. pp. Cl, 4 .

Pinucane, M. (1988, November 25). GMU lobbies for courthouse: Iau school dean wants canpus site. The Journal, p. Al5.

Fisher, J. I. (1980, October). Great expectations: what the president expects of the PR director and what you should expect in return. CASE Currents, 6(9), 14-17.

Fouler, C. R. (1983, November/Decenber). Making marketing work: Hou a coordinated approach inproved a college“s enrollaent, retention, and public image. CASE Currents, $9(10), 20-22$.

Future comes to Penwick. (1988, March 21). Broadside, pp. 4. 20 .

Gehrung, F. (1980, October). The PR pro*s roadtest: Are you at the wheel or along for the ride? CASE Currents, $\underline{6}(9)$. 8-12.

George Mason University. (1987-88). Pactbook. Fairfax, VA: Author.

Gergen, D. R. (1987, October 26). America-s best colleges [Special Report]. U.S. News \& Uorld Report. pp. 48-92.

Gill, G. (1986, Septenber 22). Johnson got mixed ratings by faculty. Broadside, pp. 1, 8 .

Gilley, J. H. (1985, September/October). Giving business its due. AGB Reports, pp. 29-31. 
Gilley, J. H. \& Ackerman, H. (1988, January). Bold strikes work for George Mason: A review of successful public relations strategy for George Mason University. (Paper available fron the Center for Policy studies in Eacation, George Mason University, Pairfax, Virginia 22030)

Gilley, J. W. , Fulmer, K. A., \& Reithlingshoefer, S. J. (1986). Searching for acadenic excellence: Twenty colleges and universities on the hove and their Ieaders. New York: Aqerican Council on Education and Macmillan Publishing.

Gilley witharaws bid for Oregon post. (1988, June 25). Richmond Times-Dispatch, p. B5.

Gilmore, G. E. (1988, April-no date). Interference at GMU cannot be tolerated. The Journal, no page nunber.

GHU considered as site for major new high tech center. (1983, September 5). The Mason Gazette, p. 1 .

Goldgehn, L. A. (1985, September). Audit your marketing program for success. Currents, $11(8), 36-39$.

Graduate catalog. (1987-1988). George Mason University, Pairfax, Virginia 22030.

Grant, G. \& Riesman, D. (1978). The perpetual dream: Reform and experiment in the American college. Chicago: University of Chicago.

Grubisich, T. (1985, August 22). GMU goes for world class status. The Burke/Braddock Connection, pp. 11-12.

Hall, C. A. (1985). The role of public relations in three Ohio liberal arts colleges (Doctoral Bissertation, Ohio State University, 1985). Comprehensive Dissertation Index, $\underline{3}(1), 199$.

Hancock, P. (1985, September 23). Johnson optinistic about GMU“s future. Broadside, pp. 1, 5.

Hancock, P. (1986, ApriI 4). CIT liaison disappoints GMU officials. Broadside, pp. 1, 4 .

Harper, N. (1984, September). Why we need narketing. Currents, 10(8), 30-33.

\#ere are the things which pleased our vanity and rubbed raw 
at our humanity over the past 12 months. (1986, Decenber 31). The dashington Times, p. B1.

Highlights of George Mason University ${ }^{-5}$ history. (1981, April 7). GMU Convocation Bulletin. (Available from Special Collections and Archives, George Mason University, Fairfax, Virginia 22030)

Hill, C. (1984, November 12). GMU teams attract business attention, support. The Mason Gazette, p. 6 .

Hi1l, C. (1986, Pebruary 14). Alunni relations: A George Hason network in high gear. The llason Gazette, p. 6 .

Hockstader, L. (1987, July 24). George Mason to Iaunch najor fund drive. The dashington Post. PP. Cl, 2.

Hodgkinson, H. L. (1983, November). College students in the 1990s: A denographic portrait. The Education Digest, $\underline{49}(3), 28-31$.

Bollister, P. (1985, Septenber). Audit your public relations for impact. Currents, $11(8), 32-34$.

Hopkins, S. C. (1981, Hinter). Johnson sets the pace. GHU Today. p. 5 .

Hornick, M. (1980). The successful warketing of schools. Jonesboro, TN: Pilgrinage.

Horowitz, H. L. ( I984). Alma nater. Nel York: Alfred Knopf.

Huddleston, T., Jr., \& Karr, M. B. (1982). Assessing college image. College and University, 56, 364-370.

Hughes, G. C. (1980, Fall). This little college goes to warket. College and University, 56, 92-94.

Intress, R. S. (1987, October 18). Acadene ${ }^{-5}$ big names lured as U.Va.. GMU state -star war. Richmond Times-Dispatch. pp. Al, 2 .

Jenkins, H. H. (1983, February 7). GHU--A public affairs voice in D.C. Broadside, pp. 1, 4.

Johnson, G. (1982, October). High technology plan for George Mason University. Unpublished speech draft. TAvailable fron Special Collections and Archives, George Mason University, Pairfax, Virginia 22030) 
Johnson, G. (1983, May 6). President's message. The Mason Gazette. p. 2.

Johnson, G. (1984, April 13). The University in 84-85: Initiative and dynamism. The Hason Gazette, pp. 12, 10.

Johnson, G. (1986, September 19). President's state of the University message. The Mason Gazette. pp. 8, 6.

Johnson is fourth GMU president. (1979, April 5). The Globe [Special innauguration edition supplement], p. 3.

Jones, D. (1986, July/August). Tap into the wires. Currents, $12(7), 57-58$.

Jordan, P. W. (1986, May 6), University sees book in popularity. The Journal, p. Al.

Keller, G. (1983). Academic strategy. Baltinore: Johns Hopkins University.

Koklanaris, M. (1987, Pebruary 4). First lady of GMU: High marks \& a national award for Joanne Johnson. The Connection. Pp. 39, 42.

Kotler, P.. \& Fox, K. P. A. (1985). Strategic marketing for educational institutions. Englewood Cliffs, NI: Prentice-Hall.

Kotler, P., Perrell, O. C., \& Lamb, C., (Eds.). (1983). Cases and readings for marketing for nonprofit organizations. Englewood Cliffs, NJ: Prentice-Hall.

Kreitler, E. (1978, April 3). Johnson named president. Broadside, pp. 1. 2.

Landers, M. (1986, June). Video viewbooks. Currents, 12(6), 30-34.

Lauer. L. (1986, January). Eight steps to a PR plan. Currents, 12(1), 28-31.

Lawmakers criticize GMU's hiring of Ginsburg. (1988, April 6).

Ri chmond Times-Dispatch, p. Bl.

Legislative lobbying: Management by initiative in virginia. (1986, June 16). Administrator: The Management Newsletter for Higher Education, no page number. 
Litten, L. H. (1981). Abuses in acadenic narketing. College and University, 56, 105-122.

Lowerre, R. T. (1988, April 25). GMU law school being packed." The Journal, no page number.

Lynton, E. A. \& Blaan, S. E. (1987). New priorities for the university: Meeting society $s$ needs for applied knowledge and competent individuals. San Francisco: Jossey-Bass.

Mackey, H. (1980, April). The selling of the sheepskin. Change, 12(3), 28-33.

Mahn, R. E. (1981, Spring). Today's president. College and University. 56, 227-232.

Mahpar, H. (1987, November 2). SCHEV reconmends more faculty/staff positions, 7 raise. Broadside, pp. 1, 28.

Marshall, J. F., \& Delman, J. M. (1984, Sumer). Researching institutional image: The development and implementation of a market research plan for educational institutions. College and University, 59, 316-333.

Master plans. (1968, 1979, 1987). (Available from Special Collections and Archives, George Mason University, Fairfax, Virginia 22030)

Mayhew, L. B. (1979). Surviving the Eighties. San Prancisco: Jossey-Bass.

McCabe, C. (1982, June 12). Education and industry merge. Broadside, p. 1 .

McDowel1, B. (1986, July--no date). The grass is always greener down the road. The Journal, no page number.

McMillan, I. (1986, Noverber 19). Business ties and shrewd planning aid George Mason-s calculated clinb to prominence. The Chronicle of Higher Education, pp. $14-15,18$.

McNair, J. (1987, Pebruary 9). Universities find efforts paying off. Richnond Tines-Dispatch, pp. B1, 8 .

Memorandum to faculty and staff fron J. N. G. Finley regarding groundbreaking ceremony. (1963. JuIy 26). (Available fron Special Collections and Archives, George Mason University, Fairfax, Virginia 22030) 
Miller, B. (1984, December 10). George Mason progress taking an artful tuist. Reprinted in The Mason Gazette, p. 12.

Miller, B. U. \& Eddy, J. P. (1983). Recruiting, marketing, and retention in institutions of higher education. Lanham, MD: University Press of Anerica.

Miller, R. I. (1979). The assessment of college performance. San Francisco: Jossey-Bass.

Mila, K. J. (1986, Spring). Faculty attitudes and involvement as regards educational marketing and student recruiting. College and University, 61, 180-193.

Hissions of the college curriculum: A contenporary review with suggestions. (1980). In The Carnegie Council on Policy Studies in Higher Education (pp. 131-141). San Prancisco: Jossey-Bass.

Moos. 19. (1981). The post land-grant university: The University of Maryland report. Adelphi. MD: University of Maryland.

Hoshos, F. (1984, Becember 10). Student recruitment: Big business and high stakes. The Mason Gazette, pp. 4, 5.

Moshos, F. (1985, March 29). Teaching through television: Mason faculty take to the airwaves. The Mason Gazette, pp. 6, 7 .

Mundy, A. (no date). George Johnson, big man on campus. Regardies. (no page number).

Muscatine, A. (1985, November 22). I0 schools in region cited in survey. The Uashington Post, no page number.

Nagel, G. S. (1980, October). Students take over PR: Presidents of public tuo-year colleges consider students to be main image-nakers. CaSE Currents, $\underline{6}(9), 18-19$.

Natale, J. A. (1984, April-no date). Giving peace a chance: GMU offers method to end madness. The Journal, pp. Al, 5 .

Natale, J. A. (1988, June 15). George Mason nanes new second-in-command. The Journal, p. Al.

Natale, J. A. (1988, July 6). New GMU provost aims for fast start. The Journal, pp. Al, I0. 
Neuberger, C. (1988, November 27). GHU says arts center to fill void. Richnond Times-Dispatch, Pp. El, 9.

New school is first in nation. (1985, April 1). Broadside, pp. 7, 6 .

Newfarmer, T. D. (1981, April). Let your people know: Good employee commication means good PR. CASE Currents. $\underline{7}(4), 32-33$.

Odin, P. (1985, February 15). To educate: Mason faculty seek common ground. The Mason Gazette, pp. 4-5.

Odin. P. (1985, September 27). The board of visitors: Taking a new look at a teenage Mason. The Mason Gazette, pp. 4-5.

Ostar, R. H. (1983, Septerber-no date). Hatchet job. The Hashington Post. no page number.

Pacheco, J. (1986, April 25). Gains and losses: GMU since 1968. The Mason Gazette, p. 8.

Pelletier, S. G., \& McNamara, W. (1985, Minter). Marketing higher education: The diminishing returns of marketing. Educational Horizons, 63, 54-60, 62-64.

Pendel, M. (985, September). Beyond Gallup. Currents.

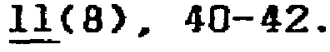

Perkins. D. R. (1983, Septenber). Marketing your own Iacocca: How you can get media mileage for your president. CASE Currents. $9(8), 22-24$.

Plant, J. P. (1985, February 1). George Mason as a conmunity of interests. The Mason Gazette, p. 8 .

Pray, P. C. (1981). Trustees must be ambassadors. Trustees" Role in Advancenent (New Di rections for Institutional Advancement No. I4, 13-19). San Francisco: Jossey-Bass.

Prospectus and adnissions materials. (1986-1987). George Mason University, Eairfax, Virginia 22030.

Raley, N. (1986, January). The plan's the thing. Currents. $\underline{12}(1), 22-26$.

Randolph, F. (1962). The American college and university: A history. New York: Vintage Books. 
Ries, A., \& Trout, J. (1981). Positioning: The battle for your gind. New York: McGraw-Bill.

Robinson professorships. (1987, September 9). The Chronicle of Higher Education, p. B9.

Roebuck, J. (1986, October 31). Buchanan sweeps national headlines. The Mason Gazette, pp. 1, 8 .

Roebuck, J. (1987, Novenber 13). Mason College Club forns to preserve past. The Mason Gazette, p. 8 .

Rosenzueig, R. H. (1986, Noveaber 5). Seeing ourselves as others see us. The Chronicle of Higher Education. p. 104 .

Roth, M. (1988, April 5). Faculty choices at GMU stir rift. The Journal, pp. Al, 4.

Rowland, A. W. (Ed.) . (1977). Handbook of institutional advancement. San Francisco: Jossey-Bass.

Ryans, C. C., \& Shanklin, W. L. (1986). Strategic planning, marketing \& public relations, and funa-raising in higher education: perspectives, readings, and annotated bibliography. Jetuchen, NJ: Scarecrow Press.

Sanders, T. (1979, April 4). New era opens for George Mason. The Fairfax Star, pp. F-Xl, 3 .

Sanders, T. (1979, April 5). GMU's president: From acadene to practical politics. The Pairfax Star, pp. F-X1, 5.

SAT test--GMU applications Iinked. (1985, November 6). The Connection, p. 28.

School \& college guide. (I987, November 8). Richmond Times-Dispatch (Supplenent).

Six presidents naned as top academic leaders. (1986, December). SCHEV On Line, p. 7 .

Saith, R. M. (1982, May/June). Knowledge is power: Research can help your marketing prograw succeed. CASE Currents, B(5), 8-12, 14 .

Solorzano, L., Walsh, U., Taylor, R. A. McGrath, A., \& Woltz, V. (1987, October 26). America-s best colleges. U.S. News \& Varld Report, pp. 48-92. 
Squires, P. C. (1987, November 7). Colleges putting big bucks into recruiting. Richmond Times-Dispatch, PPAl, 15 .

Stocker, S. (1984, March 26). High-tech links university, business. Broadside, p. 8.

Taylor, T. E. (1985). A theoretical model for urban university marketing (Doctoral Dissertation, Indiana University, 1984). Comprehensive Dissertation Index. $\underline{3}(1), 253$.

Tenth anniversary celebration. (1982, Apri1). Planning docunent. (Available fron Special Collections and Archives, George Mason University, Pairfax, Virginia 22030)

Thelin, J. R. (1982). Higher education and its useful past: Applied history in Fesearch and planning- Canbridge MA: Schenknan Books, Inc.

Thomas, A. C. (1982, September 27). Visitors hear Johnson's "country bank speech." Broadside, pp. I, 9.

Those office stories have meaning. (1988, winter). George Mason Magazine, p. 28 .

Topor, R. S. (1986). Institutional irage: How to define, iaprove, market it. Washington, DC: Council for Advancenent and Support of Education.

Topor, R. S. (1983). Marketing higher education: A practical guide. Washington, DC: Council for Advancement and Support of Education .

Townsend, J. K. (1987, October 2). Law school dean meets with SBA: Addresses student concerns. The Mason Gazette. pp. 5-6.

Tounsend, J. K. (1988, Ginter). Resolving conflict: Gif center offers alternatives to strife through analysis. education, and research. George Hason Hagazine, pp. 3-6.

Turner, G. (1987, April 10). Mason's popularity measured in flood of applications. The Mason Gazette. p. 8 .

Turner, G. (1987, December 11). Changing student population requires new look at support services. The Hason Gazette, p. 8 . 
Undergraduate catalog. (1987-1988). George Mason University, Pairfax, Virginia 22030.

Viewpoint: A question of priorities. (1978, IuIy 12). Broadside, p. 4.

Vita: George $\mathrm{d}$. Johnson. (no date). (Available fron Special Collections and Archives, George Mason University, Pairfax, Virginia 22030)

Halker, R. (1988, September 7). State council wants to keep lid on college growth. Richmond Times-Dispatch, p. B3.

Halker, R. (1988, October 16). Feisty GMU thrives in Fairfax boom. Richnond Times-Dispatch, pp. Al, 12.

Walker, R. (1988, October 23). Shenandoah College works to ensure itself a mission. Richnond Times-Dispatch, pp. Al, 18.

Watkins, B. T. (1986, June 6). Successful colleges found headed by presidents who are "people oriented," doggedly persistent. The Chronicle of Higher Education, p. 8 .

Nebster, D. S. (1986, November/December). Ranking acadenic quality: The undergraduate story. Change, pp. 34-41.

Werner, L. M. (1986, December 31), Mason University: 29, growing fast. The New York Times, no page number.

What they're saying about us. (1986, Pebruary 28). The Mason Gazette. p. 8 .

Woolf, H. B. (Ed.). (1976). Webster's new collegiate dictionary (rev. ed.). Springfield, MA: G. \& C. Herriam.

Zerby, 5. L., \& Manning, K. J. (1983, November/December). Mission improvement--translating college marketing strategies into recruitment publications that work. CASE Currents, $9(10), 28-29$.

Zimmer, P. (1986, July/August). Special delivery- Currents. $12(7), 52-54$.

The following resources were obtained $f$ ron the $C$. Harrison Mann Papers collection at George Mason University. Although some articles have inconplete references, all can be found 
in the Mann collection, Special Collections and Archives, George Mason University, Fairfax, Virginia 22030.

B. O. V. Minutes: Minutes of the Board of Visitors of the University of Virginia. (1957, March 9 \& June 7).

Bruns, A. (1958, Pebruary 2). U. Va. visitors select Herndon site for branch. Richmond Times-Dispatch, p. 4D.

Hope, P. (1958, Pebruary 2). Herndon gets OK for branch of university. The Sunday Star (Washington, D. C.), pp. Al, 13 .

Mann, C. H. (1976). Unpublished draft of history of George Hason University.

Mann hits Bowman site for Virginia U. branch. (1956, Septenber 18). The Star (dashington, D. C.), no page number.

Binutes: Committee on Extension Services. (1954, Decenber 15).

Monk, E. G. (No date). Area's college planner faces new challenge. (No source or page number).

Orndorff, B. (1958, October 12). Site near Pairfax termed -suitable for U.Va. branch. Richmond Times-Dispatch. p. 20 .

Outlook brightens for area's higher education prograw. (1957, September 27). The Arlington Journal, pp. 1-2, 4 .

Students for a CONVENIENTLY LOCATED COLLEGE. (No date). This is YouR university. Petition to the Board of Visitors of the University of virginia.

Letters of :

Simms, U. C., to the Alumni of the University of Virginia in Fairfax County, Septeaber 24, 1956

Simms, w. C., to the Editor, September 24, 1956

Steele, C. A., to Members of the City Council of Alexandria, June 1,1956

Zehmer, G. B., to J.N. G. Pinley, May 3, 1956 


\section{Vita}

Blizabeth Acosta-Lewis

Birthdate: July 7,1958

Birthplace: Richmond, Virginia

Education:

1984-89 College of Uilliam and Mary Billiansburg, Virginia

Master of Education

Certificate of Advanced Graduate Study

Doctor of Education

1977-80 Randolph-Hacon College

Ashland, Virginia

Bachelor of Arts

1976-77 Virginia desleyan College

Norfolk, Virginia 
Abstract

\section{INSTITUTIONAL IAAGE: A CASE STUDY OF GRORGE IAASON} UNI VERSITY

Elizabeth Anne Acosta-Lewis, Ed.D.

The College of Hillian and Mary in Virginia, May 1989

Chairman: Dr. Roger G. Balduin

During the past two decades, the inage of higher education institutions. collectively and individually, has becone nore important as competition among colleges and universities for students, faculty, and resources has becone more aggressive. In 1979 Mayhew asked whether it is possible for institutions that do not have well-established images to actually create then. This study addresses hayhew's question by focusing on the concept of inage at one institution, George Mason University.

This study examined both $\mathrm{GHU}^{-} \mathrm{s}$ deliberate attenpts to improve its image as well as the effects upon image of its inherent culture. Specifically, the two-part research question asked, first, hou do $\mathrm{GMU}^{-} \mathrm{s}$ efforts to improve its inage conpare and contrast to Topor's aethod of imagebuilding outlined in Institutional Image (1986) and Harketing Higher Education (1983)? And second, to add a new perspective to inage-making, how does GHU"s "culture" as defined by Deal and Kennedy (1982) affect its inage?

The study found that successful image-making at GMU involves the intimate nexus of both acadenic planning and marketing. GHU's president, George Johnson, keenly is aware of the importance of institutional image-making, and he strives to identify people, curricular programs, and projects that contribute to $\mathrm{GHU}^{-} \mathrm{s}$ positive inage. While GHU is striving to establish its oun kind of culture, one of innovation, experimentation, and uniqueness, its culture differs from that described by Deal and Kennedy (1982) in that a strong sense of shared beliefs, values, and traditions is not proninent at GHU.

GHU is an example of an institution that, indeed, is successfully creating an image that is attracting proinent faculty, better students, and increasing resaurces. The author believes, however, that more attention to building a stronger culture would provide a firmer foundation upon which to base $\mathrm{GMU}^{+} \mathrm{s}$ inage. Purther study of the role of

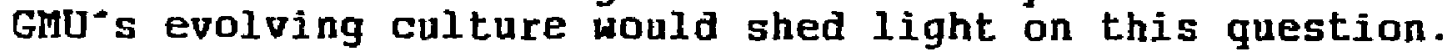

